Portland State University

PDXScholar

$11-14-2006$

\title{
Adolescent Mothers : Youth in Need of Developmentally Appropriate Services
}

Patricia Arlyne Zimmerman

Portland State University

Follow this and additional works at: https://pdxscholar.library.pdx.edu/open_access_etds

Part of the Psychology Commons

Let us know how access to this document benefits you.

\section{Recommended Citation}

Zimmerman, Patricia Arlyne, "Adolescent Mothers : Youth in Need of Developmentally Appropriate Services" (2006). Dissertations and Theses. Paper 4490.

https://doi.org/10.15760/etd.6374

This Dissertation is brought to you for free and open access. It has been accepted for inclusion in Dissertations and Theses by an authorized administrator of PDXScholar. Please contact us if we can make this document more accessible: pdxscholar@pdx.edu. 


\section{DISSERTATION APPROVAL}

The abstract and dissertation of Patricia Arlyne Zimmerman for the Doctor of

Philosophy in Social Work and Social Welfare Research were presented on

November 14, 2006, and accepted by the dissertation and the doctoral program.

COMMITTEE APPROVALS:

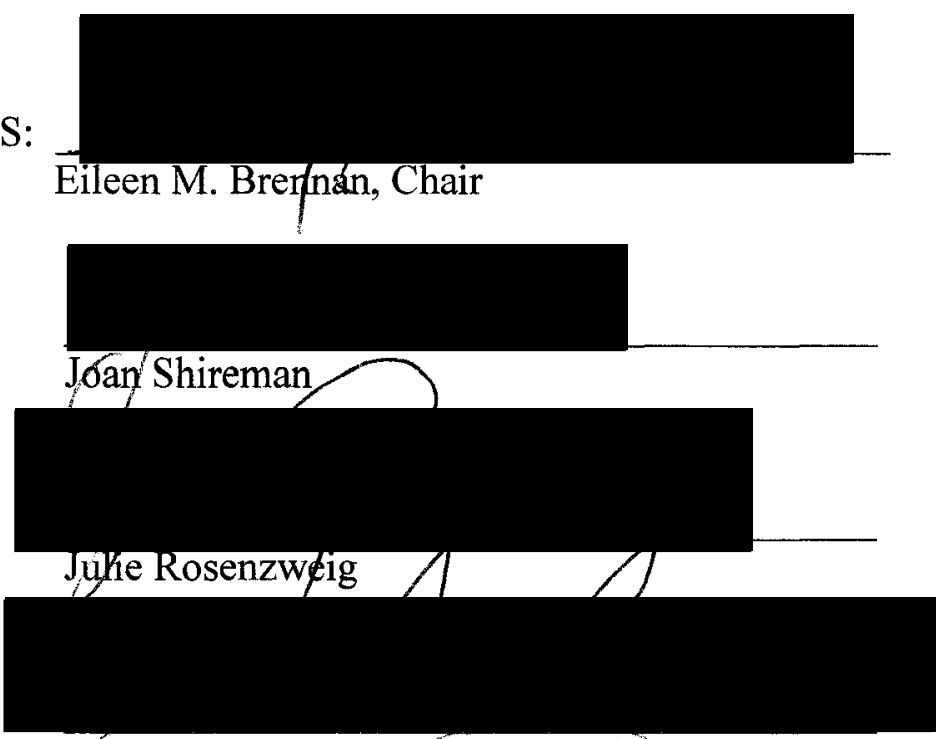

Thomas L. Crofoot
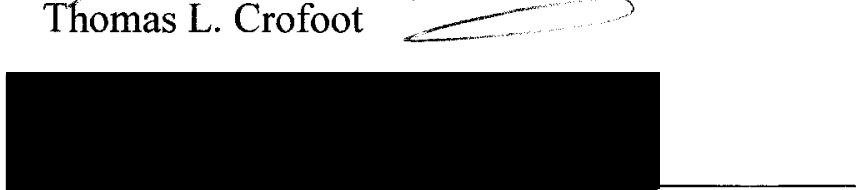

Kerth O'Brien

Representative of the Office of Graduate Studies

DOCTORAL PROGRAM APPROVAL:

Maria Talbott, Director

Social Work and Social Welfare

Research Program 


\begin{abstract}
An abstract of the dissertation of Patricia Arlyne Zimmerman for the Doctor of Philosophy in Social Work and Social Research presented November 14, 2006.
\end{abstract}

Title: Adolescent Mothers: Youth in Need of Developmentally Appropriate Services

This research examines the childhood abuse and maltreatment experiences of adolescent mothers (age 14 to $17 ; N=80$ ) to investigate if these experiences have hindered their socioemotional development and consequently, their parenting behaviors and attitudes. Data were gathered using four standardized self-report instruments: the Child Trauma Questionnaire (CTQ), the Trauma Symptom Checklist for Children (TSCC), the BarOn Emotional Quotient Inventory-Youth Version (EQi-YV), and the Adult Adolescent Parenting Inventory (AAPI-2). Two additional questionnaires were developed to gather demographic and social service information to add to the knowledge base of the field, and to examine what (if any) developmentally focused services young mothers may need.

Interitem and interscale correlations, simple regressions, and hierarchical regressions were produced and examined to determine the strength and types of 
relationships between the variables. The explanatory capabilities of sets of predictor variables were tested as well.

Overall $76.3 \%$ of participants reported experiencing childhood abuse and/or neglect above minimal levels. Predictor variables high levels of emotional neglect and depression significantly predicted lower socioemotional development $(p<.001$ and $p<.05$ ); higher levels of socioemotional development significantly predicted more positive parenting attitudes regarding corporal punishment $(p<.05)$; and socioeconomic status predicted more positive empathy and role reversal parental attitudes $(p<.05)$.

The results of the research also supported alternative hypotheses regarding the need for appropriate and specific developmental and clinical services for teenage mothers who have suffered childhood trauma and neglect. In spite of the high maltreatment rate reported by participants, only $24 \%$ of participants had received any family therapy and only $41 \%$ had received any individual therapy. Other developmental and/or clinical service provision proportions were quite low as well (range $24-54 \%$ not received). Accordingly, demographic and services data are provided, descriptively analyzed, and discussed in detail. Study limitations and practice considerations, and a new assessment and service delivery model are offered, as are suggestions for future research. 
ADOLESCENT MOTHERS: YOUTH IN NEED OF

DEVELOPMENTALLY APPROPRIATE

SERVICES

by

PATRICIA ARLYNE ZIMMERMAN

A dissertation submitted in partial fulfillment of the requirements for the degree of

DOCTOR OF PHILOSOPHY

in

SOCIAL WORK AND SOCIAL RESEARCH

Portland State University

(C)2007 


\section{DEDICATION}

This dissertation is dedicated to all teenage mothers who bear the burdens

of young parenting while trying to heal from childhoods that cruelly included child abuse and maltreatment. My hope is that for their sake, and for the sake of their children, this small study will help to remedy society's blind-eye regarding the real experiences and developmental needs of teenage mothers, and the effects of developmental trauma on teenage mothers and teen parenting.

This dissertation is also dedicated to the many workers in the field of teen parenting. Without their commitment to "the kids," in spite of the low pay and the often physically and emotionally draining work, teenage mothers would face even greater barriers to the achievement of positive development for their children and themselves.

Furthermore, this dissertation is dedicated to the three people in my world who never gave up on me and who "knew" that no matter how long it took, I would finish this piece of work - my husband, Terry, my daughter, Melissa, and my sister, Maureen. Their love, encouragement, and constant support allowed me to persist throughout this long, yet important process of my own becoming.

Finally, this dissertation is dedicated to my parents, Jack Hagan and Betty Edwards. Together they taught me that I could achieve anything. 


\section{ACKNOWLEDGEMENTS}

A work of this size and complexity is never accomplished by a single individual. Therefore, I would like to acknowledge the contributions made by a number of people who have facilitated, guided, and supported the planning and completion of this research. My appreciation and gratitude for their time, knowledge, expertise and patience is beyond measure.

Eileen M. Brennan, Ph.D. and Associate Dean (Graduate School of Social Work at Portland State University) was the first to encourage me to consider joining the Ph.D. program. Once there, she willingly took me under her angelic wing and served as my student advisor. Thankfully for me, she ultimately also guided me through my dissertation research as the chairperson of my dissertation committee. She steadfastly believed in me and in the importance of my research to increase the knowledge base in the field regarding the need for enhanced developmental and clinical services provision for teen mothers. In this regard, Dr. Brennan felt it was crucial for this information to be disseminated to advance funding for developmentally appropriate policy and program formation. Using the terms of attachment theory, I have internalized Eileen's voice, her wisdom, and her compassion into the very core of my being - her voice is pleasantly always with me. 
I also wish to acknowledge Joan Shireman, Ph.D., who also served as a student advisor to me in the early days of my Ph.D. studies. Thankfully, Joan gracefully accepted to serve on my committee as well. Joan has enthusiastically shared her specialized expertise in Child Welfare, and stood as a ready, constant, and judicious source of support. As both a teacher and an advisor her contribution to my learning has been extensive.

Julie Rosenzweig, Ph.D., first served as my M.S.W. advisor and faculty liaison in 1991-1992 when I first began to work with "the girls" (teen mothers). Thankfully, she was generous enough to extend this advisory role to include my dissertation research. I am very grateful that she continued to gift me with her vast clinical knowledge and awareness regarding teen mothers, child and adolescent development, and the impact of trauma.

Thomas Crowfoot, Ph.D., also brought a wealth of experience and knowledge to my Ph.D. committee. His field experience with adolescents, his knowledge of the child welfare system, his awareness and concern for women's issues, as well as his statistical expertise have been of incredible value to me throughout my dissertation research process. Dr. Crowfoot's consistently pleasant manner, his patient and willing support, and his well-timed words of encouragement were also so greatly needed and appreciated.

Kerth O'Brien, Ph.D., very capably served as the Graduate Studies Representative on my committee. In this role she willingly shared her vast 
experience and expertise in social psychology and community research practice. She was a very helpful resource in facilitating the expansion of my understanding of research processes and analyses.

In addition to my Ph.D. committee, I would also like to acknowledge the late Charles Shireman, Ph.D. Dr. Shireman was the epitome of the model graduate professor - wise, knowledgeable, patient, encouraging, fair, accessible, easy to listen to, and he had a delightful sense of humor as well. He was my favorite professor in my masters program and one of my first $\mathrm{Ph.D}$. advisors. Dr. Shireman greatly influenced the development of my love and respect for social work practice, policy, and history. I was blessed to have him in my life, and I miss him.

I would also like to thank Cleopatra Caldwell, Ph.D., a professor and researcher at the University of Michigan's School of Public Health and the Institute for Research on Women and Gender. Her expertise on adolescent females and adolescent childbearing helped to guide my sample demographics and the parameters of my research questions. Her help and encouragement were very appreciated.

I would also like to express my appreciation to Sondra Beatley, a close friend and professional associate who eagerly offered to work as my research assistant. Having worked with teen mothers for years herself, Sondra too believed in the need for this research to be accomplished. Sondra very cheerfully, and very 
"nicely," helped to keep me on track throughout the long and often "painful" data collection, data cleaning, and data input processes.

I especially wish to acknowledge Robin Triest-Carlson, MSW, LCSW and Executive Director of the Salvation Army's White Shield Center. For the last 15 years Robin has been both a clinical and administrative role model and mentor for me in the field of social work in general, and more specifically in regards to the many issues surrounding child and adolescent development, childhood trauma, and teen pregnancy and parenting. In her 25 years working with teen mothers, Robin has positively touched the lives of literally hundreds of teen mothers, their children, and workers in the field. She is truly an inspiration, and a dear friend. I want to be just like her "when I grow up."

My gratitude also goes out to Pati Sluys. Pati is the formatting and editing angel that God assigned to this project. She uses her computer and formatting skills like a magic wand, and thankfully for me she passed this powerful tool over this document repeatedly to prepare it for print.

For all the other very special and supportive people in my life who never gave up on me, always listened to me, always offered help when they could, and always believed in my path - Cheri Shelley, Linda Spencer, Debi Towner, Dr. Joy Degruy-Leary, Paula Mike...well, the rest of you know who you are. Thank you, thank you, thank you! 
For my first "best friend" who unknowingly placed my feet solidly on this path when we were only 14 ...I may not be able to change the past, but in your honor I will always do my best to make the future better for other adolescent mothers. 
TABLE OF CONTENTS

Page

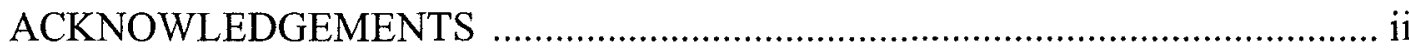

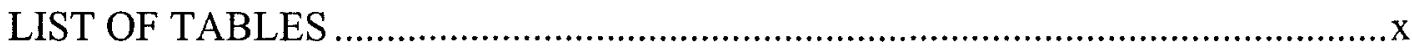

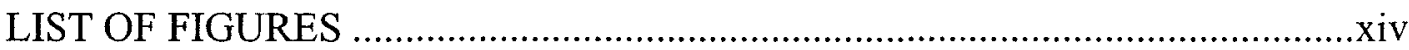

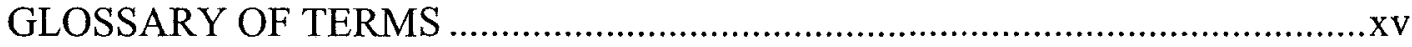

CHAPTER

I THE SOCIAL PROBLEM AND THE RESEARCH

THEORY BASE ................................................................. 1

Introduction to the Social Problem ...................................... 1

The Theory Base: A Biopsychosocial and

Neurodevelopmental Model ...............................................5

Clinical Disorders and Symptoms

Age and Gender Differences

Attachment and Socioemotional Development

Cognitive Development

Identity Development

Research and Program Evaluations.....................................26

II THE RESEARCH QUESTIONS ............................................ 31

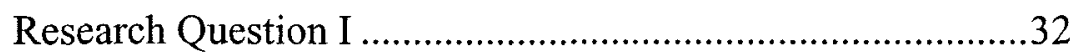

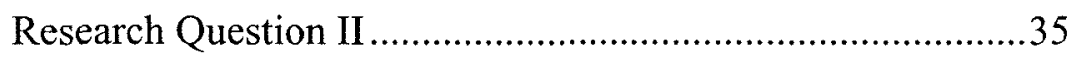

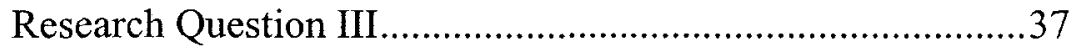

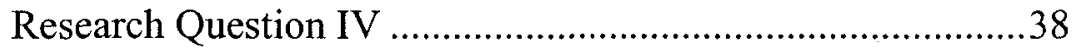


III THE RESEARCH DESIGN, METHODOLOGY, AND SAMPLE CHARACTERISTICS ...............................................41

Research Design............................................................ 41

Research Recruitment and Sample....................................4 42

Sample Demographic Characteristics ...............................44

Data Collection Procedures.................................................50

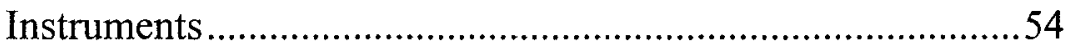

The Childhood Trauma Questionnaire

The Trauma Symptom Checklist for Children

The BarOn Emotional Quotient Inventory-Youth Version

The Adult-Adolescent Parenting Inventory-2

The Demographic Questionnaire

The Services Questionnaire

IV RESULTS .83

Research Question One .85

Hypotheses 1

Research Question Two

Hypotheses 2a-d

Research Question Three .98

Hypotheses 3.1(a-d) and 3.2

Research Question Four 103

Service Availability and Accessibility Mental Health Status 
Hypothesis 1: Childhood Trauma, Trauma Symptomology, and Socioemotional Development

Hypotheses 2a-d: Childhood Trauma,Trauma Symptomology, Socioemotional Development, and Parental Attitudes and Behaviors

Hypothesis $2 \mathrm{a}, \mathrm{c}, \mathrm{d}$

Hypothesis 2c: Corporal Punishment

Hypotheses 3.1a-d: Age, SES, and Parenting Attitudes and Behaviors

Hypothesis 3.1a: Empathy

Hypothesis 3.1b: Inappropriate Behaviors and

3.1c - Corporal Punishment

Hypothesis 3.1d: Role Reversal

Hypothesis 3.2: Age, SES, and Socioemotional Development 126

Research Question 4: Services Information 126

Contributions to the Field ................................................... 130

Implications for Practice and Policy ................................ 132

Limitations of the Study ...................................................... 133

Suggestions for Future Research......................................136

REFERENCES 138

\section{APPENDICES}

A The Services Questionnaire. 152

B The Demographic Questionnaire 163 


\section{LIST OF TABLES}

Table

Page

2.1 Hierarchical Regression Model for Research Question I...........................34

2.2 Research Model for Research Question II: Hypotheses 2a-d ......................36

2.3 Research Question III: Research Model Hypotheses 3.1 a-d and 3.2 ............38

3. 1 Participating Programs, Number of Participants, and Counties of Residence

3.2 Participant Demographic Characteristics by Age and Ethnicity .45

3.3 Relationship Characteristics of Participants, by Age and Ethnicity .46

3.4 Participants Who Are Still in a Romantic Relationship with the Father of at Least One of Their Children, by Age and Ethnicity

3.5 Participants' Household Composition: Number of Additional People Living in Home with Respondent, by Ethnicity.

3.6 Participants' Education: Number of Participants Currently Working on GED and High School Diploma, by Ethnicity

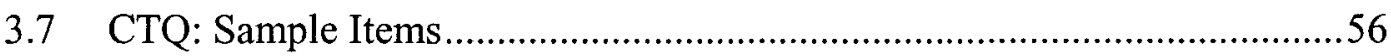

3.8 CTQ: Percentage of Participants Reporting Abuse and Neglect at the Low to Moderate, Moderate to Severe, or Severe to Extreme Levels by Ethnicity

3.9 CTQ: Validation Studies and Current Study Mean Scale Scores, Standard Deviation and Percentage Differences Between Current Study and Validation Studies (Bernstein \& Fink, 1998) 59

3.10 CTQ: Reliability Coefficients Comparison Between Validation Sample (Bernstein \& Fink, 1998) and Current Study Sample. 
3.11 TSCC: Sample Items..............................................................................63

3.12 TSCC: Participants' Subclinical and Clinical Response Percentages by Ethnicity and Total $N$........................................................................65

3.13 TSCC: Validation Study and Current Study Mean Scale Scores and

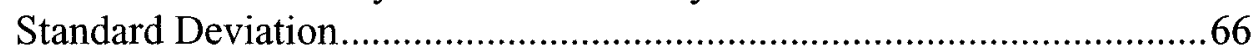

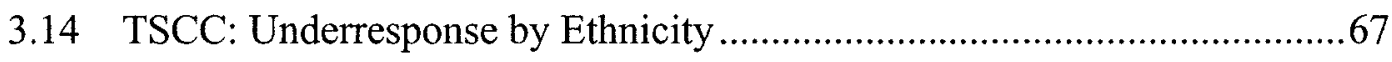

3.15 TSCC: Reliability Coefficients for Validation (Briere, 1996) and

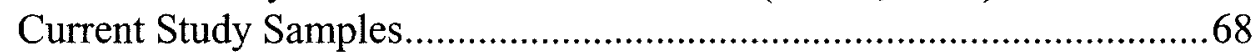

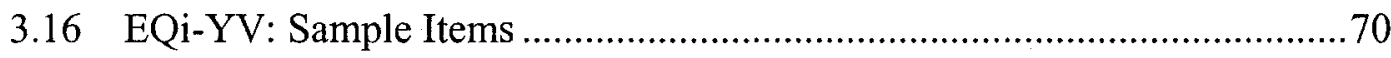

3.17 EQi-YV: Validation Study and Current Study Mean Scale Scores and Standard Deviations .......................................................................

3.18 EQi-YV: Percentage of Current Study and Validation Study Below Average Subscale Scores, by Ethnicity ......................................................72

3.19 EQi-YV: Inconsistency and Positive Impression Current Sample Score Percentages by Ethnicity and Total $N$. .73

3.20 EQi-YV: Reliability Coefficients for the Validation Study and the Current Study .74

3.21 EQi-YV: Scale/Subscale Intercorrelations for Current Study and the Validation Study 75

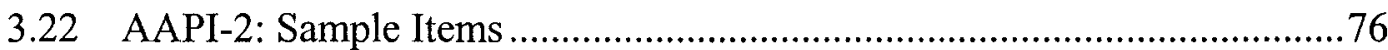

3.23 AAPI-2: Mean Scale Sten Scores, Mode, Median, and $S D$ for the Current Study .77

3.24 AAPI-2: HFJ and Salt Lake County Mean, Pre and Post Parent Training AAPI-2 Scale Sten Scores as Compared to Current Study Scale Sten Scores .78

3.25 AAPI-2: Reliability Coefficients for Original Validation Study Sample and the Current Study Sample. 80 
4.1 Hypothesis 1: Summary of Stepwise Hierarchical Analysis

Predicting EQi Total Score on the Basis of Child Abuse and

Neglect Trauma Symptomology

4.2 Hypothesis 1: Means, Standard Deviations, and Interscale

Correlations Among Study Variables - Experience of Childhood

Trauma (CTQ), Current Trauma Symptomology (TSCC), and

Emotional Quotient Total Score.

4.3 Hypothesis 2a: Summary of Stepwise Hierarchical Analysis Predicting

AAPI-2 Empathy Scale Score on the Basis of Experience of Child

Abuse and Neglect Trauma (CTQ), Current Trauma Symptomology

(TSCC), and Total Emotional Quotient Score (EQi-YV)

4.4 Hypotheses 2a-d: Means, Standard Deviations, and Interscale Correlations Among Study Variables - Experience of Childhood Trauma (CTQ), and Parental Beliefs and Behaviors (AAPI-2) .93

4.5 Hypotheses 2a-d: Means, Standard Deviations, and Interscale Correlations Among Study Variables - Parental Beliefs and Behaviors (AAPI-2) and Current Experience of Trauma Symptomology (TSCC)

4.6 Hypotheses 2a-d: Means, Standard Deviations, and Interscale Correlations Among Study Variables - Parental Beliefs and Behaviors (AAPI-2) and the EQi Total Score (EQi-YV)

4.7 Hypothesis 2d: Summary of Stepwise Hierarchical Analysis Predicting AAPI-2 Corporal Punishment Scale Score on the Basis of Experience of Child Abuse and Neglect Trauma (CTQ), Current Trauma Symptomology (TSCC), and Total Emotional Quotient Score (EQi-YV)

4.8 Hypotheses 3.1a-b \& 3.2: Means, Standard Deviations, and Interscale Correlations Among Study Variables - Parental Beliefs and Behaviors (AAPI-2), Age and SES

4.9 Hypothesis 3.1a: Summary of Multiple Regression Analysis Predicting the AAPI-2 Empathy Scale Score on the Basis of SES and Age 
4.10 Hypothesis 3.1d: Summary of Multiple Regression Analysis for Predicting the AAPI-2 Role Reversal Scale Score on the Basis of SES and Age

4.11 Research Question 4: Services Related to Finances, Medical Care, or Other Tangible Goods

4.12 Research Question 4: Services Related Directly to Parenting, Parent Training, and Childcare

4.13 Research Question 4: Services Related to Schooling, Job Skills/ Training, Vocational Training, and Independent Living Skills

4.14 Research Question 4: Services Related to Family Planning .109

4.15 Research Question 4: Services Related to Mental Health and Socioemotional Development

4.16 Research Question 4: Mental Health Diagnoses and Medication History Reported by Participants

4.17 Services: Percentage of Services Least Received, Least Offered, and Most Wanted and/or Needed by Study Participants.

4.18 Findings Summary: Research Questions 1-3 and Resultant Hypotheses 1-3.2 


\section{LIST OF FIGURES}

Figure Page

2.1 Research Question IV: Service Areas by Category ...............................39

2.2 Theoretical Research Model ..............................................................40 


\section{GLOSSARY OF TERMS}

AAPI-2 (Instrument): The Adult Adolescent Parenting Inventory (Bavolek \& Keene, 2001). The AAPI is an inventory designed to assess the parenting and child rearing attitudes of adult, adolescent, and pre-parent populations. Based on the known parenting and child rearing behaviors of abusive parents, responses to the inventory provide an index of risk for practicing behaviors known to be attributable to child abuse and neglect (Bavolek \& Keene, 2001, p. 1).

Adaptability Skills/Abilities (EQi-YV Scale): One of the Emotional Quotient Inventory-Youth Version scales (BarOn \& Parker, 2000a, p. 19). People with high scores on the adaptability scale of the EQi-YV tend to be flexible, realistic, and effective in managing change. They are good at finding positive ways of dealing with everyday problems.

Anger (TSCC Scale): One of the Trauma Symptoms Checklist for Children scales (Briere, 1996, p. 12). Scores on the anger construct of the Trauma Symptom Checklist for Children reflect the angry thoughts, feelings, and behaviors reported by the child. Items in the anger scale include feeling mad and mean, feeling hatred, having difficult de-escalating anger, wanting to yell at or hurt people, and arguing and fighting. 
Anxiety (TSCC Scale): One of the Trauma Symptoms Checklist for Children (Briere, 1996, p. 12) scales. Scores on the anxiety construct of the Trauma Symptom Checklist for Children reflect the extent which the child is experiencing generalized anxiety, hyperarousal, and worry, as well as specific fears of men or women, of the dark, and of being killed. Also tapped by this scale are episodes of free-floating anxiety and fears of impending danger.

Corporal Punishment (AAPI Scale): One of the scales of the Adult Adolescent Parenting Inventory (Bavolek \& Keene, 2001, p. 6). The authors of the AAPI-2 define corporal punishment as physical punishment as a means of discipline.

CTQ (Instrument): The Childhood Trauma Questionnaire: A Retrospective Self Report (Bernstein \& Fink, 1998, pp. 2, 32). The CTQ items/scales reflect common definitions of child abuse, maltreatment, and neglect as found in the childhood trauma literature: emotional abuse, emotional neglect, sexual abuse, physical abuse, and physical neglect.

Depression (TSCC Scale): One of the Trauma Symptoms Checklist for Children scales (Briere, 1996, p. 12). Scores on the depression construct of the Trauma Symptom Checklist for Children reflect the extent to which the child is experiencing sadness, unhappiness, and loneliness, episodes of tearfulness, and depressive cognitions such as guilt and self-denigration. 
xvii

Dissociation (TSCC Scale): One of the Trauma Symptoms Checklist for Children scales (Briere, 1996, p. 13). This scale measures the extent to which the child experiences mild-to-moderate dissociative symptomology.

Dissociation items in this scale include derealization, one's mind going blank, emotional numbing, pretending to be someone else or somewhere else, daydreaming, memory problems, and dissociative avoidance.

Emotional Abuse (CTQ Scale): One of the Childhood Trauma Questionnaire scales (Bernstein \& Fink, 1998, p. 2). For the purposes of this study, emotional abuse refers to verbal assaults on a child's sense of worth or wellbeing, or any humiliating, demeaning, or threatening behavior direct toward a child by an older person.

Emotional Neglect (CTQ Scale): One of the Childhood Trauma Questionnaire scales (Bernstein \& Fink, 1998, p. 2). The authors of this measure state that emotional neglect refers to the failure of caretakers to provide a child's basic psychological and emotional needs such as love, encouragement, belonging, and support.

Empathy (AAPI Scale): One of the Adult Adolescent Parenting Inventory scales (Bavolek \& Keene, 2001, p. 6). Empathy in this scale is defined as the ability to be aware that needs of another are a priority.

EQi-YV (Instrument): Emotional Quotient Inventory - Youth Version (BarOn \& Parker, 2000a, p. 1). The EQi-YV is a self-report instrument designed to 
measure emotional intelligence in young people aged $7-18$ years.

According to the BarOn model of emotional and social intelligence, emotional intelligence pertains to the emotional, personal, and social dimensions of intelligence and comprises abilities related to understanding oneself and others, relating to people, adapting to changing environmental demands and managing emotions.

Emotional Quotient (EQi-YV Scale): One of the Emotional Quotient InventoryYouth Version scales (BarOn \& Parker, 2000a, p. 19). People with high scores on the total emotional quotient scale are generally effective in dealing with daily demands and are typically happy.

General Mood (EQi-YV Scale): One of the Emotional Quotient Inventory-Youth Version scales (BarOn \& Parker, 2000a, p. 19). People with high scores on the general mood scale are optimistic, have a positive outlook, and are typically pleasant to be with.

Inappropriate Expectations (AAPI Scale): One of the Adult Adolescent Parenting Inventory scales (Bavolek \& Keene, 2001, p. 6). Inappropriate expectations are defined by the AAPI authors as inaccurately perceiving age and development related skills and abilities of children. Inconsistency Index (EQi-YV subscale): Respondents with high scores on this subscale are showing considerable inconsistencies in the way they have responded to similarly worded questions. They may have misunderstood 
the instructions, or may have responded in a careless or random fashion (BarOn \& Parker, 2000a).

Intrapersonal Skills/Abilities (EQi-YV Scale): One of the Emotional Quotient Inventory-Youth Version scales (BarOn \& Parker, 2000a, p. 19). People who score high on the intrapersonal skills/abilities scale understand their emotions and are able to express and communicate their feelings and needs. Interpersonal Skills/Abilities (EQi-YV Scale): One of the Emotional Quotient Inventory-Youth Version scales (BarOn \& Parker, 2000a, p. 19) scales. People with high scores on this scale are likely to have satisfying interpersonal relationships. They are good listeners and are able to understand and appreciate the feeling of others.

Physical Abuse (CTQ Scale): One of the Childhood Trauma Questionnaire scales (Bernstein \& Fink, 1998, p. 6). For the purposes of this study, physical abuse refers to bodily assaults on a child by an older person that pose a risk of, or result in, injury.

Physical Neglect (CTQ Scale): One of the Childhood Trauma Questionnaire scales (Bernstein \& Fink, 1998, p. 6). For the purposes of this study, physical neglect refers to the failure of caregivers to provide a child's basic physical needs, including food, shelter, safety and supervision, and health. 
Positive Impression (EQi-YV subscale): Individuals with high scores on this subscale may be attempting to create an overly positive self-impression or impression of self on others (BarOn \& Parker, 2000a).

PTSS (TSCC Scale): One of the Trauma Symptoms Checklist for Children scales (Briere, 1996, p. 13). This scale reflects classic posttraumatic symptoms including intrusive thoughts, sensations, and memories of painful past events; nightmares; fears of men or women and cognitive avoidance of negative thoughts and memories.

Role Reversal (AAPI Scale): One of the Adult Adolescent Parenting Inventory scales (Bavolek \& Keene, 2001, p. 8). The role reversal scale reflects the reversal of traditional parent-child role expectations by the parent, such that the child is expected to adopt some of the behaviors traditionally associated with parents. In role reversal, parents act like helpless, needy children looking to their own children for parental care and comfort.

Sexual Abuse (CTQ Scale): One of the Childhood Trauma Questionnaire scales (Bernstein \& Fink, 1998, p. 6). In the context of this measure, sexual abuse refers to sexual contact or conduct between a child and older person; explicit coercion is a frequent but not essential feature of these experiences. Sexual Concerns (TSCC Scale): One of the Trauma Symptoms Checklist for Children scales (Briere, 1996, pp. 13-14). The sexual concerns scale measures sexual distress and preoccupation that are atypical when they 
occur earlier in development than expected or with greater than usual frequency. This scale taps unwanted sexual responses, conflicts, and fears. Stress Management Skills/Abilities (EQi-YV Scale): One of the Emotional Quotient Inventory-Youth Version scales (BarOn \& Parker, 2000a, p. 19). According to the authors, people with high scores on the stress management skills/abilities scale are generally calm and work well under pressure. They are rarely impulsive and can usually respond to a stressful event without an emotional outburst.

TSCC (Instrument): Trauma Symptoms Checklist for Children (Briere, 1996) is a self-report measure of posttraumatic distress and related psychological symptomology. It is intended for use in the evaluation of children who have experienced traumatic events, including childhood physical and sexual abuse, victimization of peers, major losses, the witnessing of violence done to others, and natural disasters. This instrument consists of six clinical scales: anxiety, depression, anger, posttraumatic stress, dissociation, and sexual concerns. 


\section{CHAPTER I}

\section{THE SOCIAL PROBLEM AND THE RESEARCH THEORY BASE}

Introduction to the Social Problem

In 2004 in the United States 1,470,000 babies were born; $23 \%$ of these children were born to teenage mothers age 15-19 (Centers for Disease Control and Prevention, [CDC] 2006), another 6,600 were born to girls age 14 and under. If the field literature is correct, $50-75 \%$ (or at the least 176,000) of these girls were abused and/or maltreated as children (Alan Guttmacher Institute [AGI], 1994; Levine-Coley \& Chase-Landsdale, 1998; McCullough \& Scherman, 1991; National Research Council [NRC], 1993).

Too many view this information as just boring statistics unable to stir much concern; in short, someone else's problem. The reporting of statistics does not always include the background of the population being reported on. To bring context to the statistics reported on in this document, and to sense the tragedy behind the numbers, picture this.

If 20 million people were infected by a virus that caused anxiety, impulsivity, aggression, sleep problems, depression, respiratory and heart problems, vulnerability to substance abuse, antisocial and criminal behavior, retardation and school failure, we would consider it an urgent public health crisis.

Yet, in the United States alone, there are more than 20 million abused, neglected and traumatized children vulnerable to these problems. Our 
society has yet to recognize this epidemic, let alone develop an immunization strategy. (Perry, 2000a, p. 1)

In this small study more than three fourths of the participants may be caught in the midst of Dr. Perry's epidemic. A nationwide projection from these statistics would mean that approximately 176,000 teenage mothers may also be trapped in the epidemic.

This is no small matter. Therefore, the purpose of this research was to begin the process of identifying and illuminating the issue, and to recognize and spotlight the personal, developmental, and abuse related characteristics of teenage mothers in need of additional intervention, care, and support for recovery. 'To do this, the research design required looking much more carefully at the traumatic preparenting experiences and the consequent developmental effects of these experiences on teenage mothers. Although this specific research has not yet been taken on by others in the field, research on childhood trauma has consistently reported:

1. the deleterious effects of trauma on current and future functioning (Perry, 2000b, 2000c, 2002, 2006; Siegel, 1999; van der Kolk, 2000a),

2. the negative effects of trauma on the achievement of normal age appropriate development (Perry, 2006; van der Kolk, 2000a),

3. the intergenerational effects of traumatic socialization and traumatic experiences on parent attitudes and behaviors (Perry, 2006), 
4. the harmful secondary effects of trauma on offspring's personal, interpersonal, educational, and economic developmental outcomes (Perry, $2000 \mathrm{~b}, 2000 \mathrm{c}, 2002,2006)$, and

5. more specifically, the often negative effects of teen parenting outcomes for both the mother and her child(ren) (Black et al., 2002; Karr-Morse \& Wiley, 1997; Klerman, 1993; Maynard, 1996; Perry, 2000b, 2000c, 2001, 2006). Adolescent pregnancy and parenting has received much attention over the last several decades and has been raised as an example of the social and moral decay of America (Bachu, 1999; Levine-Coley \& Chase-Landsdale, 1998; Maynard, 1996; Osofsky, Hann, \& Peebles, 1993; Schwartz \& Rutter, 1998). Although there has been a sharp decline in adolescent parenting over the last decade, approximately 800,000 teenagers (as of 2002, age 14 to 19; AGI, 2006) become pregnant each year and approximately half of these pregnancies result in birth (349,000 in 2004; AGI, 2006).

It is estimated that nationally adolescent childbearing results in a staggering $\$ 6.9$ billion per year in taxpayer costs, with social costs such as lost productivity and resource diversion totaling as high as $\$ 29$ billion annually (Campaign for Our Children, 1998; Maynard, 1996). Not only does adolescent parenting result in huge economic and social costs to the nation, it also exacts a great personal cost from adolescent mothers and their children. Of especial public concern in this regard are the observed negative personal, social, and economic outcomes for the children of 
many of these mothers, as well as the high rates of repeat pregnancies (AGI, 1998, 1999b, 1999c; Dubowitz et al., 2001; Klerman, 1993; Levine-Coley \& ChaseLandsdale, 1998; Maynard, 1996; McCullough \& Scherman, 1991).

Society's frustration with the failure of social welfare, social service, and educational interventions to alleviate or mediate many of the problems associated with teen parenting is apparent in the research and literature on this topic. America has many programs for these young mothers (Chase-Lansdale, Brooks-Gunn, \& Paikoff, 1991; Levine-Coley \& Chase-Lansdale, 1998) that offer instruction across a variety of domains (i.e., educational, parenting, social, and occupational). Interventions are provided for adolescent mothers through a menu of programs: school based, center based, residential, home visiting, crisis centers, respite care services, occupational training, and teen parenting groups for example. The common uniting goal of most teen parenting and social welfare programs is to help these young mothers become positive and adaptive parents who are economically self-sufficient (Chase-Lansdale et al., 1991; Levine-Coley \& Chase-Landsdale, 1998).

The importance of this goal is obvious. However, this goal and the subsequent interventions do not necessarily reflect the core therapeutic and developmental needs of many adolescent mothers. This is especially so when one considers the large number of teen mothers who report being abused or maltreated as children (AGI, 1994; Levine-Coley \& Chase-Landsdale, 1998; McCullough \& 
Scherman, 1991; NRC, 1993), and the fact that research continues to show that child abuse and neglect can directly and/or indirectly negatively affect neurological structures and functioning and hence, all domains of psychosocial development (Perry, 2000b, 2000c, 2006; Perry \& Pollard, 1998; Siegel, 1999; Starr, MacLean, \& Keating, 1991; van der Kolk, 1998, 1999, 2001). Yet, clinical therapeutic services to specifically address the socioemotional, developmental, and psychological effects of child abuse and neglect are not readily or affordably available in most current teen parent service offerings.

The Theory Base: A Biopsychosocial and

Neurodevelopmental Model

Responsible parenthood and economic self-sufficiency can be challenging for those who have experienced even the most supportive and nurturing family and social environments. For adolescent mothers suffering the effects of child abuse and neglect such responsibility may be beyond their current social, emotional, and cognitive developmental capacity. Yet to date, there has been scant discussion or research regarding the effects of childhood maltreatment trauma on adolescent mothers' development or adolescent parenting (C. Caldwell, personal communication, 2000; R. Carlson, personal communication, 1999, 2000; ChaseLansdale et al., 1991; Levine-Coley \& Chase-Landsdale, 1998; Maynard, 1996; B. A. van der Kolk, personal communication, 1999, 2000). 
While there is no single symptom that exemplifies child abuse or neglect trauma (Kashani \& Allen, 1998), research has shown relatively consistent neurobiological symptoms across types of traumatic events: neglect, physical and sexual abuse for example (van der Kolk, 1998). However, the long-term individual effects of child abuse and/or neglect vary according to the age of the victim, the nature (type of abuse), the pattern (discrete or chronic), the developmental stage at the time of abuse, and the presence of protective or risk factors (Herrenkohl, Herrenkohl, Egolf, \& Wu, 1993; Perry, 1994; van der Kolk, 1998; Wolfe \& McGee, 1993).

The experience of trauma - the inescapable exposure to terrifying life events - can result in neurological, physiological, and psychological changes. Difficulties in learning, attention, physiological arousal, and affect regulation can result as well (Perry, 2006; Siegel, 1999; van der Kolk, 1987b). Aggression towards self and others, symptoms of dissociation, numbing, avoidance, chronic feelings of shame, self-blame, anxiety, and depression are common among victims of trauma, as are a victim's loss of a sense of safety, self-trust, trust in others, and self-worth. Given these effects of trauma, it is not surprising therefore that victims (especially child victims) also frequently experience the loss of, or inability to form, sustaining life beliefs and have difficulty in forming or maintaining satisfactory and healthy relationships with others (Perry, 1994, 1999, 2000c, 2006). 
Although the human response to trauma is recognized as a normal response to an abnormal event, the effects can be nonetheless chronic and crippling to one's ability to function in normal school, workplace, and social environments (Anda et al., 2005; Perry, 1994, 1999, 2000c, 2001; Rothschild, 2000; van der Kolk, 1987a, 1996a, 1996b, 1996c, 2001). Due to the tragic effects of trauma, developmental and therapeutic services may be necessary to help traumatized adolescent mothers recover from damaging early life experiences in order to function adaptively as individuals, as citizens, and as parents (Kashani \& Allan, 1998; Perry, 2006; Perry \& Azad, 1999; Rickel \& Becker, 1997; Siegel, 1999; van der Kolk, 1987a, 1987b, 1996b, 1996c, 2000a, 2000b, 2001; van der Kolk, Burbridge, \& Suzuki, 1997).

According to the child abuse and neglect literature, childhood trauma can disrupt or impair optimal development and result in a broad range of socioemotional, cognitive, and behavioral difficulties (Dubowitz et al., 2001; KarrMorse \& Wiley, 1997; Perry, 1994, 1999, 2000b, 2000c, 2006; Perry \& Azad, 1999; Perry \& Pollard, 1998; Schwartz \& Perry, 1994; van der Kolk, 1998; 2000a, 2000b, 2001; van der Kolk et al., 1997; van der Kolk \& Greenberg, 1987; van der Kolk \& McFarlane, 1996). Of the more than one million verified cases of child abuse and/or neglect in the United States each year (Sedlak \& Broadhurst, 1996) for example, it is estimated that approximately $30 \%$ of these children will develop post-traumatic stress disorder (PTSD), and more than twice as many will develop post traumatic stress syndrome (PTSS; Briere, 1992; Perry, 2000a; Perry \& Azad, 
1999). Although service providers for adolescent mothers infrequently formally assess for PTSD or PTSS, given the high occurrence of abuse reported by this population, it is likely that many of these mothers fall within these diagnostic categories (Levine-Coley \& Chase-Landsdale, 1998).

As current research makes clear, not only can child maltreatment trauma alter the developmental trajectories of its victims, they also affect the neurological functioning and psychobiological development of a child or youth (Perry, 1994, 1999, 2000a; Perry \& Pollard, 1998; Rothschild, 2000; Schwarz \& Perry, 1994; van der Kolk, 1987a, 1987b, 1996a, 1996b, 1996c, 1998, 1999; van der Kolk et al., 1997). In severe cases a child's neurological structures can be changed as well (Perry, 2006). Without appropriate therapeutic interventions these changes can be permanent. Therefore, it is crucial that teen parenting program directors, policy makers and funders understand that the negative impact of child maltreatment trauma may be an important determinant of how the past continues to shape the present and future of both mother and child (Perry, 2000a; Perry \& Pollard, 1998; Siegel, 1999; van der Kolk, 1987a, 2000a). Accordingly, interventions and treatment for these young mothers should encompass what is currently known about how abusive and neglectful experiences shape all domains of development. According to medical neuroscience experts Bessel van der Kolk (1996b, 1996c, 1998), Bruce Perry (1994, 1999, 2000b, 2000c, 2006) and Daniel Siegel (1999), uncontrollable and terrifying experiences in childhood which overwhelm 
immature neurobiological structures can have profound effects on the developing central nervous system and consequently, on fundamental physiological, cognitive, socioemotional and behavioral development (Perry, 1994, 1999, 2000b, 2000c, 2001, 2006; Perry \& Pollard, 1998; van der Kolk, 1987a, 1987c, 2001). That abused and maltreated children suffer more frequent developmental disruptions and that traumatic incidents in childhood can negatively affect specific and global functioning within and across multiple domains has been amply supported in research (Ford \& Kidd, 1999; Perry, 1994, 1999, 2000b, 2000c, 2006; van der Kolk, 1998, 2000a, 2001; van der Kolk et al., 1997).

Perry, Pollard, Blakley, Baker, and Vigilante (1995) state,

Childhood trauma has a profound impact on the emotional, behavioral, cognitive, social and physical functioning of children. Developmental experiences determine the organizational and functional status of the mature brain. There are various adaptive mental and physical responses to trauma, including physiological hyperarousal and dissociation. Because the developing brain organizes and internalizes new information in a usedependent fashion, the more a child is in a state of hyperarousal or dissociation, the more likely they are to have neuropsychiatric symptoms following trauma. The acute adaptive states, when they persist can become maladaptive traits. (pp. 1-2)

\section{Clinical Disorders and Symptoms}

The psychobiological impact of trauma can result in psychiatric disorders of childhood or adulthood, for example reactive attachment disorders, affective disorders, anxiety and panic disorders, and dissociative disorders. Additionally abused and maltreated children are diagnosed more frequently than their nonabused peers with ADD, ADHD and learning disorders, as well as with 
oppositional-defiant and conduct disorder (Compass, Conner, \& Hinden, 1998; Karr-Morse \& Wiley, 1997; Perry, 1994, 1999, 2000b, 2000c; Perry \& Pollard, 1998; Schwarz \& Perry, 1994; Starr et al., 1991; van der Kolk 1998, 1999).

Victims of chronic or pervasive trauma also frequently present with complex symptom clusters and/or with co-morbid problems such as substance abuse, somatic complaints, and eating disorders (Kashini \& Allen, 1998; Perry, 1994, 1999, 2000b, 2000c; Perry \& Pollard, 1998; Schwarz \& Perry, 1994, van der Kolk, 1987a, 1996b, 1998, 2000a, 2001). Affective lability and dysregulation, depression, anxiety, general and/or specific phobias, problems with reality testing and impulse control, emotional numbing, and sleep problems are commonly reported symptoms as well.

Furthermore, it is also not unusual for victims of childhood trauma to experience school and workplace failures, and interpersonal relationship problems (Egeland, 1993; Ford \& Kidd, 1999; Garmesky, 1987; Perry, 1994, 1999, 2000b, 2000c, 2006; Perry \& Pollard, 1998; Schwartz \& Perry, 1994; van der Kolk, 1987a, 1987b, 1996a, 1996b, 1996c, 1998; 2000a, 2001). For those with histories of child abuse and neglect, adulthood is all too often framed and defined within the context of their traumatic childhood experiences.

Age and Gender Differences

While current research on the trauma of children and adolescents continues to lag far behind that on adults (Kashani \& Allan, 1998; Perry, 1999; van der Kolk, 
1987a) recent findings show that the symptoms and rates of affective, anxiety, and behavioral disorders and symptomology frequently observed in maltreated children, progressively increase between childhood and adolescence (Egeland, 1993; Kashani \& Allan, 1998; Perry \& Pollard, 1998; Schwarz \& Perry, 1994). Further evidencing the critical need for early intervention, as these children age, moving from childhood to puberty and adolescence for example, remediation efforts for the emotional effects of trauma are frequently less effective (Schwarz \& Perry, 1994; van der Kolk \& Greenberg, 1987). Additionally, as children who have been abused and/or neglected move into adolescence, important gender differences begin to become apparent and to stabilize.

Internalizing symptoms are observed more frequently in girls and externalizing symptoms are seen more often among boys (Brown \& Gilligan, 1992; Compas et al., 1998; Perry, 1999; Perry \& Azad, 1999; Perry et al., 1995; van der Kolk, 1999, 2000a). In studies of high risk and clinically referred adolescents, girls scored significantly higher and more often met diagnostic criteria for major depression, dysphoria, anxiety, and dissociation than did clinically referred boys (Compas et al., 1998; Kashani \& Allan, 1998; Perry \& Azad, 1999; van der Kolk, 2000a). Not unexpectedly, the more conspicuous aggressive, non-compliant, and hyperactive behaviors of boys result in more frequent treatment referrals than do the internalized symptoms of girls. Perry et al. (1995) explain this lack of referral 
parity by stating, "The potential homicide threatens, the potential suicide inconveniences" (p. 11).

It has long been obvious to teen parent, child abuse and neglect service providers that many adolescent mothers have been psychologically and developmentally injured by hostile childhood experiences (Belenky, Clinchy, Goldberger, \& Tarule, 1986; Brown \& Gilligan, 1992; C. Caldwell, personal communications, 2000; R. Carlson, personal communication, 1999, 2000; B. van der Kolk, personal communication, 1999, 2000). Unfortunately, one possible outcome of the differential male/female referral process may be that traumatized girls are more likely to go unnoticed until some of these girls are referred to or seek pregnancy and parenting services, or perhaps later come to the attention of child protection or mental health agencies. Studies have shown that clinical depression is reported at statistically significant levels in adult women molested as children, and the lifetime risk for clinical depression is much greater among this population as well (Brier, 1992). Certainly, the significant gender symptomology differences, the lower rate of treatment referrals for girls, and the high number of adolescent mothers reporting experiences of abuse, suggests the need for increased clinical and research attention focusing on the early recognition and treatment of the traumatic sequelae in high-risk female children and adolescents (Compas et al., 1998; LevineColey \& Chase-Landsdale, 1998). This is especially so when one considers that the poor outcomes of adolescent parenting regrettably may suggest that the children of 
these young mothers are at risk of becoming the secondary victims of the trauma(s) experienced by their mothers (Dubowitz et al., 2001).

Attachment and Socioemotional Development

Although not all adolescent mothers abused as children are likely to have experienced attachment trauma or disruptions, research has shown that as many as $80 \%$ of children who have been abused and/or maltreated in early childhood show insecure attachment patterns (van der Kolk, 1998). Therefore it is important to understand the effects of attachment trauma on child and adolescent development to inform developmentally appropriate services for adolescent mothers abused as children. Moreover, the subject of attachment is especially significant when considering the offspring of these young mothers since there is sufficient research evidence regarding the inter-generational transmission of attachment patterns (Ainsworth, Blehar, Waters, \& Wall, 1978; Ainsworth \& Eichberg, 1991; Bowlby, 1969, 1988; Hughes, 1997; Main, 1995; Siegel, 1999; van der Kolk, 1987c)

For children abused or neglected in infancy or toddlerhood the disruption to normal attachment processes can severely inhibit all aspects of continuing development (Bowlby, 1969, 1988; Hughes, 1997; Karr-Morse \& Wiley, 1997; Perry, 1994, 1999, 2000b, 2000c; Perry \& Pollard, 1998; Schwarz \& Perry, 1994; van der Kolk, 1987c). Because primary attachment processes function to both ensure the child's biological survival and to lay the foundation for later personality and socioemotional development, van der Kolk (1987c) refers to attachment trauma 
as "the earliest and possibly most damaging [type of] psychological trauma" (p. 32).

The parent-child attachment relationship provides the building blocks for all future relationships and for the full development of the child (Hughes, 1997; Main, 1995). It is a caregiver's timely and sensitive attunement to and fulfillment of an infant's biological and emotional needs that not only enables the child's biological survival, but also creates a state of well being within the child by attesting to his/her importance and significance. It is within these moment-to-moment, day-today attunement experiences that the seeds of "self" are planted (Hughes, 1997; Main, 1995; Siegel, 1999; van der Kolk, 1987c). Though unconscious and preverbal, attachment experiences initiate the formation of the infant's inner working model or mental representations of self and others; they quite literally “...constitute the womb for the 'psychological birth' of an infant” (Hughes, 1997;

p. 3). If these experiences are positive they will nurture and facilitate fluid, timely, and healthy development while concurrently establishing a child's feelings of safety, security, self-worth, self-trust, and trust in others (Ainsworth et al. 1978; Ainsworth \& Eichenberg, 1991; Bowlby, 1969, 1988; Hughes, 1997; Main, 1995; Perry, 1994; Siegel, 1999; van der Kolk, 1987c).

Communication patterns, styles of relating and caregiving, feelings of safety and security, as well as empathetic and conscience capabilities all flow from the early working models framed in early attachment relationships (Hughes, 1997; 
Siegel, 1999; van der Kolk, 1987c). Accordingly, the importance of attachment experiences reach far beyond family and personal relationships. Attachment experiences directly affect the manner in which a child, youth, or adult is able to bond with and commit to broader social relationships in school, in the workplace, or in the community for example (Hughes, 1997; Siegel, 1999). Moreover, although attachment processes are biologically independent of innate potentials, healthy attachment experiences can serve as a key to unlock a child's inborn talents, potentials, and overall socioemotional development and functioning (Bowlby, 1969, 1988; Erikson, 1950, 1968; Hughes, 1997; Perry, 1994; Siegel, 1999; van der Kolk, 1987c).

The developmental emergence of socioemotional functioning has long been a subject of research interest in the fields of psychology and social science (BarOn $\&$ Parker, 2000b). Today there are entire programs on Social and Emotional Learning (SEL) being tested in school settings and other environments. Thus far results have been very encouraging and in support of neuropsychological approaches to learning in general, as well as for the special learning and developmental needs of children and youth who have been abused and/or maltreated (Cohen, 1999a, 1999b; Elias \& Bruene-Butler, 1999; Marans \& Cohen, 1999; Shriver, Schwab-Stone, \& DeFalco, 1999).

Although often thought of as acquired skills or abilities, socioemotional development has much in common with conceptualizations used in studies in the 
fields of attachment, social, developmental, motivational, behavioral, social learning, and personality psychology. Common theoretical constructs include selfawareness, assertiveness, self-regard, self-actualization, autonomy, perception, attribution, attachment, empathy, social responsibility, intrapersonal awareness, and interpersonal relationships, adaptability, problem solving, coping and stress management, and impulse control (BarOn \& Parker, 2000b; Goleman, 1995; Saarni, 1999).

Frequently reported research findings (Fish-Murray, Koby, \& van der Kolk, 1987; Kashani \& Allan, 1998; Siegel, 1999; van der Kolk \& McFarlane, 1996) discuss abuse related delays in socioemotional development, delays in the development of identity, and difficulties in developing healthy relationships with peers and adults. Correspondingly, many studies have found that children who have been abused often have difficulties interpreting the intentions of others (FishMurray et al., 1987; Perry 2000b, 2000c; Siegel, 1999) and are regularly described in research as "withdrawn, apathetic, but hypervigilant" (Fish-Murray et al., 1987, p. 97; see also Wolfe \& McGee, 1993). This is perhaps not surprising when one considers the feelings of stigmatization, betrayal, and powerlessness that injured children endure. These psychological and cognitive dynamics reorganize both the child's affective and cognitive operations leading to deficits in self-concept and self-efficacy, and damaged perceptions of the world as safe and just (Briere, 1992). 
In the case of adolescent mothers suffering from attachment trauma and the subsequent socioemotional developmental problems, the provision of clinical treatment to directly address distorted images of self and others can improve overall socioemotional and relational functioning while enhancing all continuing development (van der Kolk, 1987b, 1987c, 1989, 1996a; 1996b, 1996c, 1998, 2000a, 2000b; van der Kolk \& Greenberg, 1987). These types of services may also greatly decrease the risk that the offspring of these mothers will also experience attachment trauma and/or socioemotional and other developmental problems (Carter, Osofsky, \& Hann, 1991; Osofsky et al., 1993).

Cognitive Development

Child maltreatment trauma also negatively influences victims' thinking, reasoning, and perceptual capabilities. Several decades of research evidence has indicated that child abuse and neglect potentiates impaired cognitive functioning (Egeland, 1993; Kashani \& Allen, 1998; Perry, 1999, 2000b, 2000c; Perry \& Pollard, 1998; van der Kolk, 1987a, 1996a, 1996b, 1996c, 1998, 1999) across several domains (Fish-Murray et al., 1987; Siegal, 1999; Wolfe \& McGee, 1993). Since so many adolescent mothers report having experienced child maltreatment, understanding how these experiences can affect overall cognitive functioning would prove useful when planning, implementing, and evaluating treatment strategies for these young mothers. 
Fish-Murray et al. (1987) in a review of the research on cognitive development and child abuse effects report that overall, when compared with nonabused control groups, children who have been abused or maltreated produce lower scores on full scale IQ and other cognitive measures (also see Egeland, 1993; Herrenkohl et al., 1993; Kashani \& Allan, 1998; van der Kolk \& McFarlane, 1996; Wolfe \& McGee, 1993). Researchers have also found that children who have suffered abuse and/or neglect show an unusual tendency to oscillate across and between cognitive operational levels (Inhelder as cited in Fish-Murray et al., 1987). More domain specific studies have found that these children also frequently display difficulties in auditory, visual, and verbal reception and expression.

Researchers (Fish-Murray et al., 1987) specifically examining scientific inferential thinking, knowledge of self, and understanding of others, found similar results. The children in their study who had been abused or neglected generally scored lower in tests of scientific-mathematical logic and showed less self or other awareness and knowledge. Furthermore these children had more difficulty responding and associating to verbal and semantic stimuli, and performed less well on measures of interactive thought processes. Moreover, as opposed to control children, these children had a more pronounced "here and now" orientation and displayed more difficulty with time sequencing tasks.

Fish-Murray et al. (1987) also found that on measures of motivating cognitive schemas (i.e., concepts of justice, responsibility for rules, and authority) 
comparison group children were more able than the children who had been abused to understand the social purpose of authority and rules, and subscribed less to physical punishment as being the primary reason to avoid conflict. The abused children in this study were also noted to be disproportionately developmentally self-centered and exhibited more difficulty with reciprocity. Their ability to use imagination to anticipate solutions to problems was likewise inhibited (also see Egeland, 1993; Wolfe \& McGee, 1993). Similar to studies of learned helplessness, the powerlessness of the victim can lead to attributional errors, self-perceptions of inadequacy, and premature prediction of negative outcomes (Briere, 1992). As such, children's avoidance of or procrastination toward simple or challenging tasks can result in acute or chronic underachievement in school and other environments. They may quite simply believe that meaningful self-change or growth would be either impossible or insufficient.

Additionally study children (Fish-Murray et al., 1987) were reported to have "markedly impaired" (p. 100) functioning on projective measures of accommodation and self-correction as manifested by extreme over or under responsiveness to testing materials. The researchers surmised that these "all or nothing" reactions were representative of the hyper-reactive to dissociative (fight, flight, or freeze) traumatic response continuum. In synopsizing their research, Fish-Murray et al. clearly elucidate some of the psychobiological effects of trauma on cognitive functioning: 
...our strongest finding in these abused children has been the inflexibility of organized schematas and structures in all domains. When we studied them, they were at an age when rigid classification boundaries of early preoperational thought should have been loosened. Instead, function and structure were frozen so that dynamic change could not take place. Accommodation was not operating efficiently, apparently because autonomic nervous system arousal and steady state anxiety caused by conditioned fear and anticipatory frustration inhibited the ability to make guiding plans, to play with alternative approaches, or to anticipate probabilities at age-appropriate levels.... Since personality development depends on a continuous rethinking of boundaries, abused children are at a distinct disadvantage; they are stuck and [unable] to experiment. (p. 101)

Typically, research guided clinical services for children suffering from the effects of maltreatment are provided whenever possible to enhance and advance positive behavior, interpersonal communications and relationships, self-control, self-regulation, problem solving capabilities, as well as cognitive competencies, self-efficacy expectations, and academic achievement (Goleman, 1995; Kashani \& Allan, 1998; Perry \& Azad, 1999; Rickel \& Becker, 1997; Siegel, 1999; van der Kolk, 1987a, 1987b, 1996b, 2000a, 2000b; van der Kolk et al., 1997). Because young mothers abused as children differ from other youth who have been abused or neglected only in relation to their parenting status, they too would likely benefit from these types of focused developmental and clinical services. Furthermore, timely and appropriate developmentally based interventions could significantly improve these young mothers' chances for successfully transitioning to adult status and its subsequent responsibilities, including parenting. 


\section{Identity Development}

The period of adolescence is critical not only to the expanding development of social and cognitive capacities, but also to the interrelated development of selfidentity. Like cognition, the development of "self" can be severely disrupted or complicated by the experience of child maltreatment (Bowlby, 1969, 1988; Brown \& Gilligan, 1992; Ford \& Kidd, 1999; Garmesky, 1987; Johnson \& Roberts, 1999; Kashani \& Allan, 1998, Siegel, 1999; Starr et al., 1991; van der Kolk, 2000a, 2000b; Wolfe \& McGee, 1993). Whether or not the victim experienced neglect, physical and/or sexual abuse, maltreatment can assault a person's perception of self as valuable or competent.

Problems in self-referencing can be further exacerbated for victims when abusers justify their behavior by blaming, criticizing, and implying the abuse was deserved (Briere, 1992). The resulting confusion and self-blame can cause disruptions or complications in the process of healthy identity development and ultimately result in a youth's inability to make healthy choices based on positive internalized images of self and others. One's understanding or acceptance of family and social values can be greatly damaged as well (Erikson, 1950, 1968).

Child maltreatment can also impair the ability to consciously perceive and then reflect upon one's thoughts, feelings and experiences. Such mental activity is critical to the development of self-identity, and correspondingly, to the development of self-regulation and self-motivation (Siegel, 1999; van der Kolk, 
1996a, 1996b, 1996c, 2000a). The ability to learn from one's experiences is closely related to these key developmental tasks as well. However, for some children and youth who have been abused, the neuropsychological effects of abuse make these tasks very difficult to achieve (Siegel, 1999; van der Kolk, 1996a, 1996b, 1996c, 2000a). It is likely therefore, that many adolescent mothers abused as children are also struggling to attain these important developmental milestones (C. Caldwell, personal communication, 2000; R. Carlson, personal communication, 1999, 2000; B. van der Kolk, personal communication, 1999, 2000).

Belenky et al. (1986) describe the adolescent mothers who participated in their study on women's identity development as, “...the youngest and the most socially, economically, and educationally deprived" (p. 23). These experiences of deprivation, produced by indifferent and hostile environments and experiences, inhibited their ability to develop a healthy and authentic self-identity. In expanding their description of these young mothers, Belenky et al. write,

...the silent women have no more confidence in their ability to learn from their own experience than they have in learning from the words that others use. Because [they] have relatively underdeveloped representational thought, the ways of knowing available to them are limited to the present (not the past or the future); to the actual (not the imaginary and the metaphorical); to the concrete (not the deduced or the induced); to the specific (not the generalized or the contextualized); and to behaviors actually enacted (not values and motives entertained). (pp. 26-27)

Unfortunately many adolescent mothers abused as children may be numbered among this "silent" population. For many of these young mothers, their "inner voice" may not be representative of a private and public personae developed 
across time and experience (Belenky et al., 1986; Briere, 1992; Harway \& Liss, 1999; Johnson \& Roberts, 1999). The voices they hear and respond to instead are perhaps the incessant internalized recordings of their own and other's disapproving and polarized appraisals (Artz, 1998; Belenky et al., 1986; Brown \& Gilligan, 1992; Harway \& Liss, 1999; Johnson \& Roberts, 1999; Siegel, 1999; van der Kolk, $1989,2000 \mathrm{a}, 2000 \mathrm{~b})$. If so, these false inner voices, which lack the contextual and rational totality of the young mother's experience, nevertheless serve to frame, define, explain, and locate "her-self" in the past, present, and perceived future. The fluid and additive processes of an evolving authentic self are rendered dormant by the unconscious acceptance of cruel and fallacious self-portrayals untempered by history or conscious self-awareness (Belenky et al., 1986; Brown \& Gilligan, 1992; Harway \& Liss, 1999; Johnson \& Roberts, 1999; Siegel, 1999; van der Kolk, 1989, 1998, 2000a, 2000b). The internalization of others' negative portrayals and judgments, and the intransigent nature of these messages are exceedingly difficult to change (Briere, 1992). Until these young mothers acquire the ability to question, revise, replace, and transform unforgiving and limited self and self-other representations, their capacity to intentionally use life experiences to facilitate a healthy and positive identity can be severely limited.

However, for those who have suffered childhood trauma, conscious selfawareness is not an easy facility to develop. Psychobiological responses (and selfrepresentations) are shaped by and closely attuned to past traumatic experiences 
(Siegel, 1999; van der Kolk, 1987a, 1989, 1998, 2000a, 2000b). Highly charged emotional experiences, experiences associated with feelings of shame or guilt for example, carry more valence in memory and are therefore more readily recognized, retrieved, responded to and hence, more deeply engrained. As such, inhibition of self-reflection limits the likelihood that constructive thoughts or positive memories of self will be either generated or integrated into implicit representational memory systems or identity processes (Rothschild, 2000; Siegel, 1999; van der Kolk, 1987a, 1989, 1998, 2000a, 2000b).

Accordingly, adolescent mothers with traumatic histories and underdeveloped self-identities, experiencing themselves and the world through fear and detachment, may have difficulty developing conscious self-awareness to facilitate a coherent and complete identity (Belenky et al., 1986; Brown \& Gilligan, 1992; Siegel, 1999; van der Kolk, 1987a, 1989, 2000a, 2000b). Without the ability to be consciously self-aware and self-reflective, internal and external stimuli may be primarily mediated by autonomic nervous system (ANS) sensitization.

When ANS sensitization or kindling occurs, intentional thoughts and behaviors supportive of flexible and adaptive choices and decisions cannot be easily mobilized (Siegel, 1999; van der Kolk, 1987a, 2000a, 2000b). Paradoxically, authentic and healthy self-identity in adolescence is strengthened through experiences in which the conscious and autonomous decisions and actions of youth result in improved social, emotional, cognitive, and behavioral 
competence (Catalano, Berglund, Ryan, Lonczak, \& Hawkins, 1998; Gardner, 1993; Kashani \& Allan, 1998; Rickel \& Becker, 1997; Siegel, 1999; van der Kolk, 1987a, 1987b, 1989, 1996b, 2000a, 2000b; Weinfield, Egeland, \& Ogawa, 1999; Weissberg \& Greenberg, 1997; Zaslow \& Eldred, 1998). Lacking these experiences, it may be difficult for an adolescent to either recognize or capitalize on personal strengths and assets, environmental supports, or interpersonal, educational, or occupational opportunities (van der Kolk, 1989, 2000a, 2000b; van der Kolk \& Greenberg, 1987).

Developmentally appropriate clinical services may be necessary to help traumatized adolescent mothers reconnect, reorder, and reset conscious, unconscious, and biological response patterns (Goleman, 1995; Kashani \& Allan, 1998; Perry \& Azad, 1999; Rickel \& Becker, 1997; Siegel, 1999; van der Kolk, 1987a, 1987b, 1996b, 2000a, 2000b; van der Kolk et al., 1997). Failing this, adolescent mothers abused as children may be left to experience and to recall themselves, their children and personal relationships, as well as social expectations and responsibilities, from within an internally and externally imposed figurative pressure cooker. Under such conditions it may be very difficult to think about, reflect upon, or respond to inner or outer probes regarding "who you are," "who you want to become," "what the distant future may bring," let alone concerns about the present and future developmental needs of their children. 
Research and Program Evaluations

Although the development of the children of adolescent mothers has been the subject of much discussion and research, it appears that the developmental experiences of young mothers have thus far fallen outside the direct notice of child abuse, neglect, and developmental research. It is perhaps because of this that research-informed treatment recommendations and strategies for those who have been abused also appear to have fallen outside the consideration of teen parenting funding bodies, policy makers, and program designers (see Furstenberg, 1991; Geronimus, 1991; Institute on Educational Leadership, 1999; Klerman, 1993; Levine-Coley \& Chase-Lansdale, 1998; Rickle \& Becker, 1997; for some general discussion of these issues). Certainly literature in the field mentions the high abuse rates amongst adolescent mothers, yet treatment recommendations continue to focus on educational and parenting skills needs without fully considering the developmental and mental health necessities of this population as well. Therefore, programs utilizing potentially unrealistic outcome performance standards to evaluate and determine service provision, may be doomed to inadequacy and poor long-term outcomes for both the mother and her child.

Lack of adequate program evaluations and the continuing less than adequate program outcomes have been a concern for many in the field (Chase-Lansdale et al., 1991; Furstenberg, 1991; Geronimus, 1991; Klerman, 1993; Weinfield et al., 1999; Zaslow \& Eldred, 1998). Accordingly, more comprehensive evaluations 
have been launched. Findings from one particularly comprehensive and intensive program, the New Chance Demonstration Program for high-risk pregnant and parenting adolescents (or mothers who were adolescents at the birth of their first child) and their children, suggest that these concerns may indeed be valid (Weinfield et al., 1999; Zaslow \& Eldred, 1998). This 18-month program provided participants with parenting skills and training classes, family planning classes, life skills training, adult basic education classes, job skills training, group and individual counseling to address problems “...emerging [italics added] in the mothers' lives, including problems with the children" (Zaslow \& Eldred, 1998, p. 7). Health care and child care assistance, as well as six to twelve months of follow-up services were also provided to program participants. Regarding this program Zaslow and Eldred state,

Interestingly, the New Chance program did have positive effects on parenting. These appeared on both survey interviews and observational measures. However, other influences such as maternal psychological well being, including stress and depression, combined with the effects of parenting behavior on children. Thus, the positive parenting differences were not sufficient to bring about effects on child outcomes, no matter how the parenting and child outcomes were measured. (p. 3)

Furthermore, the evaluation found that mothers who were at high-risk for depression had lower scores (than baseline) on many of the study's measures at the 18-month follow-up survey interviews. In fact mothers in the experimental group were found to be more rather than less depressed, reported less life satisfaction, and reported that they were using more controlling disciplinary practices with their 
children than control group mothers (Weinfield et al., 1999; Zaslow \& Eldred, 1998). Correspondingly, it is this writer's belief that when social welfare and social service systems working with teenage mothers are driven by primarily economic theories with their subsequent policies and practices, young mothers abused as children are frequently unintentionally "set up" to sustain multiple personal, social, and productive failures as they attempt to function adaptively in spite of mental health challenges and developmental delays. Such failures may further impair their ability to develop positive identities and motivation, effective coping skills, positive relationships, genuine feelings of self-efficacy, favorable parenting abilities, or timely economic self-sufficiency.

To gain a more thorough understanding of how the outcomes of adolescent parenting may be associated with the mothers' experiences of maltreatment, what is known about the effects of childhood abuse and neglect (i.e., on attachment, cognition and identity development) must be directly applied to what has been observed clinically, programmatically, and in research amongst adolescent mothers and their children. However, since there is a paucity of research on the effects of childhood trauma in relation to adolescent mothers' developmental and parenting outcomes, the theory base for this research has extensively drawn from research on other populations. By comparing and contrasting this literature to what is known about adolescent mothers and adolescent parenting, the complex interplay of biological and psychological components (i.e., neurobiological, 
psychophysiological, affective, cognitive, socioemotional, and identity) that are likely involved (but largely unstudied), in adolescent parenting outcomes become more apparent. The therapeutic and developmental needs of these young mothers thus also become more evident.

Even so, following an extensive literature search and discussions with a number of clinicians and researchers in the fields of child abuse, development, and teen parenting (C. Caldwell, personal communication, 2000; R. Carlson, personal communication, 1999, 2000; B. D. Perry, personal communication, 2004, 2006; J. Waggoner, personal communication, 2003, 2006; B. A. van der Kolk, 1999, 2000) it has become apparent that child abuse, developmental, and teen parenting researchers have not yet explored the extent to which the negative outcomes of adolescent parenting can be attributed to adolescent parenting alone or to adolescent parenting by mothers suffering from the neuropsychological developmental consequences of child abuse and neglect trauma.

In this regard and for the purposes of this research project, the subject of maltreatment trauma, and its effects on adolescent mothers was narrowed considerably. In an effort to capture the essence of the psychologically and developmentally damaging effects of child abuse and neglect trauma, while at the same time designing a practical, useful, and manageable research project, this research primarily focused on the effects of maltreatment trauma and trauma symptomology on the socioemotional development, and parenting attitudes and 
behaviors of the participants. In attunement with these subjects, this study also considered the developmental and clinical service provision to teenage mothers maltreated in childhood. 


\section{CHAPTER II}

\section{THE RESEARCH QUESTIONS}

While current services for teen mothers are indeed necessary and useful, they may be sequentially misaligned and inadequate for those who have experienced child abuse and/or child neglect trauma (Dubowitz et al., 2001; Klerman, 1993, Levine-Coley \& Chase-Landsdale, 1998). For these reasons, if we as a society wish to decrease some of the social and economic costs of teen parenting, we may need to actively and directly address not only the educational and economic needs of adolescent mothers, but the developmental and therapeutic needs arising from unresolved childhood trauma as well. The question that arises is, "Does childhood trauma produce specific and/or global negative effects on the mothers' socioemotional development and their subsequent parenting attitudes, behaviors, and abilities, and thus teen parenting outcomes in general?"

Given this overarching question, four specific research questions have been formulated. Research questions one and two and their related hypotheses 1 and 2(a-d) focus on the experience of childhood trauma, current trauma symptomology, current socioemotional development, and current parenting attitudes and behaviors. Research question three and the hypothesis that flows from it, considers whether age and social economic status can predict socioemotional development and the 
parenting attitudes and behaviors of the sample. The complete research model for hypotheses 1, 2, and 3 can be seen in Figure 2.2 on page 40.

The fourth research question focuses on gathering and descriptively analyzing data to generally expand the knowledge base of the field regarding the services most received, most desired, and perhaps most needed developmentally speaking, by the adolescent mothers within the sample.

\section{Research Question I}

Do greater exposure to child abuse and/or neglect trauma and higher levels of current experience of trauma symptoms predict lower overall socioemotional skills or abilities?

With this research question and the consequent hypothesis, it was expected that childhood history of maltreatment trauma would predict lower socioemotional skills as measured by the Emotional Quotient Inventory-Youth Version (Eqi-YV) Total Scale Score. High scores by respondents (indicating more trauma experienced) on the individual or multiple scales of the Childhood Trauma Questionnaire (CTQ) would predict lower scores on the Eqi-YV Total Scale. Furthermore, high scores on the subscales of the Trauma Symptom Checklist for Children (TSCC; indicating more current trauma symptomology) would also predict lower scores on the EQi Total Scale score (EQi-YV).

For this question the scales of the CTQ were used as predictor variables to measure the experience of trauma, the types of trauma experienced, and the degree 
or severity of trauma experienced. The scales of the CTQ are: emotional abuse, physical abuse, sexual abuse, emotional neglect, and physical neglect. The TSCC scales were also used as predictor variables to measure the level of current trauma symptoms. The scales of the TSCC include: anxiety, depression, anger, PTSS, and sexual concerns.

Socioemotional developmental status amongst the research sample was used as the criterion variable, and was measured by the EQi-YV Total Scale score. The total scale score of the EQi-YV is a statistical compilation of the scores from the instrument's individual subscales. These subscales are: interpersonal, intrapersonal, adaptability, stress management, and general mood.

The youth version of the EQi-YV was developed for measuring socioemotional constructs with children and adolescents. According to this model, socioemotional intelligence is comprised of an array of developmental factors that are components of specific developmental tasks. Of primary importance to the model is the postulation that the more factors that have been positively developed in a youth or adult, the more positive the outcomes of socioemotional development and thus, overall functioning (BarOn \& Parker, 2000a, 2000b). Research has in fact shown that the scales and subscales of the BarOn model are closely and statistically related to other concepts critical to positive (or negative) functioning, for example: emotional stability, impulse and anger control, cognitive functioning, family functioning, and conscientiousness (BarOn \& Parker, 2000a). From both a 
social work practice and psychological perspective, many of the problems associated with teenage parenting, and with the outcomes of teenage parenting seem to congregate within these concepts as well.

Table 2.1 provides the hierarchical regression model for hypothesis one. The statistical analyses plan for this research question included calculating interscale correlations (EQi Total Score and CTQ; EQi Total Score and TSCC; CTQ and TSCC). It was expected that not only would the interscale correlations be significant, and be in the theoretically expected directions, but that hierarchical multiple regression analysis would be significant at levels of $p<.05$. In hypothesis one predictor variables were input into the regression in blocks.

Table 2.1

Hierarchical Regression Model for Research Question I

\begin{tabular}{ccc}
\hline Block 1 & Block 2 & \\
Predictor & Predictor & Criterion \\
Variables & Variables & Variable \\
Child Trauma & Current Trauma & Socioemotional \\
Experiences (CTQ) & Dymptoms (TSCC) & Development \\
\hline Emotional Abuse & Anxiety & EQi Total Scale Score \\
Physical Abuse & Depression & \\
Sexual Abuse & Anger & \\
Emotional Neglect & PTSS & \\
Physical Neglect & Sexual Concerns & \\
\hline
\end{tabular}




\section{Research Question II}

Do greater exposure to child abuse and/or neglect trauma, higher levels of current experience of trauma symptoms, and lower levels of socioemotional development predict less positive parenting attitudes and behaviors?

The statistical analyses plan to test this question once again utilized hierarchical regression analyses. The following blocks of predictor variables: (a) childhood history of child abuse and/or neglect trauma (CTQ), (b) levels of current trauma symptoms (TSCC), and (c) socioemotional skills/abilities (EQi-YV) were expected to predict less positive parenting attitudes and behaviors (AAPI-2).

This question assumes that participants who had experienced child maltreatment, had current trauma symptomology, and lessened emotional development would also have lower scores on parenting attitudes and behaviors as determined by the Adult Adolescent Parenting Inventory-2 (AAPI-2). Lower scores on the AAPI- 2 would indicate less positive parenting beliefs and behaviors.

The Adult Adolescent Parenting Inventory, a widely used instrument in the field of parenting was chosen as a set of dependent measures to test this hypothesis. The purpose of this instrument is to profile and provide a risk index for abusive and/or neglectful parenting attitudes and behaviors for parenting adolescents and adults. The five parenting constructs are: (a) inappropriate expectations of children, (b) parental lack of empathy, (c) strong belief in the use of corporal punishment as a means of discipline, (d) reversing parent and child role responsibilities, and (e) 
oppressing children's power and independence. Among these constructs, the most field tested and utilized are concepts a to $d$ and accordingly, these are the AAPI-2 scales used in this research.

The statistical analyses plan for this research question included calculating interscale correlations (AAPI and CTQ; AAPI and TSCC; AAPI and the EQi-YV total scale score). It was expected that not only would the interscale correlations be significant, and be in the theoretically expected directions, but that the hierarchical multiple regression analysis would be significant at levels of $p<.05$.

Table 2.2 displays the research model for hypothesis two. The independent or predictor variables (the scale scores from the CTQ and the TSCC), were entered into the equation in blocks, after which the EQi-YV total score was entered into the regression. The scale scores from the AAPI-2 served as the dependent or criterion variables.

Table 2.2

Research Model for Research Question II: Hypotheses 2a-d

\begin{tabular}{|c|c|c|c|}
\hline Block 1 & Block 2 & Block 3 & $\begin{array}{l}\text { Hypotheses } 2 \mathrm{a}-\mathrm{d} \\
\text { Regressions a to } \mathrm{d}\end{array}$ \\
\hline $\begin{array}{l}\text { Predictor } \\
\text { Variables }\end{array}$ & $\begin{array}{l}\text { Predictor } \\
\text { Variables }\end{array}$ & $\begin{array}{l}\text { Predictor } \\
\text { Variable }\end{array}$ & $\begin{array}{l}\text { Criterion } \\
\text { Variables }\end{array}$ \\
\hline $\begin{array}{c}\text { Child Trauma } \\
\text { Experiences (CTQ) }\end{array}$ & $\begin{array}{c}\text { Current Trauma } \\
\text { Symptoms (TSCC) }\end{array}$ & $\begin{array}{c}\text { Socioemotional } \\
\text { Development }\end{array}$ & $\begin{array}{c}\text { Parenting Attitudes } \\
\text { and Behavior (AAPI-2) }\end{array}$ \\
\hline $\begin{array}{l}\text { Emotional Abuse } \\
\text { Physical Abuse } \\
\text { Sexual Abuse } \\
\text { Emot. Neglect } \\
\text { Physical Neglect }\end{array}$ & $\begin{array}{l}\text { Anxiety } \\
\text { Depression } \\
\text { Anger } \\
\text { PTSS } \\
\text { Sex. Concerns }\end{array}$ & EQi Total Score & $\begin{array}{l}\text { a. Empathy } \\
\text { b. Corporal } \\
\text { Punishment } \\
\text { c. Inappropriate } \\
\text { Expectations } \\
\text { d. Role Reversal }\end{array}$ \\
\hline
\end{tabular}




\section{Research Question III}

What are the effects of the age and socioeconomic status (SES) of teenage mothers on their parenting attitudes and behaviors and socioemotional development?

The prediction for research question three was that there would be a positive relationship between the predictor variables of SES and age, and scores (high or low) on the criterion variable measure of parenting attitudes and behaviors (3.1a-d; as measured by the AAPI-2) and the EQI-YV total score 3.2).

The first set of hypotheses 3.1(a-d) for this question assumes that age and SES may be factors related to the parenting attitudes and behaviors of teenage mothers. That is, the lower the age or SES of the mother (as measured by participants' mothers' education), the lower will be her scores on the individual scales of the AAPI-2. The expectation was that age and SES would be significant at the $p<.05$ level.

The second hypothesis 3.2 that flows from research question 3, explores whether age and SES predict the total scale score of the EQi. That is, the lower the age or SES of the mother, the lower will be her EQi total score. The expectation was that age and SES would be shown to be significant predictors at the $p<.05$ level. 
Table 2.3 provides the research model for hypotheses 3.1 a-d and 3.2. Five multiple regression analyses were performed using age and SES as the predictor variables and the individual scales of the AAPI-2, as well as the EQi total scale score as the criterion variables.

Table 2.3

Research Question III: Research Model Hypotheses 3.1 a-d and 3.2

\begin{tabular}{|c|c|}
\hline Predictor Variables & Criterion Variables \\
\hline \multicolumn{2}{|l|}{ Hypothesis: } \\
\hline 3.1 a Age and SES & Empathy (AAPI-2) \\
\hline 3.1b Age and SES & Corporal Punishment (AAPI-2) \\
\hline 3.1c Age and SES & Inappropriate Expectations (AAPI-2) \\
\hline 3.1d Age and SES & Role Reversal (AAPI-2) \\
\hline 3.2 Age and SES & EQi Total Scale Score \\
\hline
\end{tabular}

\section{Research Question IV}

What types of services are more frequently offered and utilized by adolescent mothers, and furthermore what types of services do adolescent mothers find most useful, least useful, and most needed?

It was expected that gathering and analyzing services data would provide the field of teenage parenting with key information regarding what services teenage mothers are receiving and perhaps more importantly, what developmentally focused services may need to be provided given the abuse experiences reported by 
this population. Figure 2.1 provides the service areas inquired about in the services questionnaire. Furthermore, listening to the opinions of these mothers regarding their service needs may be very helpful in guiding program planning to match service provision and prioritization to meet the developmental needs of this vulnerable population.

\begin{tabular}{|c|c|c|}
\hline \multirow[b]{2}{*}{ Basic Needs } & ervice Areas & \\
\hline & Parenting Needs & $\begin{array}{l}\text { Developmental \& } \\
\text { Therapeutic Needs }\end{array}$ \\
\hline Food Stamps & Parent Training & Anger Management \\
\hline TANF & Home Visitation & Domestic Violence \\
\hline Adoption Counseling & Childcare & Sex Abuse Groups \\
\hline Options Counseling & Transportation & or therapy \\
\hline Independent Living & & 1:1 Therapy \\
\hline Social Skills & & Family Therapy \\
\hline Job Skills & & Peer Groups \\
\hline
\end{tabular}

Figure 2.1. Research question IV: Service areas by category.

As previously mentioned, Figure 2.2 provides a schematic of the research model for research questions 1-3. 
1.
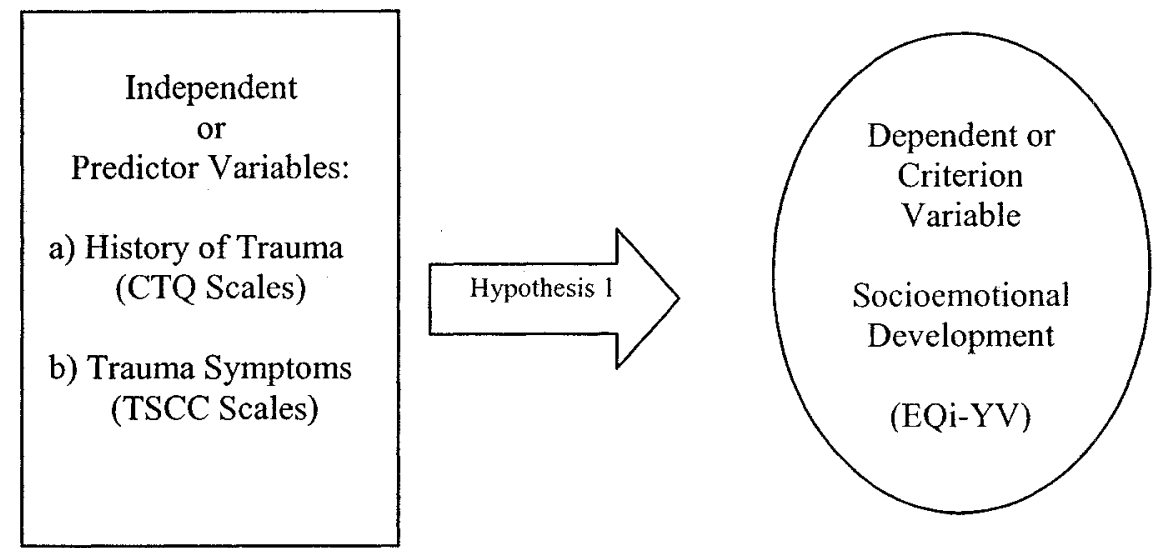

2.

Independent
or
Predictor Variables:
a) History of Trauma
(CTQ Scales)

b) Trauma Symptoms (TSCC Scales)

c) Socioemotional Development (EQi-YV Total Score)

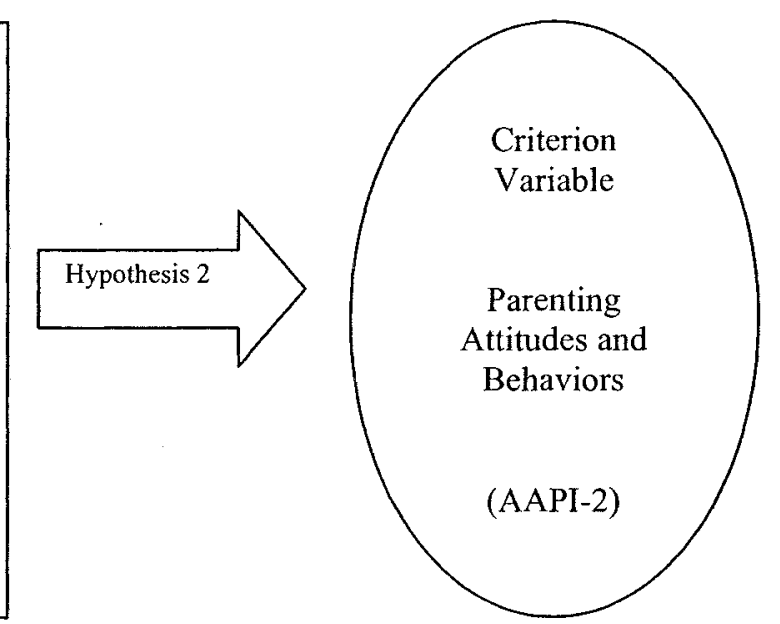

3.
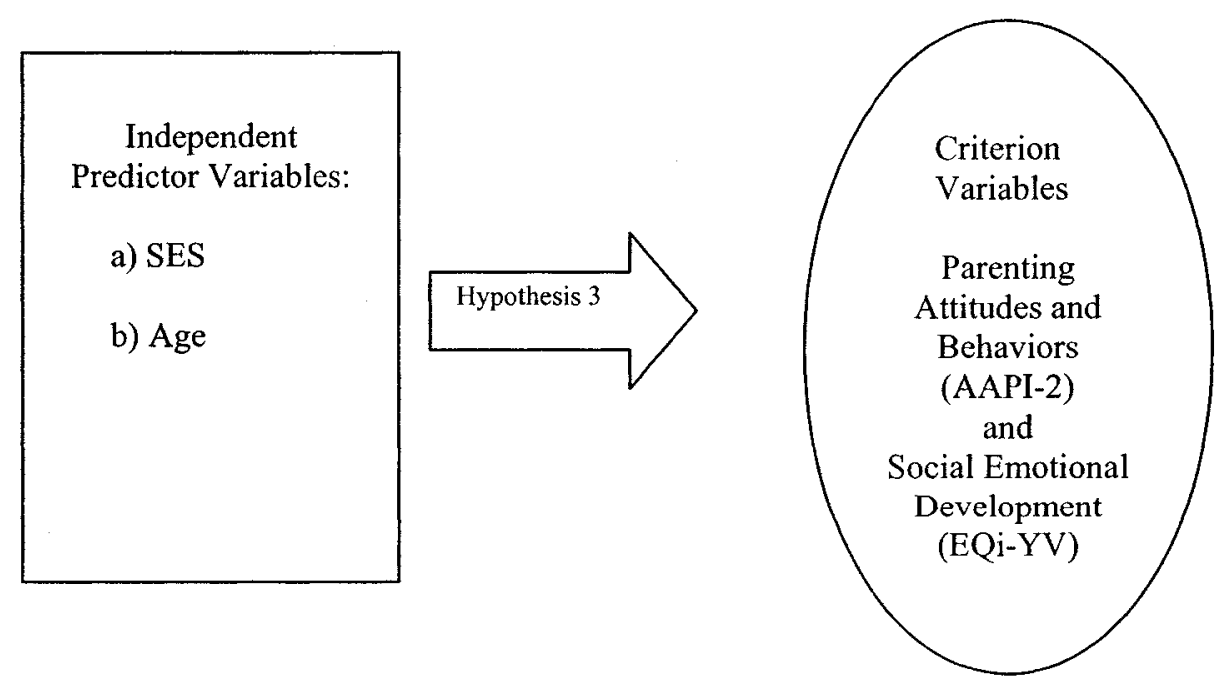

Figure 2.2. Theoretical research model. $X_{1,2, \ldots}(\mathrm{IV})$ predicts $\mathrm{Y}_{1,2, \ldots}(\mathrm{DV})$. 


\section{CHAPTER III \\ THE RESEARCH DESIGN, METHODOLOGY, AND SAMPLE CHARACTERISTICS \\ Research Design}

To gain a deeper understanding of the socioemotional developmental and parenting attitudes and behaviors of adolescent mothers abused or neglected as children, cross-sectional quantitative social research methods were used.

Quantitative methods were selected to allow consideration of the similarities and differences of this study's results to previous research informing the child maltreatment, child development, and adolescent parenting fields.

All data were self-reported by the research participants and collected chiefly through psychometrically standardized research measures focusing on concepts of child trauma history, trauma symptomology, socioemotional development and functional skills, as well as parenting attitudes and behaviors. Questionnaires designed for this study were used to gather participant demographic and services data. As can be seen in Table 3.1 data collection activities took place in 12 different program sites in Oregon's Clackamas, Marion, Multnomah, and Washington counties. In order to meet the practical, protective, and confidentiality needs of the research subjects all data collection occurred in service or educational settings. 
Table 3.1

Participating Programs, Number of Participants, and Counties of Residence

\begin{tabular}{|c|c|c|c|c|c|}
\hline & Location & Freq & $\%$ & County & $\begin{array}{c}\text { Data } \\
\text { Sessions }\end{array}$ \\
\hline 1. & High School for Teen Mothers & 7 & 8.8 & Marion & 1 \\
\hline 2. & Teen Parent Program & 1 & 1.3 & Clackamas & 1 \\
\hline 3. & Teen Parent Program & 4 & 5.0 & Washington & 1 \\
\hline 4. & Teen Parent Program & 1 & 1.3 & Multnomah & 1 \\
\hline 5. & Teen Parent Program & 1 & 1.3 & Washington & 1 \\
\hline 6. & Teen Parent Program & 2 & 2.5 & Multnomah & 1 \\
\hline 7. & Teen Parent Program & 19 & 23.8 & Clackamas & 3 \\
\hline 8. & Community Program for Teens & 3 & 3.8 & Multnomah & 2 \\
\hline 9. & Homes for Young Mothers (3) & 3 & 3.8 & Marion & 3 \\
\hline 10. & High School Program for Teen Mothers & 11 & 13.8 & Marion & 2 \\
\hline 11. & $\begin{array}{l}\text { Residential Treatment Center for Pregnant } \\
\text { and Parenting Teens }\end{array}$ & 18 & 22.5 & Multnomah & 4 \\
\hline \multirow[t]{2}{*}{12.} & High School for Teen Mothers & 10 & 12.5 & Clackamas & 3 \\
\hline & Totals & 80 & ----- & & 23 \\
\hline
\end{tabular}

A small pilot study ( 2 participants) occurred prior to beginning the formal data collection processes. The pilot study resulted in formatting changes on the services questionnaire.

\section{Research Recruitment and Sample}

A purposive sample of 80 subjects was recruited for this research.

Participants were limited to adolescent mothers (currently parenting their child or children) who were 14 to 17 years of age, and who were currently receiving teen parenting services in the state of Oregon through public institutions and/or community social service agencies (i.e., public schools, educational service district alternative schools, teen parenting programs or service centers, residential centers, as well as job or vocational training programs). 
Research participants were contacted through the agency or institution providing services. The director and/or principal of each institution, program, or agency in which data collection occurred agreed to allow staff at his or her site to serve as a contact intermediary for the researcher. Each director/principal signed a formal agreement approving all research activities. Only two state agencies required additional supervisory and/or oversight body approval for data collection to proceed. One high school for pregnant and parenting teens required the approval of both the school principal and the district supervisor.

Sites were chosen for contact in a number of ways: researcher knowledge of sites, referral from other field practitioners, as well as phone book and internet city and county searches. Sites were first contacted by phone. In most cases the researcher knew in advance the name and position of the person to contact; when this information was not known the researcher asked to speak to the Executive Directors, Program Directors, Program Supervisors, or Principals.

With the exception of only one or two sites, once the researcher was able to discuss the research itself and the research processes with the appropriate person, the researcher was invited to proceed. Supervisors and staff at all participating sites were very helpful and expressed their support for the research goals and their agreement with the need for the research to occur. Supervisors and staff also felt that in many cases their students/clients could benefit from improved services, especially social skills training and mental health services. 
The researcher agreed to conduct staff training seminars on teenage parenting, the neuropsychology of trauma, youth development, and/or program needs assessments and evaluations for participating sites. Participating sites will also receive an overview of the research results. The reciprocity and cooperation between the researcher and program administration and staff reflected the mutual advantages in action oriented community based research.

\section{Sample Demographic Characteristics}

Early in the process of planning this study my committee chair and I met with Cleopatra Caldwell, Ph.D. to help guide research parameters (C. Caldwell, personal communication, 2002). Dr. Caldwell is a professor and researcher at The University of Michigan's School of Public Health and the Institute for Research on Women and Gender, and is a national expert on adolescent females and adolescent childbearing. Accordingly, due to the small sample $N$, and the even smaller group $n$ 's involved in this research, Dr. Caldwell recommended that ethnicity not be a focus of consideration except within descriptive analyses. The hierarchical regression analyses in Hypotheses 1 and 2 have too many variables to adequately analyze the small cultural/ethnic group $n$ 's within this study (Caucasian $=29$, Latina $=35$, and Other $=16$ ). However, these small group $n$ 's are very appropriate for descriptive (frequency and crosstab) analyses and in fact provide a far broader and more personal portrait of study participants.

As can be seen in Table 3.2, all participants in this study were 14- to 17-year-old mothers. The majority of the sample was 17 years old (75\%), with 
16-year-olds representing $18.7 \%$ of the total sample, 15 -year-olds comprising $5 \%$ of participants, and one 14-year-old (1.3\%) was a participant in the study.

Table 3.2

Participant Demographic Characteristics by Age and Ethnicity

\begin{tabular}{lcccccc}
\hline Characteristics & Age 14 & Age 15 & Age 16 & Age 17 & Total & $\% N$ \\
\hline Caucasian & -- & 3 & 11 & 15 & 29 & 36.3 \\
Latina & 1 & 1 & 3 & 30 & 35 & 43.8 \\
Other &.-- &.-- & 1 & 15 & 16 & 20.0 \\
Total & 1 & 4 & 15 & 60 & 80 & 100.0 \\
\hline
\end{tabular}

Table 3.2 also provides details regarding the ethnicity and age of the sample. The reported cultural and/or racial heritage of the study sample consisted of 35 Latinas (43.8\%), 29 Caucasians (36.3\%), and 16 participants designated as "other" (20\%). With $20 \%$ of sample participants reporting ethnic designations other than Latina or Caucasian, all other designations were recoded into the variable "other" $(n=16)$. Within this designation are the following reported cultural/ethnic heritages: African American (5), Native American (2), Asian/Pacific Islander (1), Caucasian/Latino (4), Latino/Native American (1), Caucasian/African American (1), Caucasian/Native American (1), and African American/Native American (1).

The age range of participants' children was $1-48$ months ( $S D=19$ months), with a mean of 17 months, a median of 12 months, and a mode of 4 months. There were seven participants $(8.6 \%)$ who had two children. All of these mothers were 17 years old. 
As can be seen in Table 3.3, overall, the research sample favors "being in relationship" (68.8\%). Eight participants report being married (10\%) and of these, Latinas represent the largest group. Of all participants, $17(21.3 \%)$, reported living with their boyfriends, and 30 participants $(37.5 \%)$ reported they were in a romantic relationship, but are not cohabitating. On the whole, less than one third of participants (31.2\%) report not being currently involved in any romantic relationship.

Table 3.3

Relationship Characteristics of Participants, by Age and Ethnicity

\begin{tabular}{|c|c|c|c|c|c|c|c|}
\hline & Age 14 & Age 15 & Age 16 & Age 17 & Total & $\%$ to $N$ & $\% n$ \\
\hline \multicolumn{8}{|l|}{ Married } \\
\hline Caucasian & --- & $-\cdots$ & -- & 1 & 1 & 1.3 & 3.4 \\
\hline Latina & $-\cdots$ & -- & 1 & 5 & 6 & 7.5 & 17.1 \\
\hline Other & -- & --- & -- & 1 & 1 & 1.3 & 6.3 \\
\hline \multicolumn{8}{|c|}{ Living with Boyfriend } \\
\hline Caucasian & --- & --- & 1 & 4 & 5 & 6.3 & 17.2 \\
\hline Latina & -- & -- & $-\ldots$ & 7 & 7 & 8.7 & 20.0 \\
\hline Other & -- & --- & -- & 5 & 5 & 6.3 & 31.3 \\
\hline Total & -- & --- & 1 & 16 & 17 & 21.3 & --- \\
\hline \multicolumn{8}{|c|}{ Have Boyfriend but not Cohabitating } \\
\hline Caucasian & --- & 2 & 3 & 3 & 8 & 10.0 & 27.6 \\
\hline Latina & --- & -- & 2 & 14 & 16 & 20.0 & 45.7 \\
\hline Other & -- & --- & -- & 6 & 6 & 7.5 & 37.5 \\
\hline \multicolumn{8}{|c|}{ Not in a Romantic Relationship } \\
\hline Caucasian & --- & 1 & 7 & 7 & 15 & 18.7 & 51.7 \\
\hline Latina & 1 & 1 &.- & 4 & 6 & 7.5 & 17.1 \\
\hline Other & --- & --- & 1 & 3 & 4 & 5 & 25 \\
\hline Total & 1 & 2 & 8 & 14 & 25 & 31.2 & --- \\
\hline
\end{tabular}

Note. $n$ for Caucasians $=29$, Latinas $=35$, and Other $=16$.

A further exploration of the sample relationship data also reveals that of all ethnicities, Latinas are more likely to be married $(17.1 \%$ of $n)$, live with a 
boyfriend $(20 \%$ of $n)$, be in a romantic relationship while living apart $(45.7 \%$ of $n)$, or be in a romantic relationship with the father of at least one of their children (68.6\%; see Table 3.4$)$.

Table 3.4

Participants Who Are Still in a Romantic Relationship with the Father of at Least One of Their Children, by Age and Ethnicity

\begin{tabular}{lccccccc}
\hline & Age 14 & Age 15 & Age 16 & Age 17 & Total & $\% N$ & $\% n$ \\
\hline Caucasian & --- & --- & 1 & 6 & 7 & 8.8 & 24.1 \\
Latina & --- & --- & 2 & 22 & 24 & 30.0 & 68.6 \\
Other & --- & -- & --- & 9 & 9 & 11.3 & 56.3 \\
Total & --- & -- & 3 & 37 & 40 & 50.0 & -- \\
\hline Note. $n$ for Caucasian & $=$ & 29, Latina & $=35$, and Other $=$ & 16. & & &
\end{tabular}

It is also worthy of note that $58.8 \%$ of participants $(n=10)$ who reported they were living with their boyfriends, also reported the age of these young men. The age range reported for these boyfriends was 16 to 20 years old, and the age range for the female respondents was 16 to 17 years old. Therefore few if any of these relationships are in opposition to Oregon Statutory Rape Laws (ORS 163.427; i.e., $>3$ years difference in age). The age range for married female respondents was 16 to 17 years old and the reported age range of the husbands was 19 to 23 years old.

Table 3.5 provides information on participants' household composition. Household composition data for the study sample were available for only $62(78 \%)$ of the total 80 participants. The remaining 18 participants were all living in group home or residential treatment settings (9 Caucasians, 6 Latinas, 3 Other). Amongst the household composition data reported, the mean number of household members 
was $2.74(S D=2.18)$, the mode was 0 , and the median was 3 . The response range of number of household members not including the participants or their child(ren) was from 1 to 12 . When including the participants and their child(ren) the majority of the 62 responding participants $(96.7 \%)$ lived within households of 3 to 7 members.

Table 3.5

Participants' Household Composition: Number of Additional People Living in Home with Respondent, by Ethnicity

\begin{tabular}{lccccccc}
\hline & $1-2$ & $3-4$ & $5-6$ & $7-8$ & $9-10$ & $11-12$ & Total \\
\hline Caucasian & 9 & 11 & --- & --- & -- & --- & 20 \\
Latina & 7 & 21 & --- & 1 & --- & --- & 29 \\
Other & 5 & 7 & --- & -- & --- & 1 & 13 \\
Total & 21 & 39 & --- & 1 & --- & 1 & 62 \\
$\%$ to $N$ & $33.8 \%$ & $62.9 \%$ & --- & $1.6 \%$ & -- & $1.6 \%$ & -- \\
\hline Note. $n$ for Caucasian & $=20$, Latina $=29$, and Other $=13(N=62)$. & &
\end{tabular}

Sixty-eight percent of the adolescents reported living with their mother and $32.3 \%$ of participants' mothers were single parents; none of the sample reported living with their father as a single parent. This percentage is very close to the national statistic that $31 \%$ of households are headed by a single parent (Annie E. Casey Foundation, 2006). In $27.4 \%$ of participant responses both the biological mother and father lived in the home, and $66.1 \%$ of participants reported living with siblings in their home as well. Only $4.8 \%$ of respondents reported the presence of a stepfather in the home, and very few (3.2\%) indicated that their mothers had a boyfriend living in the home. Grandparents cared for $3.2 \%$ of the participants and one respondent reported living with only extended family members (i.e., aunts and 
cousins). Extended family members however (cousins, nephews, nieces), live with $4.8 \%$ of participants and their families. Family friends lived in the homes of $6.5 \%$ of respondents and one (1.6\%) participant reported living only with friends.

Of the eight $(10 \%)$ respondents who were married, in three of these cases the participant, her husband, and her child(ren) lived with the husband's parents. Seventeen participants reported living with their boyfriends, and in seven of these situations the participant, her child(ren), and her boyfriend lived with either her parent(s) or his parent(s).

As can be seen in Table 3.6, at the time of data collection all participants were still attending school and had completed eighth to eleventh grade. Eighth grade completion was reported by one (1.3\%) participant, $16.7 \%$ of participants had completed ninth grade, $32.1 \%$ of the sample had completed tenth grade, and $50 \%$ of participants had completed eleventh grade. Overall participants of all ethnicities favored working on a high school diploma (92.2\%) as opposed to a GED $(8.7 \%)$.

\section{Table 3.6}

Participants' Education: Number of Participants Currently Working on GED and High School Diploma, by Ethnicity

\begin{tabular}{lcccccc}
\hline & GED & \multicolumn{5}{c}{ HS } \\
& $n$ & $\% n$ & $\% N$ & $n$ & $\% n$ & $\% N$ \\
\hline Caucasian & 3 & $10.3 \%$ & $3.7 \%$ & 26 & $89.7 \%$ & $32.5 \%$ \\
Latina & 2 & $5.7 \%$ & $2.5 \%$ & 33 & $94.2 \%$ & $41.2 \%$ \\
*Other & 2 & $12.5 \%$ & $2.5 \%$ & 14 & $87.5 \%$ & $17.5 \%$ \\
Total & 7 & --- & $8.7 \%$ & 73 & --- & $91.2 \%$ \\
\hline Note. $n$ for Caucasian & $=29$, Latina $=35$, and Other $=16$.
\end{tabular}


Of the 80 participants in this study $16(20 \%)$ reported being employed. The mean hours per week that employed participants worked was 17.9 hours $(S D=$ 8.6), the mode was 20 hours, and the median was 20. Participant SES is discussed in further depth in chapter 4, Results. It is important to note however, that $62.5 \%$ of participants reported that they did not currently receive any state or federal cash assistance, and yet $96.3 \%$ reported having yearly incomes of under $\$ 10,000$. All of these participants therefore fell below the national poverty index (U.S. Department of Health and Human Services, 2006). Furthermore, of the 50 respondents reporting total household income (i.e., participant plus family members), at least $44 \%$ of households fell below the federal poverty guidelines.

\section{Data Collection Procedures}

Program staff distributed research recruitment flyers to potential participants. Prior to any contact between the researcher and potential participants, program staff thoroughly described the research project to the adolescent mothers using information given to them by the researcher. When potential participants volunteered to take part in the study, schedules for data collection dates, times, and onsite locations were arranged between the researcher, site supervisors, and program staff. Data were primarily collected in small groups of 2 to 11 respondents, although in three cases the researcher collected data from only one individual.

Before any data collection activities, the researcher read the Informed Consent document aloud to all participants and answered any questions within the 
total group environment. The only question that arose during this process was in regards to the definition of the term "anonymous."

Prior to proceeding with data collection processes, the researcher also explained her mandated legal, professional, and ethical responsibility to report to child protection authorities any form of child maltreatment, or child endangerment that she might be made aware of by participants. This information was also included in the Informed Consent document. The researcher also explained that since all collected data would be anonymous, she would not be able to determine from a written questionnaire if a particular participant had been or was currently being maltreated. After clarifying this issue for participants, the researcher then also explained that should participants decide they wanted or needed help due to past or present abusive situations or experiences they could tell the researcher and/or research assistant and help would be immediately provided and child protection authorities contacted if appropriate. Once all of this was discussed, questions asked and answered, and participants had signed the Informed Consent document, data collection activities began.

Additionally, because there was the potential that some of the items within the questionnaires could be emotionally upsetting (as detailed in the Informed Consent document), as each participant completed the data collection process, the researcher met briefly and individually with her. During this brief meeting the researcher personally gave each participant a list of local counseling resources and inquired if the respondent found any of the processes or questions emotionally 
upsetting. None of the participants reported being disturbed in any way by either the questionnaires or the processes.

In only one case did the researcher feel concerned about a participant's emotional state following data collection. Although this particular participant denied being emotionally upset by her participation in the study, her non-verbal communication clearly conveyed otherwise. When speaking privately and at more length with the participant, the young mother informed the researcher of her depression because of the recent death of her second child. Eventually, the participant allowed the researcher to bring in and inform program supervisory staff to assure that appropriate counseling resources would be put in place.

The only participant volunteers screened from taking part in the study were those who did not meet participant criteria requirements. In addition, five Latina participants at one site were not able to participate in the study because of their inability to read, write, or understand English well enough to assure valid data.

The order in which the research questionnaires were given to research participants was as follows:

1. The Services Questionnaire - The services questionnaire was the most complicated of all the questionnaires so all the data collection sessions were begun with it. Once this questionnaire was completed participants were able to move through all other instruments fairly easily. 
2. The Adult-Adolescent Parenting Inventory-2 (AAPI-2) was given prior to any measures which could alter participants' candid responses regarding their parenting attitudes and behaviors.

3. The BarOn EQi-YV (The EQi-YV) was given prior to measures about traumatic experiences or symptoms so that participants' responses did not reflect perceived response expectations. Also, because there was a potential for participants to become sad, angry, etc., when responding to questions regarding traumatic experiences or trauma symptoms, giving the EQi-YV prior to the trauma related measures potentially lessened the possibility that a participant's responses were in some way shaped by these emotions.

4. The Trauma Symptoms Checklist for Children (TSCC) - Again, in an effort to lessen the possibility that participant's responses were shaped by questions about their personal trauma experiences, the TSCC was given prior to the Childhood Trauma Questionnaire.

5. The Child Trauma Questionnaire (CTQ) - This measure was the last of the standardized scales given to participants. It is a relatively brief scale ( 28 items, 5-10 minute average completion time). The placement of this measure as fifth out of six measures was planned to lessen the possibility that any memories or emotions activated by this scale would skew participants' responses on other scales. And, should a respondent become upset by this measure she had only the demographic questionnaire left to complete the data collection session. 
6. The demographic questionnaire - This questionnaire is brief and relatively benign in content. Therefore it was used to complete the data collection process. Furthermore, because this questionnaire only asked participants to provide basic information regarding themselves or their family, it was hoped that closing the data collection with demographic questions would provide a grounding experience by affording participants some intellectual and emotional distance from previous questions regarding any traumatic experiences or symptoms they may have had.

Additionally, all participants received a $\$ 20$ gift certificate to local stores in their areas for the completion of all the instruments. The order of the measures and the completion of data collection with participants receiving a gift certificate worked very well to bring a positive closure to the data collection process.

\section{Instruments}

In this section, the instruments used in this study are discussed. For the four standardized instruments, original validation research is presented including results for reliability and validity. Scale constructs are discussed and information provided. Where available, mean validation study scores are compared with scores for the current study. Reliability coefficients and scale/subscale interitem correlations are shown for the instruments' validation study and the current study. For the demographic and services questionnaires developed for this study, general information are provided. Statistical hypotheses analyses including interscale correlations and multiple regression analyses are presented in chapter 4 , Results. 
Construct descriptions for all the psychometric measures used in this study can be found in the glossary.

\section{The Childhood Trauma Questionnaire}

The Childhood Trauma Questionnaire (CTQ) is a 28-item retrospective selfreport inventory of traumatic events experienced in childhood (Bernstein \& Fink, 1998). As such it has been used in research and in a wide variety of clinical and residential treatment settings with a broad range of individuals.

In validation studies for this instrument, samples included clinical and nonclinical referred adult substance abusers, adolescent psychiatric inpatients, adult psychiatric outpatients, pain patients, college students, and HMO members. Study participants were diverse as to age, income, and ethnicity.

Table 3.7 provides sample items from each of the CTQ scales. The CTQ produces clinical cutoff scores for five scales of child abuse and neglect: emotional abuse, physical abuse, sexual abuse, emotional neglect, and physical neglect. The CTQ also includes three minimization/denial scale items to distinguish under or over reporting of traumatic experiences (Bernstein \& Fink, 1998). According to the scale's originator, the CTQ is “... a highly sensitive screening measure that can be administered quickly and non-invasively..." (p. 2) to detect child abuse and/or neglect.

The design process of the CTQ utilized "...common definitions of child abuse and neglect" (Bernstein \& Fink, 1998, p. 2), and in most cases, the items describe childhood events in a nonjudgmental and objective fashion to minimize 
responder disclosure reservations and negative emotional response patterns. At the same time, the CTQ is capable of eliciting responses which can be used to produce a comprehensive and quantitative report of childhood abuse and neglect experiences (Briere as cited in Bernstein \& Fink, 1998).

Table 3.7

CTQ: Sample Items

\begin{tabular}{ll}
\hline Scale & Questions \\
\hline EMOTIONAL ABUSE & $\begin{array}{l}\text { "People in my family call me things like 'stupid,' 'lazy,' or } \\
\text { 'ugly."” } \\
\text { "I thought that my parents wished I had never been born." }\end{array}$ \\
PHYSICAL ABUSE & $\begin{array}{l}\text { "People in my family hit me so hard that it left me with bruises } \\
\text { or marks." } \\
\text { "I believe I was physically abused." }\end{array}$ \\
SEXUAL ABUSE & $\begin{array}{l}\text { "Someone tried to make me do sexual things or watch sexual } \\
\text { things." }\end{array}$ \\
"Someone threatened to hurt me or tell lies about me unless I \\
did something sexual with them." \\
"I felt loved." \\
"MyOTIONAL NEGLECT family was a source of strength and support."
\end{tabular}

CTQ items are endorsed on a 5-point Likert-type scale (never true, rarely true, sometimes true, often true, and very often true). Scales are individually scored based on the frequency and weighting of the responses which result in scale clinical cut-off scores. There is no total scale score produced with this questionnaire. 
Table 3.8 displays the percentage of participants who reported experiencing some level of abuse or neglect on the individual CTQ scales. On the whole however, "none to minimal" was reported by $56.2 \%$ of participants on the emotional abuse scale, $70 \%$ of participants on the physical abuse scale, $58.7 \%$ of participants on the sexual abuse scale, $55 \%$ of participants on the emotional neglect scale, and $47.5 \%$ of participants on the physical neglect scale. Of all types of abuse and neglect reported by the study sample, $76.3 \%$ of participants reported having experienced at least one type of child abuse or neglect above the minimal level. Accordingly, this study's sample confirms previous literature reporting that 50 $75 \%$ of teenage mothers report having experienced some type of abuse and/or neglect, and thus further validates the potential need for additional developmentally and clinically focused services (AGI, 1994; Levine-Coley \& Chase-Landsdale, 1998; McCullough \& Scherman, 1991; NRC, 1993).

Table 3.8

CTQ: Percentage of Participants Reporting Abuse and Neglect at the Low to Moderate, Moderate to Severe, or Severe to Extreme Levels by Ethnicity

\begin{tabular}{lccccc}
\hline Scale & $\begin{array}{c}\text { Emotional } \\
\text { Abuse } \\
\%\end{array}$ & $\begin{array}{c}\text { Physical } \\
\text { Abuse } \\
\%\end{array}$ & $\begin{array}{c}\text { Sexual } \\
\text { Abuse } \\
\%\end{array}$ & $\begin{array}{c}\text { Emotional } \\
\text { Neglect } \\
\%\end{array}$ & $\begin{array}{c}\text { Physical } \\
\text { Neglect } \\
\%\end{array}$ \\
\hline Caucasian & 55.2 & 34.5 & 51.7 & 51.7 & 48.3 \\
Latina & 28.6 & 25.7 & 31.4 & 37.1 & 54.3 \\
Other & 56.3 & 31.3 & 43.7 & 50.0 & 56.3 \\
$\%$ Total & 43.8 & 30.0 & 41.3 & 45.0 & 52.5 \\
\hline Note. $n$ for Caucasians $=29$, Latinas $=35$, and Other $=16(N=80)$.
\end{tabular}


It is also interesting to note that in spite of previous research focusing on the experience of sexual abuse and teenage mothers (AGI, 1999c; Compas et al., 1998; Klerman, 1993; Levine-Coley \& Chase-Landsdale, 1998; Saewyc, Magee, \& Pettingell, 2004), the mothers in this sample reported having experienced emotional abuse, emotional neglect, and physical neglect at higher levels than sexual abuse.

Table 3.9 provides the mean scores and standard deviations for two samples involved in the CTQ validation studies (Bernstein \& Fink, 1998) and for the current study. In the first validation study presented, the sample consisted of 235 female adolescent psychiatric inpatients; the second sample consisted of 51 female college undergraduates. Overall this study's participants' mean scores on average are 19\% less than the first validation study with adolescent psychiatric inpatients, and $18 \%$ higher on average than the undergraduate college students in the second validation study. When exploring the individual scale scores however, the current study's sample scores are less in all domains except physical neglect in comparison to adolescent psychiatric inpatients, and yet are remarkably higher in all domains except emotional abuse when compared to the college students (i.e., physical abuse, sexual abuse, and physical neglect).

When considering the overall child abuse and child neglect responses by participants, it is also important to consider participants' scores on the CTQ's minimization and denial scale. Scores of 3 on this scale represent very likely minimization and denial on the part of the responder, scores of 2 represent likely minimization and denial, and scores of 1 represent potential minimization and 
denial. When totaling these three levels of minimization and denial, $24 \%$ of the current study sample shows some minimization and denial response patterns.

Table 3.9

CTQ: Validation Studies and Current Study Mean Scale Scores, Standard Deviations and Percentage Differences Between Current Study and Validation Studies (Bernstein \& Fink, 1998)

\begin{tabular}{|c|c|c|c|c|c|}
\hline & $\begin{array}{c}\text { Emotional } \\
\text { Abuse }\end{array}$ & $\begin{array}{c}\text { Physical } \\
\text { Abuse }\end{array}$ & $\begin{array}{l}\text { Sexual } \\
\text { Abuse }\end{array}$ & $\begin{array}{c}\text { Emotional } \\
\text { Neglect }\end{array}$ & $\begin{array}{l}\text { Physical } \\
\text { Neglect }\end{array}$ \\
\hline \multicolumn{6}{|l|}{ Validation Studies $1 \& 2$} \\
\hline 1. $M$ Scores & 13.7 & 9.3 & 9.5 & 13.9 & 8.5 \\
\hline$S D$ & 6.1 & 5.4 & 6.6 & 5.4 & 4.1 \\
\hline 2. $M$ Scores & 10.6 & 6.3 & 5.6 & 9.2 & 6.1 \\
\hline$S D$ & 5.2 & 2.4 & 1.4 & 4.4 & 1.9 \\
\hline \multicolumn{6}{|c|}{ Current Study Sample Scores } \\
\hline$M$ Scores Current Study & 9.2 & 7.95 & 8.6 & 10.6 & 8.5 \\
\hline *1. Validation Study & $-33.0 \%$ & $-15.0 \%$ & $-9.0 \%$ & $-24.0 \%$ & $-\cdots$ \\
\hline *2. Validation Study & $-13.0 \%$ & $+26.0 \%$ & $+53.6 \%$ & $+15.2 \%$ & $+39.3 \%$ \\
\hline SD Current Study & 4.7 & 5.3 & 5.9 & 5.0 & 3.8 \\
\hline *1. Validation Study & $-23.0 \%$ & $-2.0 \%$ & $-11.0 \%$ & $-7.0 \%$ & $-7.0 \%$ \\
\hline *2. Validation Study & $-10.0 \%$ & $+121.0 \%$ & $+321.0 \%$ & $+14.5 \%$ & $+100.0 \%$ \\
\hline
\end{tabular}

Reliability. During the standardization process, data from the CTQ's total validation sample of over 2,200 respondents were used to determine the scales' internal reliability (Bernstein \& Fink, 1998). Table 3.10 displays reliability coefficients for the norming sample and for this study's sample. Internal consistency reliability coefficients were computed using Cronbach's alpha for each of the CTQ subscales. The resulting reliability coefficients in the validation study 
ranged from a moderately satisfactory .57 for the physical abuse construct and .60 for the physical neglect construct, to a more acceptable .72 for the sexual abuse construct. The reliability coefficients for the current study fell well within an acceptable range for all scale constructs.

Table 3.10

CTQ: Reliability Coefficients Comparison Between Validation Sample (Bernstein \& Fink, 1998) and Current Study Sample

\begin{tabular}{lccccc}
\hline & Emotional & Physical & Sexual & Emotional & Physical \\
Sample & Abuse & Abuse & Abuse & Neglect & Neglect \\
\hline Validation Sample & $.83-.94$ & $.57-.92$ & $.72-.95$ & $.81-.93$ & $.60-.83$ \\
Current Study Sample & .86 & .94 & .97 & .84 & .73 \\
\hline
\end{tabular}

Since the data from the original validation study were collected from a diverse sample of respondents (i.e., age, income, and ethnicity) these results also suggest adequate representative reliability. To confirm this, factor analysis of the five factor, 25-item CTQ (less the three minimization/denial items) was done to test the fit of the measure across diverse populations. The CTQ items performed well across all groups, and similar factor relationships were found across sample groups (Bernstein \& Fink, 1998).

Test-retest reliability was established using a smaller validation sample composed of adult substance abus/ers with testing intervals ranging from 1.6 to 5.6 months. High interclass correlations on each of the subscales of the CTQ revealed acceptable stability across time and test administration settings (Bernstein \& Fink, 1998). 
Validity. The CTQ utilizes the most used and accepted construct definitions, thus assuring both face and content validity. Construct validity for the CTQ was established initially through exploratory factor analyses on data from two samples. To further narrow the measure while maintaining the measure's reliability and validity, items consisting of high inter-rater and equivalence reliability and which did not cross-load onto other factor constructs were retained (Bernstein \& Fink, 1998).

The ability of the CTQ to discriminate between clinical and non-clinical samples was confirmed throughout the validation study and with all validation samples as well. As predicted, psychiatrically referred groups consistently scored higher for abuse and neglect than did non-clinically referred groups.. Furthermore, in examining convergent validity, select samples were given similar trauma related measures (e.g., Childhood Trauma Interview - CTI, Child Maltreatment Interview - CMI, and the Evaluation of Lifetime Stressors Ratings - ELS). Overall bivariate correlations showed factor pairs to be highly correlated at statistically significant levels (Bernstein \& Fink, 1998).

The Beck Depression Inventory which measures symptoms of trauma such as depression, posttraumatic stress disorder, dissociation, and alexithymia, was used to test for concurrent validity by comparing the hypothesized constructs of the CTQ to similar indicators of trauma; in this case trauma symptomology or 
outcomes. Once again correlations were found to be strong and statistically significant (Bernstein \& Fink, 1998).

Within the current study concurrent and discriminant validity is also shown by acceptable interitem correlations between the CTQ's scales. Within the sample the scales positively covaried in theoretically expected ways. All intercorrelations were adequate and statistically significant at a $p<.01$ level, and ranged from .32 to .75 .

The Trauma Symptom Checklist for Children

The Trauma Symptom Checklist for Children (TSCC) is a 54-item selfreport measure used clinically and in research to evaluate posttraumatic stress and symptoms in children and adolescents who have experienced traumatic events such as physical abuse, sexual abuse, victimization from peers (physical or sexual), major losses, witnessing of violence, and natural disasters.

Table 3.11 provides sample items for each of the TSCC six symptom scales: anxiety (ANX), depression (DEP), anger (ANG), posttraumatic stress (PTS), dissociation (DIS), and sexual concerns (SC). Raw scores from each subscale are easily adapted to a $T$-score and clinical cut-off scores are provided for interpretation and research purposes. For all scales (except Sexual Concerns) $T$-scores greater than or equal to 65 (exceeds $94 \%$ of validation subjects) are considered clinically significant and $T$-scores of 60-64 reflect significant but sub-clinical symptomology. For the sexual concern scale the clinical cut-off point is a $T$-score of 70 or above (Briere, 1996). 
Table 3.11

TSCC: Sample Items

\begin{tabular}{|c|c|}
\hline Scale & Questions \\
\hline ANXIETY & $\begin{array}{l}\text { "Feeling afraid something bad might happen." } \\
\text { "Feeling jumpy or nervous inside." }\end{array}$ \\
\hline DEPRESSION & $\begin{array}{l}\text { "Feeling sad or unhappy." } \\
\text { "Feeling like nobody likes me." }\end{array}$ \\
\hline ANGER & $\begin{array}{l}\text { "Wanting to yell and break things." } \\
\text { "Getting into fights." }\end{array}$ \\
\hline PTSS & $\begin{array}{l}\text { "Scary ideas or pictures just pop into my head." } \\
\text { "Bad dreams or nightmares." }\end{array}$ \\
\hline DISSOCIATION & $\begin{array}{l}\text { "Going away in my mind, trying not to think." } \\
\text { "Feeling like things aren't real." }\end{array}$ \\
\hline SEXUAL CONCERNS & $\begin{array}{l}\text { "Thinking about sex when I don't want to." } \\
\text { "Not trusting people because they might want sex." }\end{array}$ \\
\hline
\end{tabular}

The TSCC was normed using three separate groups of children and adolescents from non-clinical settings $(N=3,008)$. The validation sample of children and adolescents were diverse as to age, geographic areas (inner city, urban and suburban neighborhoods), as well as to racial and socioeconomic backgrounds. Additionally, respondents were $53 \%$ female and $47 \%$ male.

While all age groups ( 8 to 16 year olds) were represented, $83 \%$ of the validation sample was between the ages of 13 and 16 (Briere, 1996). For the purposes of this research it is important to note that clinicians or researchers utilizing this measure have found it to be appropriate for and useful with children 
and adolescents who are one year younger and one year older than the specified age range (i.e., 7 years old and 17 years old).

Because of the instrument's sensitivity to demographic variables such as age, gender, and ethnicity, the TSCC uses separate standardized scores to reflect both male and female respondents and two age groupings ( 8 to 12 and 13 to 16 ) to achieve representative reliability (Briere, 1996). Although differences were shown as to ethnicity, the magnitude was small (variance $=0.1$ to $1.5 \%$ ) and hence it was determined that separate norms specific to ethnicity were not required (Briere, 1996). This instrument does not provide a total item scale; each scale is scored and rated individually using four point Likert-type scaling (never, sometimes, lots of times, almost all of the time) and takes approximately 15-20 minutes to complete.

Table 3.12 presents the proportion of study participants' scores for anxiety (ANX), depression (DEP), anger (ANG), PTSS (PTS), dissociation (DIS), and sexual concerns (SC) that are of significant subclinical and clinical levels (Briere, 1996). This table also presents these findings by total $N$, and by the smaller group $n$ 's. It is interesting to observe the notable score differences between the ethnic groups. Overall within the study sample "none to minimal" scores were reported by $85 \%$ of participants for anxiety, $90 \%$ for depression, $93.8 \%$ for anger, $87.5 \%$ for PTSS, $88.7 \%$ for dissociation, and $85 \%$ for sexual concerns. 
Table 3.12

TSCC: Participants'Subclinical and Clinical Response Percentages by Ethnicity and Total $N$

\begin{tabular}{lrrrrrr}
\hline Scale & $\begin{array}{c}\text { ANX } \\
\%\end{array}$ & $\begin{array}{c}\text { DEP } \\
\%\end{array}$ & $\begin{array}{c}\text { ANG } \\
\%\end{array}$ & $\begin{array}{c}\text { PTSS } \\
\%\end{array}$ & $\begin{array}{c}\text { DIS } \\
\%\end{array}$ & $\begin{array}{c}\text { SC } \\
\%\end{array}$ \\
\hline Subclinical: & & & & & & \\
$\quad$ Caucasian & 3.4 & 10.3 & 6.9 & 6.9 & 6.9 & --- \\
$\quad$ Latina & 8.6 & 5.7 & 2.9 & --- & --- & -- \\
$\quad$ Other & 18.8 & --- & --- & 18.8 & 12.5 & --- \\
& & & & & & \\
Clinical: & & & & & & \\
$\quad$ Caucasian & 10.3 & 3.4 & 6.9 & 3.4 & 13.8 & 27.6 \\
$\quad$ Latina & 5.7 & 2.9 & --- & 8.6 & --- & 2.9 \\
$\quad$ Other & --- & 6.3 & --- & 6.3 & 6.3 & 18.7 \\
*otal \% of $N$ & $15.1 \%$ & 10.0 & 6.3 & 12.6 & $11.3 \%$ & 15.0 \\
& & & & & & \\
Total \% of $n$ by ethnic group & & & & & & \\
$\quad$ Caucasian & 13.7 & 13.7 & 13.8 & 10.3 & 20.7 & 27.6 \\
$\quad$ Latina & 14.3 & 8.6 & 2.9 & 8.6 & --- & 2.9 \\
$\quad$ Other & 18.8 & 6.3 & --- & 31.4 & 23.8 & 18.7 \\
\hline
\end{tabular}

Note. Caucasian $=29$, Latina $=35$, Other $=16 ;{ }^{*}$ Total consists of all significant subclinical and clinical scores.

Table 3.13 provides a comparative percentage of the current sample's mean scale scores and standard deviations to standardization sample scores. The validation study sample in this case consisted of over 1,286 general population females age 13 to 16 years old on all scales except the sexual concern scale. The sexual concern (SC) scores for the standardization study consist of an $N$ of 46. 
Table 3.13

TSCC: Validation Study and Current Study Mean Scale Scores and Standard Deviations

\begin{tabular}{lcccccc}
\hline Sample Groups & ANX & DEP & ANG & PTS & DIS & SC \\
\hline $\begin{array}{l}\text { Current Study } \\
\quad M \text { Scores }\end{array}$ & 5.8 & 6.8 & 6.4 & 8.0 & 7.0 & 4.5 \\
*VS $M$ Scores & 7.0 & 7.9 & 9.3 & 9.9 & 7.9 & 3.0 \\
\% difference & $-17.0 \%$ & $-13.9 \%$ & $-31.2 \%$ & $-19.2 \%$ & $+11.4 \%$ & $+50.0 \%$ \\
Current Study $S D$ & 4.4 & 4.7 & 5.6 & 6.0 & 5.0 & 4.6 \\
& & & & & & \\
*VS SD & 4.7 & 5.5 & 6.3 & 6.4 & 5.5 & 2.2 \\
\% difference & $-6.3 \%$ & $-14.0 \%$ & $-11.1 \%$ & $-6.3 \%$ & $-9.1 \%$ & +109.1 \\
\end{tabular}

Note. ${ }^{*}$ VS is the abbreviation for the validation study group (Briere, 1996).

Overall children, adolescents, and adults who have been maltreated report much higher levels of trauma symptoms than the general population (Brier, 1996; Nicholson \& Williams, 2006; Perry \& Azad, 1999; Rickel \& Becker, 1997; Siegel, 1999; van der Kolk, 1987a, 1987b, 1996b, 2000a, 2000b; van der Kolk et al., 1997). Since $76.3 \%$ of the overall sample for this study reported having experienced some type of maltreatment, the same result would be expected for this study's participants. However, respondents overall reported comparatively low levels of trauma symptomology. Underresponse on the TSCC items may be one possible reason for participants' lower scale scores.

The TSCC has embedded within the scale's items two non-clinical scales to alert test administrators to underresponse (UND) and hyperresponse (HYP). According to the scale's author, under or hyperresponse patterns can reflect 
respondent denial of symptoms, the need to appear especially symptomatic, or the experience of being overwhelmed by symptoms (Briere, 1996).

Table 3.14 provides information regarding underresponse patterns by ethnicity. Of all participants in the sample, $76.2 \%$ of the scores did not reflect underresponse patterns. The remaining $23.8 \%$ of scores did however reflect potential and highly probable underresponding according to the TSCC scoring guidelines. As can be seen in the table there is a noteworthy difference in response patterns by group, especially in regards to Latina respondents. Only one participant's scores reflected an over or hyperresponse pattern on the TSCC hyperresponse scale.

Table 3.14

TSCC: Underresponse by Ethnicity

\begin{tabular}{lccc}
\hline & $\begin{array}{c}\text { \% Potential } \\
\text { Underresponse }\end{array}$ & $\begin{array}{c}\text { \% Probable } \\
\text { Underresponse }\end{array}$ & $n \& N$ \\
\hline Caucasian & 10.3 & 3.4 & $13.7(n)$ \\
Latina & 11.4 & 25.7 & $37.1(n)$ \\
Other & --- & 12.5 & $12.5(n)$ \\
$\%$ to Total & 8.8 & 15.0 & $23.8(N)$ \\
\hline
\end{tabular}

Note. Caucasian $=29$, Latina $=35$, Other $=16$. $*$ Total combines potential and probable underresponse scoring patterns.

Reliability. The final validation study for the TSCC consisted of 3,008 nonclinically referred children. Internal item consistency was found to be quite high for five of the six clinical scales (.82 to .89$)$, and moderate for the sexual concern scales (.77). Table 3.15 displays reliability coefficients for the original validation sample and for this study's sample. This study's reliability coefficients fall well 
within an acceptable range for all scale constructs, showing strong internal consistency. In the validation study the under- and hyperresponse subscales showed reliability at the .85 and .66 levels respectively. For the current study under- and hyperresponse reliability coefficients were higher, .88 and .77 respectively.

Table 3.15

TSCC: Reliability Coefficients for Validation (Briere, 1996) and Current Study Samples

\begin{tabular}{lcccccc}
\hline Scale & ANX & DEP & ANG & PTSS & DIS & SC \\
\hline Validation Sample $M$ & .82 & .86 & .89 & .87 & .83 & .77 \\
Current Study ample & .83 & .86 & .91 & .90 & .86 & .86 \\
\hline
\end{tabular}

Validity. In the TSCC validation study testing for concurrent and discriminant validity, intercorrelations of the TSCC's scales and subscales covaried as theoretically expected with similar scales correlating in a positive fashion. Most results were in the low to moderate range $(.37$ to .81$)$. For the current research study, TSCC scale and subscale correlations were quite adequate ranging from a moderate .59 to a high of .86 . All of these correlations were statistically significant at the $p<.01$ level.

Also in the TSCC validation study, criterion validity was established using both youth and parent report versions of the Child Behavior Checklist (CBCL), the Children's Depression Inventory (CDI), the Revised Children's Manifest Anxiety Scale (RCMAS), and the Children's Impact of Traumatic Events Scale Revised 
(CITES-R; Briere, 1996). Intercorrelations between the TSCC and each of these scales were acceptable.

In an additional study of construct and predictive validity (Elliot \& Briere as cited in Briere, 1996), scale scores of 399 children with validated sexual abuse (boys and girls) were higher than scale scores for non-sexually abused children. Diaz (as cited in Briere, 1996), similarly found that scores on the TSCC were able to discriminate between abused and non-abused children.

Several additional studies with maltreated children utilized the TSCC as a pre- and post-intervention measure. As expected, reported trauma symptomology was higher before therapeutic intervention and scores decreased significantly following treatment (Briere, 1996).

The BarOn Emotional Quotient Inventory-Youth Version (EQi-YV)

The (EQi-YV) is a 60-item, self-report instrument designed to measure the emotional, personal, and social dimensions of intelligence as defined by the BarOn model of emotional and social intelligence (BarOn \& Parker, 2000b). It is appropriate for use with children and youth 7 to 18 years old.

As previously discussed, in the BarOn model emotional intelligence is defined as "an array of emotional, personal, and interpersonal abilities that influence one's overall ability to cope with environmental demands and pressures, (BarOn \& Parker, 2000a, p. 33)...[and the EQi-YV is comprised] of abilities related to understanding oneself and others, relating to people, adapting to changing environmental demands, and managing emotions" (BarOn \& Parker, 2000a, p. 1). 
The EQi-YV uses a 4 point Likert-type format (very seldom true of me, seldom true of me, often true of me, very often true of me) and takes on average 25 minutes to complete. Lower subscale and total scale scores indicate lower levels of emotional intelligence development and abilities. The EQi-YV measures a crosssection of abilities and competencies that according to the authors represent "...the core features of emotional intelligence" (BarOn \& Parker, 2000b, p. 2).

Table 3.16 presents sample items for the EQi-YV five construct subscales intrapersonal (Intra), interpersonal (Inter), adaptability (Adapt), stress management (Stress), and general mood (Mood), and the positive impression scale score. To determine the final overall emotional intelligence score a $T$-score is calculated from raw subscale scores (BarOn \& Parker, 2000a).

Table 3.16

EQi-YV: Sample Items

\begin{tabular}{|c|c|}
\hline Scale & Question \\
\hline INTRAPERSONAL & $\begin{array}{l}\text { "It is easy to tell people how I feel." } \\
\text { "It is hard to talk about my deep feelings." }\end{array}$ \\
\hline INTERPERSONAL & $\begin{array}{l}\text { "I am good at understanding the way other people feel." } \\
\text { "I feel bad when other people have their feelings hurt." }\end{array}$ \\
\hline ADAPTABILITY & $\begin{array}{l}\text { "I can understand hard questions." } \\
\text { "I can easily use different ways of solving problems." }\end{array}$ \\
\hline STRESS MANAGEMENT & $\begin{array}{l}\text { "When I get angry, I act without thinking." } \\
\text { "I know how to keep calm." }\end{array}$ \\
\hline GENERAL MOOD & $\begin{array}{l}\text { "I think that most things I do will turn out okay." } \\
\text { "I know how to have a good time." }\end{array}$ \\
\hline POSITIVE IMPRESSION & $\begin{array}{l}\text { "I like everyone I meet." } \\
\text { "Nothing bothers me." }\end{array}$ \\
\hline
\end{tabular}


Table 3.17 presents a comparative percentage of the current sample's mean scale scores and standard deviation to validation sample scores. The validation study in this case consisted of 16- to 18-year-old females from the general population $(N=711)$. Overall the current sample's mean scores are less than the validation study participants, although not remarkably so. This finding is interesting when one considers the negative effects of child maltreatment on neurodevelopmental tasks such as measured by the EQi-YV. However, the standard deviations for the current sample show surprisingly less or more variance amongst the sample (i.e., intra, inter, adapt, total EQi). One could speculate that these differences may be due in some part to the high maltreatment rates $(76.3 \%)$ and variability of types and severity of maltreatment in the current sample.

Table 3.17

EQi-YV: Validation Study and Current Study Mean Scale Scores and Standard Deviations

\begin{tabular}{lcccccc}
\hline Sample Groups & Intra & Inter & Adapt & Stress & Mood & EQiTS \\
\hline Current Study & & & & & & \\
$\quad M$ Scores & 15.1 & 38.7 & 28.0 & 33.2 & 42.7 & 56.5 \\
*VS $M$ scores & 15.3 & 40.7 & 28.5 & 34.0 & 45.0 & 58.1 \\
\% difference & -1.3 & -4.9 & -1.8 & -2.3 & -5.1 & -2.8 \\
& & & & & & \\
Current Study $S D$ & 3.3 & 4.8 & 5.1 & 7.0 & 6.6 & 6.2 \\
*VS SD & 4.2 & 4.5 & 4.8 & 6.9 & 6.7 & 6.8 \\
\% difference & -21.4 & +6.7 & +6.3 & +1.4 & -1.5 & -8.8 \\
\hline Note. *VS is the abbreviation for validation study (BarOn \& Parker, 2000a). &
\end{tabular}

Table 3.18 presents the percentage of the current study's respondents (by ethnicity) who scored below average on all EQi-YV scales and subscales (except Positive Impression). As a comparison, validation study scores are also provided. 
Table 3.18

EQi-YV: Percentage of Current Study and Validation Study Below Average Subscale Scores, by Ethnicity

\begin{tabular}{lrrrrrr}
\hline & Intra & Inter & Adapt & Stress & Mood & EQiTS \\
\hline Current Study & & & & & & \\
Caucasian & $31 \%$ & $52 \%$ & $31 \%$ & $35 \%$ & $41 \%$ & $38.0 \%$ \\
Latina & $6 \%$ & $29 \%$ & $20 \%$ & $31 \%$ & $14 \%$ & $17.0 \%$ \\
Other & $31 \%$ & $38 \%$ & $38 \%$ & $13 \%$ & $63 \%$ & $25.0 \%$ \\
$\%$ to $N$ & $20 \%$ & $39 \%$ & $28 \%$ & $29 \%$ & $34 \%$ & $26.0 \%$
\end{tabular}

\begin{tabular}{lllllll} 
Validation Study & $24 \%$ & $21 \%$ & $24 \%$ & $24 \%$ & $19 \%$ & $23.0 \%$ \\
\hline Note Caucasians
\end{tabular} (BarOn \& Parker, 2000a).

The EQi-YV also provides two subscales measuring under, over, or minimal effort response patterns: the positive impression scale and the inconsistency index. The positive impression scale has a cut-off score of $\geq 19$; the authors recommend that scores above 19 be carefully analyzed for clinical and intervention planning purposes (BarOn \& Parker, 2000a). As reflected in Table 3.19 , within the current sample for this research, $10 \%$ of the respondents scored above 19. Since overall the EQi scale and subscale scores were higher than expected (Total EQ $M=56.64)$ and fell within the range of average when compared to the validation sample, this may be a reflection in part of these positive impression responses. Scoring on the Inconsistency Index for this sample indicated that $10 \%$ of the sample's scores reflected inconsistency response patterns (the EQi-YV manual does not provide the mean scores on the Inconsistency Index for the validation study). 
Table 3.19

EQi-YV: Inconsistency and Positive Impression Current Sample Score Percentages by Ethnicity and Total $N$

\begin{tabular}{lcc}
\hline & $\begin{array}{c}\text { Positive Impression Index } \\
\%\end{array}$ & $\begin{array}{c}\text { Inconsistency Index } \\
\%\end{array}$ \\
\hline Current Study & 6.9 & 3.4 \\
Caucasian & 14.3 & --- \\
Latina & 6.3 & 19.0 \\
Other & 10.0 & 10.0 \\
$\%$ to $N=80$ & & \\
Validation Study & 4.9 & -- \\
\hline
\end{tabular}

Reliability. The EQi-YV was standardized using a large sample (total $N=$ 9,172; 4,625 males and 4,547 females) of Caucasian, African American and Hispanic/Latino children and adolescents who were 7 to 18 years old, attending regular schools and classes (i.e., no alternative or special education students were included in the sample; BarOn \& Parker, 2000a).

Statistical calculations for comparison group scores (age, gender) revealed the measure to be sensitive to both age and gender. Accordingly, separate standardized scores are used for each age group of males and females. One-way ANOVAs were also used to test response differences amongst racial and ethnic subgroups and according to the authors, "...effects for ethnicity were quite negligible" (BarOn \& Parker, 2000a). Test-retest or stability reliability correlations were calculated with data re-collected three weeks following the first administration and the subsequent scale correlation coefficients were quite sufficient (.77 to .89; BarOn \& Parker, 2000a, p. 42). 
Table 3.20 presents reliability coefficients for the validation study (13-18 year old females) and for the current study's scores. Internal reliability of the scale was tested in validation studies using Cronbach's Alpha. The scale's internal consistency was high for all subscales and for the EQi Total Scale in the current study; alphas ranged from .71 to .90 .

Table 3.20

EQi-YV: Reliability Coefficients for the Validation Study and the Current Study

\begin{tabular}{lcccccc}
\hline & Intra & Inter & Adapt & Stress & Mood & EQiTS \\
\hline Validation Study & .85 & .82 & .87 & .88 & .89 & .90 \\
Current Study & .71 & .76 & .87 & .88 & .85 & .90 \\
\hline Note. BarOn and Parker (2000a). & & & & &
\end{tabular}

Validity. Construct validity was tested for the EQi-YV in several ways. The factor structure of the measure was analyzed using the total normative sample, and interscale and subscale correlations between the total EQi-YV total scale and subscales were analyzed. The interscale correlations were adequate and statistically significant at the $p<.05$ level and ranged from .29 to .72 . According to the authors (Bar-On \& Parker, 2000a) the statistically significant $(p<.05)$ low to moderate correlations are consistent with the EQi-YV's purpose of measuring different dimensions of emotional intelligence.

Table 3.21 presents the intercorrelations among the EQi-YV's total scale and subscales for both the current study and the validation study. Similar to the EQi's validation studies, the current study findings also revealed a good deal of variance in the intercorrelations. Overall, the size and direction of the interitem 
correlations makes theoretical sense, with the exception of the size and the direction of the adaptability/stress management intercorrelation $(r=-.09)$ which was nonsignificant.

Table 3.21

EQi-YV: Scale/Subscale Intercorrelations for Current Study and the Validation Study (BarOn \& Parker, 2000a)

\begin{tabular}{|c|c|c|c|c|c|}
\hline & EQi-YV & Intra & Inter & Adapt & Stress \\
\hline EQi-YV & --- & -- & --- & $-\cdots$ & --- \\
\hline $\begin{array}{c}\text { Intra } \\
* V S\end{array}$ & $\begin{array}{l}.61^{* *} \\
.72^{*}\end{array}$ & --. & --- & $-\cdots$ & --.. \\
\hline $\begin{array}{l}\text { Inter } \\
* V S\end{array}$ & $\begin{array}{l}.69^{* *} \\
.69^{*}\end{array}$ & $\begin{array}{l}.13 \\
.30^{*}\end{array}$ & --- & --- &.-- \\
\hline $\begin{array}{c}\text { Adapt } \\
\text { *VS }\end{array}$ & $\begin{array}{l}.54^{* *} \\
.71^{*}\end{array}$ & $\begin{array}{l}.16 \\
.29^{*}\end{array}$ & $\begin{array}{l}.30^{* *} \\
.48^{*}\end{array}$ & $\cdots$ & --- \\
\hline $\begin{array}{c}\text { Stress } \\
* V S\end{array}$ & $\begin{array}{l}.61^{* *} \\
.68^{*}\end{array}$ & $\begin{array}{l}.12 \\
.29^{*}\end{array}$ & $\begin{array}{l}.40^{* *} \\
.29^{*}\end{array}$ & $\begin{array}{l}-.09 \\
.28^{*}\end{array}$ & --- \\
\hline $\begin{array}{c}\text { Mood } \\
\text { *VS }\end{array}$ & $\begin{array}{l}.60^{* * *} \\
60^{*}\end{array}$ & $\begin{array}{l}.29^{* *} \\
.31^{*}\end{array}$ & $\begin{array}{l}.51^{* *} \\
.57^{*}\end{array}$ & $\begin{array}{l}.34^{* *} \\
.50^{*}\end{array}$ & $\begin{array}{l}.37^{* *} \\
.35^{*}\end{array}$ \\
\hline
\end{tabular}

The Adult-Adolescent Parenting Inventory-2

The Adult-Adolescent Parenting Inventory-2 (AAPI-2) is a 40-item selfreport measure that is thought to assess the parenting attitudes and behaviors of both adults and adolescents 13 to 18 years old. The AAPI- 2 measure uses a 5-point Likert-type scale (strongly agree, agree, uncertain, disagree, strongly disagree). It is written at a fifth grade reading level, and requires approximately 20 minutes on average to complete. According to the authors, the AAPI-2 is, “...based on the known parenting and child rearing behaviors of abusive parents" (Bavolek \& 
Keene, 2001, p. 1), and scores from this inventory therefore are meant to provide a risk index of child abuse or neglect potential. The original AAPI and more currently, the AAPI-2 have been widely used in the field of parenting for more than 20 years for both pre- and post- parent training assessment and evaluation.

Table 3.22 provides the four scales of the AAPI- 2 used in this study inappropriate expectations of children, parental lack of empathy toward children's needs, strong belief in the use of corporal punishment as a means of discipline, and reversing parent-child role responsibilities. Construct five, oppressing children's power and independence, was not utilized in this study.

Table 3.22

AAPI-2: Sample Items

\begin{tabular}{ll}
\hline Scale & Questions \\
\hline EMPATHY & $\begin{array}{l}\text { "Children should keep their feelings to themselves." } \\
\text { "Babies need to learn how to be considerate of the needs } \\
\text { of their mother." }\end{array}$ \\
INAPPROPRIATE & "Good children always obey their parents." \\
EXPECTATIONS & "Parents need to push their children to do better." \\
CORPORAL PUNISHMENT & "Time-out is an effective way to discipline children." \\
"Spanking teaches children right from wrong." & "Parents should be able to confide in their children." \\
"Children should be aware of ways to comfort their & parents after a hard day's work."
\end{tabular}

The AAPI-2 does not provide an overall total scale score (Bavolek \& Keene, 2001). Raw scores for each of the scales are transformed into standardized scores (sten scores) by age, gender and parenting status. Norm tables are provided. 
Final sten scores of 1-4 indicate a higher risk for potential abusive parenting practices, scores of 5-7 are representative of the general population, and scores of 8-10 more closely represent nurturing and non-abusive parenting styles (Bavolek \& Keene, 2001). Table 3.23 presents the mean sten scores as well as the median, mode, and standard deviation scores by scale for the current study sample.

Table 3.23

AAPI-2: Mean Scale Sten Scores, Mode, Median, and SD for the Current Study

\begin{tabular}{lcccc}
\hline & $\begin{array}{c}\text { Inappropriate } \\
\text { Expectations }\end{array}$ & Empathy & $\begin{array}{c}\text { Corporal } \\
\text { Punishment }\end{array}$ & $\begin{array}{c}\text { Role } \\
\text { Reversal }\end{array}$ \\
\hline Mean Sten Scores & 7.3 & 6.3 & 7.4 & 6.4 \\
Mode & 8.0 & 6.0 & 8.0 & 6.0 \\
Median & 8.0 & 6.0 & 8.0 & 6.0 \\
SD & 1.8 & 2.4 & 1.7 & 2.2 \\
\hline
\end{tabular}

The AAPI-2 scores for the current sample were quite unexpected in this study (lower scores were expected) and do not compare to other studies on parents at risk for abuse (e.g., Bavolek \& Keene, 2001; Buzarnescu, 2006; Gisseman, 2005; Healthy Families Jacksonville Evaluation Team [HFJ], 2000).

It is important to note that all of the adolescent mothers recruited for this sample had received some level of parent training through their schools or community service agencies. This study however, was unable to capture how much training individually or on average participants had received.

As a comparison sample, Table 3.24 presents mean sten scores by scale for the current study and two field evaluation projects. The first evaluation was done in 2000 for a large community program, Healthy Families Jacksonville 
(Jacksonville, FL; $N=227-361 ; \mathrm{HFJ}, 2000$ ). The second evaluation was done by the Youth Services Division in Salt Lake county, Utah $(N=39)$.

Table 3.24

AAPI-2: HFJ and Salt Lake County Mean, Pre and Post Parent Training AAPI-2 Scale Sten Scores as Compared to Current Study Scale Sten Scores

\begin{tabular}{lcccc}
\hline & $\begin{array}{c}\text { Inappropriate } \\
\text { Expectations }\end{array}$ & Empathy & $\begin{array}{c}\text { Corporal } \\
\text { Punishment }\end{array}$ & $\begin{array}{c}\text { Role } \\
\text { Reversal }\end{array}$ \\
\hline $\begin{array}{l}\text { Current Sample } \\
\text { *VS1 - HFJ }\end{array}$ & 7.3 & 6.3 & 7.4 & 6.4 \\
Pre-class score & 3.2 & 3.7 & 5.1 & 3.5 \\
*VS2 - Salt Lake & & & & \\
Pre-class scores & 4.8 & 4.4 & 4.6 & 5.3 \\
Post-class scores & 5.4 & 5.6 & 5.1 & 5.1 \\
\hline Note. *VS1 \& 2 are the two comparative evaluation study groups (Bavolek \& Keene, 2001).
\end{tabular}

The scores for the HFJ sample were gathered before the HFJ participants had received any parenting training or services from the program. The participants' age range was 12 to 43 years old $(M=22.8)$, and of this population $24.4 \%$ were under the age of 18 . The HFJ sample is similar in a number of demographic characteristics (e.g., education, marital status, income, etc.) to the current study sample.

The first set of scores (VS 2) listed for the Salt Lake county parents were also gathered before the participants had received any parent training classes. The second set of scores was the post-parenting class scores (seven sessions) of these same participants. Unfortunately, the Salt Lake county evaluation report does not provide any parent demographic information, although it is useful for comparative purposes nonetheless. What is of course so informative is the comparison of these 
two groups' AAPI-2 sten scores, both pre- and post- parent training with the current sample. The current sample scored considerably higher than participants in the field evaluation projects.

Further support for the theoretical, clinical, and practical problems experienced with the AAPI-2 in the current research study was found in a recent study of 194 teenage mothers. The original research design for the study included all the scales of the AAPI- 2 to assess the parenting attitudes of the participant mothers (Black et al., 2002). During data analyses however the researchers "...used [only] the Lack of Empathy scale because it was the only scale in which the scores reflected deficiencies in parenting attitudes in comparison with the general population norms" (p. 578).

Finally, another study funded by the National Center on Child Abuse and Neglect and, in collaboration with the National Resource Center on Family Based Services at the University of Iowa School of Social Work and the Northwest Indian Child Welfare Association (Nelson et al., 1994), found that the AAPI-2 did not perform well with Native American populations. According to the authors, "the AAPI subscales, particularly the empathy subscale, differed in the expected direction between the neglect and comparison group in the non-Indian sample, but failed to differentiate between them, or reversed direction in the Indian sample" (pp. 4-5).

Reliability. According to the originators of the AAPI-2, the constructs of the AAPI-2 were fully aligned with the original constructs of AAPI- 1 which for 
years has been used in the parenting and parent education fields. More than 53 agencies and 1,400 respondents nationwide participated in the 2-year validation study process for the AAPI-1. Using these data, internal reliability coefficients were computed using Cronbach's Alpha. The resulting reliability coefficients for the AAPI-2 were high for all constructs, ranging from .82 to .92 . (Bavolek $\&$ Keene, 2001). Table 3.25 shows the reliability coefficients for both the original AAPI-1 validation study sample and the current study sample.

Table 3.25

AAPI-2: Reliability Coefficients for Original Validation Study Sample and the Current Study Sample

\begin{tabular}{lcccc}
\hline Study Sample & $\begin{array}{c}\text { Inappropriate } \\
\text { Expectations }\end{array}$ & Empathy & $\begin{array}{c}\text { Corporal } \\
\text { Punishment }\end{array}$ & $\begin{array}{c}\text { Role } \\
\text { Reversal }\end{array}$ \\
\hline Validation Study & .82 & .88 & .92 & .82 \\
Current Study & .72 & .84 & .70 & .69 \\
\hline
\end{tabular}

Although the reliability coefficients for the current study are adequate, they are notably lower than the results produced in the validation study. As discussed further in chapter 5, Discussion, in the current study the AAPI did not perform as predicted in comparison to previous research on adolescent mothers.

Validity. Criterion validity was established for the AAPI-2 using the AAPI-1. High correlations between the scales were found, as would be expected. Using data from the validation sample, a factor analysis was performed to determine the conceptual validity of the measure's principal constructs as represented by the 40 items contained the measure's scales. However, it does not 
appear that during standardization processes the constructs of the AAPI-1 and 2 were tested against other measures of parenting beliefs and behaviors.

In field research however, Gordon and Gordon (as cited in Bavolek \& Keene, 2001) compared correctional clients' scores $(N=21)$ from the "At Risk" scale of the MMPI to these same participants' scores on the AAPI-1. Individuals who rated at risk for potential child abuse perpetration also scored poorly on the AAPI-1. Minor, Karr, and Jain (as cited in Bavolek \& Keene, 2001) also used the AAPI-1 and the MMPI with correctional inmates $(N=49)$ to examine potential relationships between parenting attitudes and personality characteristics. Results revealed that prisoners' scores indicated a significantly higher risk for child abuse than the general population. Finally Green and Calder (as cited in Bavolek \& Keene, 2001) compared the AAPI-1 and Eysenck Personality Questionnaire scores of 150 general population high school students. Only the Eysenck psychoticism scale showed significant relationships with the responses of the AAPI-1.

Interitem correlations on the scales of the AAPI-2 during the standardization process were moderate in strength ranging from .54 to .77 . For the current study, interitem correlations were statistically significant at the $p<.01$ level and ranged from .40 to .73 .

Scores from the AAPI-2 are believed to significantly discriminate between parents who are known to be abusive or neglectful and those who are not (Bavolek \& Keene, 2001). In studies of abused and non-abused adolescents, MANOVA and 
discriminant function analyses revealed that only approximately $13 \%$ of nonabused adolescents' scores reflected potentially abusive parenting attitudes.

\section{The Demographic Questionnaire}

The purpose of the Demographic Questionnaire was to obtain relevant descriptive information about the sample population. It included standard questions as to age, ethnicity, education, income, family structure, and SES. Data from this questionnaire were analyzed for relationships amongst research variables and to provide a descriptive and comparative overview of the sample population. The majority of the results from this questionnaire were reported earlier in this chapter in the discussion regarding participant characteristics.

\section{The Services Questionnaire}

The purpose of the services questionnaire was to determine what services specific to pregnant and parenting teenage mothers had been offered (educational,

agency based, social welfare, etc.), what services respondents had most utilized, and reasons for non-utilization of services. The services questionnaire also sought to gather fairly specific data regarding the extent of mental health services the sample population had received. Additionally, three open-ended questions asked the respondents to discuss what services they had found the most and least helpful, as well as what services they felt they needed or services they need to receive more extensively. Results of the services questionnaire are reported in chapter 4, Results. 


\section{CHAPTER IV}

\section{RESULTS}

The purpose of this chapter is to report the empirical results of this research study. Each of the four research questions, resulting hypotheses, and statistical or descriptive analyses used are discussed consecutively. Statistically, hypotheses one through two were tested using hierarchical stepwise multiple regression analyses with key construct variables. Interitem and interscale correlation coefficients were closely examined as well to explore the relationships between independent and dependent variables. Hypothesis three used simple multiple regression analyses. Quantitative data for research question four are descriptively analyzed.

All standardized scales and subscales used in this research were calculated according to procedures described in their respective test administration manuals. Prior to performing any regression analyses, the data from each instrument were examined for missing or invalid responses. After data had been reviewed it was given to a supervisor at the Survey Research Laboratory in the Graduate School of Social Work's Regional Research Institute, Portland State University, for input into SPSS. Once data input for each instrument was complete, a $20 \%$ random questionnaire check was performed for each instrument to test for accuracy.

Following this, descriptive and bivariate analyses were used to establish score frequencies, distributions, correlation coefficients within and between scales 
and other variables (i.e., demographic and service variables). Scatterplots were examined for outliers and to determine whether linear relationships were present. Research assumptions for multiple regression analyses were met for each of the regressions conducted for this research. Variables used in regression analyses were all above the nominal level of measurement, expected relationships between predictor and criterion variables were linear in either positive or inverse directions, and all data observation and inclusion was independent. Overall raw data and residuals were found to approximate normal distributions with the exception of participant age. Three single case scores were removed as outliers in three separate regressions when they were found to exceed three $S D$ s distance from mean dependent variable scores. These cases were also checked for random scoring patterns or response bias, and none were found.

All missing data were managed by imputing the item-level group mean for each individual question involved. Overall missing data were not a significant problem with any of the instruments and questionnaires. Out of 2,240 total data points possible on the CTQ, only $30(1.3 \%)$ were missing; 5 scores $(.12 \%)$ were missing out of a potential 4,320 on the TSCC; on the EQi-YV, of a total of 4,800 possible data points only 8 scores $(.17 \%)$ were missing, and 14 scores $(.44 \%)$ were missing from a potential 3,200 scores on the AAPI-2. No cases were removed from the statistical analyses due to missing data, social desirability, or under/over response patterns. 
Following the regression analyses of each hypothesis the Condition Index, Variance Inflation Factor (VIF) statistics, and Tolerance Levels were examined to determine if multicolinearity was a problem between any of the independent variables (Cohen \& Cohen, 1983). Tolerance values ranged between .337 and .977, none of the variance inflation factors exceeded 2.97, and the condition index of all variables was found to be $<5.32$.

\section{Research Question One}

Do greater exposure to child abuse and/or neglect trauma and the current experience of trauma symptoms predict lower overall socioemotional skills or abilities?

\section{Hypothesis 1}

It was expected that childhood history of child maltreatment trauma would predict lower socioemotional skills as measured by the EQi-YV Total Scale Score. High scores by respondents (indicating more trauma experienced) on the individual or multiple scales of the CTQ would predict lower scores on the EQi Total Scale. Furthermore, high scores on the subscales of the TSCC (indicating more current trauma symptomology) would also predict lower scores on the EQi Total Scale Score.

Table 4.1 presents the results for the stepwise hierarchical multiple regression analysis performed to determine the contribution of: (a) the experience of child abuse and neglect (emotional abuse, physical abuse, sexual abuse, emotional neglect, and physical neglect), and (b) current experience of trauma 
symptomology (anxiety, depression, anger, PTSS, dissociation, and sexual concerns) variables to the prediction of the total emotional quotient score as measured by the EQi-YV Total Scale score.

Table 4.1

Hypothesis 1: Summary of Stepwise Hierarchical Analysis Predicting EQi Total Scale Score on the Basis of Child Abuse and Neglect Trauma Symptomology

\begin{tabular}{lcccc}
\hline Predictor Variables & $B$ & $S E B$ & $\beta$ & $\begin{array}{c}\text { Change } \\
\text { Statistics }\end{array}$ \\
\hline Step 1 (CTQ) & & & & \\
Emotional Neglect & -.314 & .135 & $-.255^{*}$ & \\
$F(1,78)$ & & & & $5.429^{*}$ \\
$R^{2}$ & & & & .065
\end{tabular}

\begin{tabular}{|c|c|c|c|c|}
\hline \multicolumn{5}{|l|}{ Step 2 (Adding TSCC) } \\
\hline Emotional Neglect & -.146 & .128 & -.119 & \\
\hline Depression & -.589 & .137 & $-.447^{* *}$ & \\
\hline$F(2,77)$ & & & & $12.573^{* * *}$ \\
\hline$R^{2}$ & & & & .246 \\
\hline$R^{2}$ change & & & & .181 \\
\hline$F$ change & & & & $18.500^{* * *}$ \\
\hline
\end{tabular}

This analysis revealed that $24.6 \%$ of variance in the participants' total emotional quotient scores was explained by the predictor variables. On step one of the regression emotional neglect made a unique and significant contribution to the prediction $(\beta=-.255, p<.05)$ explaining $6.5 \%$ of the variance on the EQi Total Scale Score. When trauma symptom variables were added to the regression in step two, the variable depression also significantly added into the prediction $(\beta=-.447$, $p<.001)$ after all other variables were controlled for. Therefore, since there is a significant relationship between the experience of child maltreatment (emotional 
neglect), trauma symptomology (depression), and participants' total emotional quotient score, the null hypothesis is rejected.

As can be seen in Table 4.2, interitem and interscale correlations were run between and amongst the constructs of the CTQ, the TSCC, and the EQi Total Scale Score. With the exception of the correlations between anxiety/emotional neglect and PTSS/emotional neglect, all other interscale correlations of the predictor variables are significant at the $p<.01$ level. Some of the correlations are low to moderate, indicating that the CTQ and TSCC items are measuring different but related constructs. Overall these scales were significantly related in the expected theoretical direction, i.e., the higher the level of child abuse or neglect experienced, the greater the current occurrence of trauma symptoms.

Correlations of the CTQ and the TSCC with the EQi Total Scale were also low to moderate (-.03 to -.49). The correlation between emotional neglect and EQi Total Scale Score although low, was significant $(p<.01)$. In all cases the theoretical direction of the associations was negative as expected. That is to say, as the level of abuse or neglect experienced by participants increased, their level of socioemotional skills/abilities decreased. All of the interscale correlations between the TSCC and the EQi Total Scale were low to moderate but significant at the $p<$ .01 level. The expected inverse theoretical direction is supported, indicating that as participants' experience of current trauma symptoms increases, their socioemotional skills/abilities are less developed. 
Table 4.2

Hypothesis 1: Means, Standard Deviations, and Interscale Correlations Among Study Variables - Experience of Childhood Trauma (CTQ), Current Trauma Symptomology (TSCC), and Emotional Quotient Total Score

\begin{tabular}{|c|c|c|c|c|c|c|c|c|c|c|c|c|}
\hline & 1 & 2 & 3 & 4 & 5 & 6 & 7 & 8 & 9 & 10 & 11 & 12 \\
\hline \multicolumn{13}{|l|}{ CTQ Scales } \\
\hline $\begin{array}{l}\text { 1. Emotional } \\
\text { Abuse }\end{array}$ & -- & & & & & & & & & & & \\
\hline 2. Physical Abuse & $.67^{* *}$ & -- & & & & & & & & & & \\
\hline 3. Sexual Abuse & $.55^{* *}$ & $.64 * *$ & -- & & & & & & & & & \\
\hline 4. Emot. Neglect & $.62 * *$ & $.47 * *$ & $.32 * *$ & $\cdots$ & & & & & & & & \\
\hline 5. Physical Neglect & $.69 * *$ & $.58 * *$ & $.46^{* *}$ & $.46^{* *}$ & --- & & & & & & & \\
\hline \multicolumn{13}{|l|}{ TSCC Scales } \\
\hline 6. Anxiety & $.39 * *$ & $.33^{* *}$ & $.34 * *$ & .20 & $.35 * *$ & --- & & & & & & \\
\hline 7. Depression & $.48 * *$ & $.33 * *$ & $.31 * *$ & $.31 * *$ & $.41 * *$ & $.81^{* *}$ & --- & & & & & \\
\hline 8. Anger & $.48 * *$ & $.28 * *$ & $.33^{* *}$ & $.40^{* *}$ & $.39 * *$ & $.66^{* *}$ & $.70^{* *}$ & --- & & & & \\
\hline 9. PTSS & $.45^{* *}$ & $.34 * *$ & $.42 * *$ & .21 & $.39 * *$ & $.86^{* *}$ & $.81^{* *}$ & $.61 * *$ & --- & & & \\
\hline 10. Dissociation & $.50^{* *}$ & $.34 * *$ & $.35^{* *}$ & $.32^{* *}$ & $.38^{* *}$ & $.81^{* *}$ & $.80^{* *}$ & $.69 * *$ & $.81 * *$ & -- & & \\
\hline \multicolumn{13}{|l|}{ 11. Sexual } \\
\hline Concerns & $.40^{* *}$ & $.35 * *$ & $.46^{* *}$ & $.27 * *$ & $.37 * *$ & $.66^{* *}$ & $.61 * *$ & $.59 * *$ & $.66^{* *}$ & $.70^{* *}$ & $\cdots$ & -- \\
\hline \multicolumn{13}{|l|}{ EQi-YV } \\
\hline $\begin{array}{l}\text { 12. Eqi-YV Total } \\
\text { Scale }\end{array}$ & -.15 & -.03 & -.08 & $-.26^{*}$ & -.16 & $-.39 * *$ & $-.48 * *$ & $-.48 * *$ & $-.40^{* *}$ & $-.45^{* *}$ & $-.33 * *$ & ... \\
\hline Variable Means & 9.18 & 7.95 & 8.59 & 10.61 & 8.50 & 5.78 & 6.76 & 6.38 & 7.95 & 6.98 & 4.47 & 56.45 \\
\hline Variable $S D$ s & 4.67 & 5.31 & 5.86 & 5.04 & 3.75 & 4.36 & 4.70 & 5.55 & 6.03 & 5.01 & 4.60 & 6.19 \\
\hline
\end{tabular}


Research Question Two

Do greater exposure to child abuse and/or neglect trauma, the current experience of trauma symptoms, and lower socioemotional development predict less positive parenting attitudes and behaviors?

Hypothesis $2 a-d$

The following blocks of predictor variables, childhood history of child abuse and/or neglect trauma (CTQ), subclinical and clinical levels of trauma symptomology (TSCC), and socioemotional skills/abilities (EQi-YV) were expected to predict less positive parenting attitudes and behaviors (as measured by the AAPI-2).

Higher scores by respondents on CTQ scales (physical abuse, emotional abuse, sexual abuse, physical neglect, and emotional neglect) indicate more trauma experienced. Elevated TSCC scale scores (anxiety, depression, anger, posttraumatic stress, dissociation, and sexual concern) indicate subclinical and clinical significance. Lower scores by respondents on the EQi Total Scale indicate fewer socioemotional skills/abilities, and lower scores on the AAPI-2 scales identify respondents who have less positive parenting attitudes and behaviors.

Once again, hierarchical multiple regression analyses were conducted in a stepwise fashion to test the extent to which the individual scales and subscales 
(CTQ, TSCC, EQi-YV Total Scale) would predict the variance of the individual AAPI-2 scales on parenting attitudes and behaviors. Four separate regressions were performed; one for each of the AAPI-2 scales:

1. 2a - Empathy (DV),

2. $2 b$ - Corporal Punishment (DV),

3. 2c - Inappropriate Expectations (DV), and

4. 2d - Role Reversal (DV).

Hypothesis 2a: Empathy. The results of the regression, with empathy as the dependent variable, are shown in Table 4.3. Overall, results were in an unexpected direction. Emotional abuse, physical neglect, and the EQi Total Scale score did predict a combined total of $16.7 \%$ of the variance for empathy. In step one of the regression emotional abuse accounted for $11.2 \%$ of variance $(\beta=.334, p<.01)$ however, the positive direction of the beta was unexpected (e.g., as the experience of emotional abuse increases, empathy also increases).

In step two of the regression the combination of emotional abuse and physical neglect increased the prediction of the variance to $16.6 \%$ with a robust significance for physical neglect $(\beta=-.325, p<.001)$. However, the positive direction of the emotional abuse Beta is once again unexpected. 
Table 4.3

Hypothesis 2a: Summary of Stepwise Hierarchical Analysis Predicting AAPI-2 Empathy Scale Score on the Basis of Experience of Child Abuse and Neglect Trauma (CTQ), Current Trauma Symptomology (TSCC), and Total Emotional Quotient Score (EQi-YV)

\begin{tabular}{|c|c|c|c|c|}
\hline Predictor Variables & $B$ & $S E B$ & $\beta$ & Change Statistics \\
\hline \multicolumn{5}{|l|}{ Step 1 (CTQ) } \\
\hline Emotional Abuse & .443 & .142 & $.334 * *$ & \\
\hline$F(1,78)$ & & & & $9.79 * *$ \\
\hline$R^{2}$ & & & & .112 \\
\hline \multicolumn{5}{|l|}{ Step 2 (Adding TSCC) } \\
\hline Emotional Abuse & .743 & .192 & .560 & \\
\hline Physical Neglect & -.538 & .239 & $-.325 * * *$ & \\
\hline$F(2,77)$ & & & & $7.68^{* * *}$ \\
\hline$R^{2}$ & & & & .166 \\
\hline$R^{2}$ change & & & & $.055^{* *}$ \\
\hline$F$ change & & & & $5.06^{* *}$ \\
\hline \multicolumn{5}{|c|}{ Step 3 (Adding EQi Total Scale Score) } \\
\hline Emotional Abuse & .741 & .193 & .558 & \\
\hline Physical Neglect & -.541 & .241 & -.327 & \\
\hline EQi Total Scale Score & -.018 & .106 & -.018 & \\
\hline$F(3,76)$ & & & & $5.07 * *$ \\
\hline$R^{2}$ & & & & .167 \\
\hline$R^{2}$ change & & & & .000 \\
\hline$F$ change & & & & .028 \\
\hline
\end{tabular}

The EQi-YV Total Scale score was added in step three of the regression. Although the model including the combination emotional abuse, physical neglect and the total EQi total scale score was significant at a $p<.01$ level, the positive direction of the relationships, as reflected in the standardized coefficients of emotional neglect $(\beta=.334, .560, .558$ respectively), and the negative beta of the EQi Total Scale Score $(\beta=-.018)$, do not support the hypothesized direction. However, because step two of the initial regression analysis showed a moderate 
beta value in the predicted direction for physical neglect, plus a very significant $F$ $(p<.001)$, another simple regression was conducted to test the ability of physical neglect as a independent variable to predict the variance of empathy; it was nonsignificant. Therefore, for hypothesis $2 \mathrm{a}$ the null hypothesis is not rejected.

Tables $4.4,4.5$, and 4.6 provide the interscale correlations between the dependent variables of the AAPI-2 scales, and the independent variables of the CTQ, TSCC, and the EQi-YV Total Scale Score. As might be expected from the directional inconsistencies of emotional abuse in the regression analysis for hypothesis $2 \mathrm{a}$, the correlation between emotional abuse and empathy although statistically significant $(r=.33, p<.01)$, is also in a positive and unexpected direction. Overall, empathy is correlated with the child trauma scales only at very low levels, and the direction of the relationships was not as theoretically predicted. This indicates that the two instruments share only a very small conceptual relationship.

Furthermore, the fact that none of the independent trauma variables met the criteria for inclusion in step two of the regression analysis, may also be explained by the lack of correlation between these variables and the empathy construct (see Table 4.5). Additionally, the direction of the correlations are, like the child trauma variables, opposite of the hypothetical prediction (i.e., as the experience of current trauma symptoms increase, it would be expected that the level of empathy would decrease). 
Table 4.4

Hypotheses 2a-d: Means, Standard Deviations, and Interscale Correlations Among Study Variables - Experience of Childhood Trauma (CTQ), and Parental Beliefs and Behaviors (AAPI-2)

\begin{tabular}{llllllllll}
\hline & & & & & & & & \\
& 1 & 2 & 3 & 4 & 5 & 6 & 7 & 8 \\
\hline
\end{tabular}

\section{AAPI Scales}

1. Inappropriate Expectations

2. Empathy

3. Corporal Punishment

4. Role Reversal

$57 * *$

$.57^{* *} \quad---$

$40^{* *} \quad .55^{* *}$

$.50 * * \quad .73 * *$

$--$

CTQ Scales

5. Emotional Abuse

6. Physical Abuse

7. Sexual Abuse

8. Emotional Neglect

9. Physical Neglect

Variable Means

Variable $S D$ s

Note. ${ }^{* *} p<.01 ; N=80$.

\begin{tabular}{|c|c|c|c|c|c|c|c|c|}
\hline .06 & $.33 * *$ & .19 & $.30^{* *}$ & $-\cdots$ & & & & \\
\hline .01 & .09 & .12 & .03 & $.67^{* *}$ & $\cdots$ & & & \\
\hline .05 & .09 & .13 & .015 & $.55^{* * *}$ & $.64 * *$ & -- & & \\
\hline .004 & .03 & .04 & .16 & $.62 * *$ & $.47^{* *}$ & $.32^{* *}$ & -- & \\
\hline .05 & .06 & .12 & .18 & $.69 * *$ & $.57^{* *}$ & $.46^{* *}$ & $.77 * *$ & -- \\
\hline 23.72 & 39.73 & 44.11 & 24.44 & 9.18 & 7.95 & 8.59 & 10.61 & 8.50 \\
\hline 4.71 & 6.20 & 6.32 & 4.69 & 4.67 & 5.31 & 5.86 & 5.04 & 3.75 \\
\hline
\end{tabular}


Table 4.5

Hypotheses 2a-d: Means, Standard Deviations, and Interscale Correlations Among Study Variables - Parental Beliefs and Behaviors (AAPI-2) and Current Experience of Trauma Symptomology (TSCC)

\begin{tabular}{|c|c|c|c|c|c|c|c|c|c|c|}
\hline & 1 & 2 & 3. & 4 & 5 & 6 & 7 & 8 & 9 & 10 \\
\hline \multicolumn{11}{|l|}{ AAPI Scales } \\
\hline $\begin{array}{l}\text { 1. Inappropriate } \\
\text { Expectations }\end{array}$ & $\cdots$ & & & & & & & & & \\
\hline 2. Empathy & $.57^{* *}$ & --- & & & & & & & & \\
\hline 3. Corporal Punishment & $.40^{* *}$ & $.55^{* *}$ & --- & & & & & & & \\
\hline 4. Role Reversal & $.50 * *$ & $.73^{* *}$ & $.41^{* *}$ & --- & & & & & & \\
\hline \multicolumn{11}{|l|}{ TSCC Scales } \\
\hline 5. Anxiety & .17 & .05 & .05 & .08 & -- & & & & & \\
\hline 6. Depression & .19 & .19 & .04 & $.23 *$ & $.81^{* *}$ & -- & & & & \\
\hline 7. Anger & .17 & .18 & .06 & .21 & $.66^{* *}$ & $.70 * *$ & --- & & & \\
\hline 8. PTSS & .18 & .04 & .07 & .11 & $.86^{* *}$ & $.81^{* *}$ & $.61 * *$ & -- & & \\
\hline 9. Dissociation & .17 & .10 & .07 & .19 & $.81^{* *}$ & $.80^{* *}$ & $.69 * *$ & $.81^{* *}$ & --- & \\
\hline 10. Sexual Concerns & .08 & .14 & .11 & .21 & $.66^{* *}$ & $.61^{* *}$ & $.59 * *$ & $.66^{* *}$ & $.70^{* *}$ & \\
\hline Variable Means & 23.72 & 39.73 & 44.11 & 24.44 & 5.78 & 6.76 & 6.38 & 7.95 & 6.98 & 4.47 \\
\hline Variable $S D$ s & 4.71 & 6.20 & 6.32 & 4.69 & 4.36 & 4.70 & 5.55 & 6.03 & 5.01 & 4.60 \\
\hline
\end{tabular}


Finally, with the exception of adaptation, the EQi subscales and total scale scores and the AAPI-2 scale scores, correlations were quite low and once again the theoretical directions were not as predicted. Table 4.6 illustrates the lack of relationship between the EQi total scale score and the AAPI-2 scales.

Table 4.6

Hypotheses 2a-d: Means, Standard Deviations, and Interscale Correlations Among Study Variables - Parental Beliefs and Behaviors (AAPI-2) and the EQi Total Scale Score (EQi-YV)

\begin{tabular}{|c|c|c|c|c|c|}
\hline & 1 & 2 & 3 & 4 & 5 \\
\hline \multicolumn{6}{|l|}{ AAPI-2 Scales } \\
\hline 1 Inappropriate Expectations & --- & & & & \\
\hline 2. Empathy & $.57^{* *}$ & -- & & & \\
\hline 3. Corporal Punishment & $.40^{* *}$ & $.55^{* *}$ & -- & & \\
\hline 4. Role Reversal & $.50^{* *}$ & $.73^{* *}$ & $.41 * *$ & --- & \\
\hline \multicolumn{6}{|l|}{ EQi-YV Total Scale } \\
\hline 5. EQi & -.17 & -.05 & .19 & -.18 & -- \\
\hline Variable Means & 23.72 & 39.73 & 44.11 & 24.44 & 56.64 \\
\hline Variable $S D$ & 4.71 & 6.20 & 6.32 & 4.69 & 6.19 \\
\hline
\end{tabular}

Note. ${ }^{* *} p<.01 ; N=80$.

Hypothesis 2b: Corporal punishment. In hypothesis $2 \mathrm{~b}$, a three step hierarchical regression process was again selected to analyze the effects of the CTQ, TSCC, and the EQi-YV Total Scale Score predictor variables when the AAPI-2 dependent variable corporal punishment was regressed upon them. In this regression one case was removed from the analysis because there was one particularly low outlier score in corporal punishment scores. This score was not the result of a random response pattern however. 
The CTQ scale scores were the first entered into the regression as a block in a stepwise manner. The TSCC scales were entered on step two of the regression, again as a block and in a stepwise fashion. The EQi total scale score was last to be entered into the equation.

Table 4.7 presents the key results for hypothesis $2 \mathrm{~b}$. In this analysis the EQi total scale score was the only independent variable to meet the criteria for inclusion into the regression. All CTQ and TSCC scales were removed. The EQi YV total scale score was able to explain $5.7 \%$ of the variance of corporal punishment, and was significant at the $p<.05$ level $(p=.034)$. Therefore the null hypothesis is rejected.

As can be seen in the correlation matrixes in Tables 4.4, 4.5, and 4.6, with the exception of corporal punishment and the EQi total, all of the correlations between corporal punishment and the predictor scales are quite low and once again in opposition to the hypothesized results. 
Table 4.7

Hypothesis 2b: Summary of Stepwise Hierarchical Analysis Predicting AAPI-2 Corporal Punishment Scale Score on the Basis of Experience of Child Abuse and Neglect Trauma (CTQ), Current Trauma Symptomology (TSCC), and Total Emotional Quotient Score (EQi-YV)

\begin{tabular}{lcccc}
\hline Predictor Variables & $B$ & $S E B$ & $\beta$ & Change Statistics \\
\hline Step 1 (CTQ) & & & & \\
CTQ Scales & -- & -- & -- & \\
Step 2 (Adding TSCC) & & & & \\
TSCC Scales & -- & -- & --- &.- \\
Step 3 (Adding EQi Total Scale Score) & & & & \\
EQi Total Scale Score & .231 & .107 & $.239^{*}$ & \\
$F(3,76)$ & & & & $4.67^{*}$ \\
$R^{2}$ & & & & .057 \\
\hline
\end{tabular}

Note. ${ }^{*} p<.05 ; N=79 ; \mathrm{DV}$ - Corporal Punishment.

Hypothesis 2c: Inappropriate expectations. The statistical analysis for hypothesis $2 \mathrm{c}$ varied from hypothesis $2 \mathrm{a}$ and $2 \mathrm{~b}$ only in the dependent variable. In this regression the criterion variable was inappropriate expectations, another scale of the AAPI-2. None of the independent variables representing child abuse and neglect trauma (CTQ) or current experience of trauma (TSCC) met the necessary criteria to be included into the statistical regression analysis. The EQi Total Scale Score was however included and analyzed to determine its predictive ability of the variance of inappropriate expectations. For the EQi total scale score the $R^{2}$, was small, as was the Beta, and the regression was not significant. The null hypothesis is not rejected.

Hypothesis $2 d$ : Role reversal. The regression for hypothesis $2 \mathrm{~d}$ tested the experience of trauma variables (CTQ), the current experience of trauma 
symptomology (TSCC) variables, and the EQi-YV total scale score to determine the extent to which these variables would add to the prediction of variance on the role reversal scale of the AAPI-2. Similar to hypotheses $2 \mathrm{a}$ and $2 \mathrm{c}$, the relational direction of role reversal was still in conflict with the hypothesis and with the predictor variables emotional abuse and EQi total scale. Therefore the null hypothesis cannot be rejected.

However, since the direction of physical abuse and role reversal were related in the predicted direction $(\beta=-.312)$ and the significance after physical abuse was reentered into the equation was strong $(p<.01)$ an additional simple regression was performed to determine if this variable would predict any variance for role reversal. In this additional regression however, physical abuse showed no significance.

\section{Research Question Three}

Does the age and social economic status (SES) of teenage mothers, predict less positive parenting attitudes and behaviors?

\section{Hypotheses 3.1(a-d) and 3.2}

In the hypotheses that flow from this question it was predicted that there would be a relationship between the predictor variables of SES and Age, and scores (high or low) on the criterion variable measures of (3.1a-d) parenting attitudes and behavior (as measured by the four individual scales of the AAPI-2). Furthermore, it was expected that there would also be a relationship between the same predictor variables and the EQI-YV total scale score (3.2). 
To determine how SES would be measured for this study, first, the education levels of the parents of the participants (mothers $n=74$, fathers $n=59$ ) were correlated for comparative purposes $(r=.58, p<.01, n=59)$. Once it was determined that there was a strong and significant correlation between the parents' education levels, the mother's education level was selected as the SES indicator since more complete data were available. Mothers' education level was then recoded from the original eight categories into four new categories for simplification purposes: 1 = grade school or less, $2=$ some high school, $3=$ high school graduate, and $4=$ some college or vocational school. With this study's sample only 74 participants provided information regarding their mother's education, therefore the $N$ for both Hypotheses 3.1a-d and 3.2 is 74 (unless otherwise noted).

It is important to note however that interpretation of the data analyses on SES must be viewed with caution since the adolescent mothers were being asked to provide information on their parents' education. Due to responses matching the response option of "don't know," on the participants' mothers' education variable, the data pool was decreased by $7.5 \%(n=6)$. With the 74 participants who did respond to this question by providing a response other than "don't know," these data too must be viewed and interpreted with caution since responses may indicate the respondents" "best guess" as opposed to a valid representation of parents' education. A good example of this is the fact that 21 participants did not know the level of their father's education. 
education. A good example of this is the fact that 21 participants did not know the level of their father's education.

As can be seen in Table 4.8, the analyses for hypothesis $3.1 \mathrm{a}-\mathrm{d}$ and 3.2 also included examining correlation coefficients for all the independent and dependent variables.

Table 4.8

Hypotheses 3.1 $a-b \&$ 3.2: Means, Standard Deviations, and Interscale Correlations Among Study Variables - Parental Beliefs and Behaviors (AAPI-2), Age and SES

\begin{tabular}{|c|c|c|c|c|c|c|c|}
\hline & 1 & 2 & 3 & 4 & 5 & 6 & 7 \\
\hline \multicolumn{8}{|l|}{ AAPI Scales } \\
\hline $\begin{array}{l}\text { 1. Inappropriate } \\
\text { Expectations }\end{array}$ & --- & & & & & & \\
\hline 2. Empathy & $.57^{* *}$ & --- & & & & & \\
\hline 3. Corporal Punishment & $.40^{* *}$ & $.55^{* *}$ & --- & & & & \\
\hline 4. Role Reversal & $.50^{* *}$ & $.73 * *$ & $.41^{* *}$ & -- & & & \\
\hline $\begin{array}{l}\text { 5. EQi Total Scale } \\
\text { Score }\end{array}$ & --- & -- & -- & $\cdots$ & -- & -.083 & -.179 \\
\hline 6. Age & -.073 & -.159 & .019 & .003 & -.083 & -.. & -.151 \\
\hline 7. SES & .035 & .36 & .176 & $.33^{* *}$ & -.179 & -.15 & --- \\
\hline Variable Means & 23.75 & 39.73 & 44.51 & 24.44 & 57.1 & 16.68 & 2.55 \\
\hline Variable $S D$ & 4.75 & 6.20 & 6.09 & 4.69 & 5.8 & .62 & 1.12 \\
\hline
\end{tabular}

Hypothesis 3.1a: Empathy. Hypothesis 3.1a examined the effect of participant SES and age on respondents' level of empathy for their child(ren). These two variables served as the predictor variables in the regression model. Empathy was the dependent variable. One case was removed from this regression due to an extremely low outlying score on the dependent variable. This was not 
The independent variables were added into the equation and both met the criteria for regression analysis. Table 4.9 presents the results for this regression. SES was a main effect variable accounting for $16.7 \%$ of the variance $\left(R^{2}=.167\right)$. Participant age showed no significance. The Beta for SES was .386 , and $F(2,71)=$ 7.02 was significant $(p=.002)$.

Table 4.9

Hypothesis 3.1a: Summary of Multiple Regression Analysis Predicting the AAPI-2 Empathy Scale Score on the Basis of SES and Age

\begin{tabular}{lrrrr}
\hline Predictor Variables & $B$ & $S E B$ & $\beta$ & \\
\hline Age & -1.33 & 1.06 & -.147 & \\
SES & 1.91 & .55 & $.39^{*}$ & \\
$F(2,71)$ & & & & $7.02^{*}$ \\
$R^{2}$ & & & & .167 \\
\hline Note. ${ }^{*} p<.05 ; N=73$; DV - Empathy. & & &
\end{tabular}

Since participant age added nothing to the prediction of empathy, and was not significant, the significance in this analysis is due to SES. Therefore, the positive results of this regression are significant and hence, the null hypothesis is rejected.

Hypothesis 3.1b: Inappropriate expectations. Hypothesis $3.1 \mathrm{~b}$ investigated the effect of SES and participant age regarding whether respondents' expectations for their child(ren) were developmentally appropriate. The results of this regression revealed very small Betas, $F$ values, and $R^{2}$, and were not significant. The null hypothesis for $3.1 \mathrm{~b}$ is not rejected.

Hypothesis 3.1c: Corporal punishment. Hypothesis 3.1c differed from 3.1b only in the identification of the dependent variable. In this regression, SES and 
participant age were once again the independent variables and corporal punishment was the criterion variable. This regression examined respondents' attitudes toward the use of corporal punishment with their children, and whether or not there was a significant predictive relationship between the criterion variable and participants' age or SES.

Once again both of the predictor variables were added into the equation at the same time. Betas, $F$ values, and $R^{2} \mathrm{~s}$ were all inadequate, and neither predictor variable resulted in any statistical significance. The null hypothesis is not rejected for hypothesis 3.1c.

Hypothesis 3.1d: Role reversal. Participants' age and SES were used as the independent variables for hypothesis $3.1 \mathrm{~d}$, but the dependent variable for this regression was role reversal. Role reversal refers to participants' abilities to maintain appropriate parent-child roles and boundaries. As in the previous three regressions, the independent variables were entered simultaneously in a nonstepwise fashion.

As can be seen in Table 4.10, in the results of this analysis SES predicted $11.4 \%(p<.01)$ of the variance of role reversal. Although participant age was included in the final analysis, its beta was quite small, and was non-significant. However, due to the positive direction of the predictive results of SES and role reversal, the null hypothesis for $3.1 \mathrm{~d}$ is rejected. 
Table 4.10

Hypothesis 3.1d: Summary of Multiple Regression Analysis for Predicting the AAPI-2 Role Reversal Scale Score on the Basis of SES and Age

\begin{tabular}{lrrll}
\hline Predictor Variables & $B$ & $S E B$ & $\beta$ & \\
\hline Participant Age & .41 & .84 & .056 & \\
SES & 1.41 & .47 & $.342^{*}$ & \\
$F(2,71)$ & & & & $4.59^{* *}$ \\
$R^{2}$ & & & .114 \\
\hline Note. ${ }^{* *} p<.01 ; N=74 ;$ DV - Role Reversal. & & & \\
\end{tabular}

Hypothesis 3.2. In the regression for this hypothesis both independent variables (participants' age and SES) were entered into the equation simultaneously in a non-stepwise fashion to determine if these variables would explain a proportion of the variance in the EQi Total Scale Score. However, the correlation coefficients among all the variables prior to the regression were small, nonsignificant, and contradictory to the hypothesized direction. Similarly, in the regression analysis, the $R^{2}$ was small, as were the betas and $F$ values, and the direction of the standardized coefficient did not match the predication. Accordingly, this regression was not significant. For hypothesis 3.2 therefore, the null hypothesis is not rejected.

\section{Research Question Four}

What types of services are more frequently offered and utilized by adolescent mothers and furthermore, which services do adolescent mothers find most useful, least useful, and most needed? 
Data from the Services Questionnaire were explored and descriptively analyzed to determine the frequencies, distributions, and central tendencies of participants' responses to various services categories.

Service Availability and Accessibility

Overall, teenage mothers receive, or are offered many practical and necessary services to prepare them for adulthood, independence, and increasing responsibilities. This study explored the services adolescent mothers most often receive, and perhaps more importantly, the services they do not receive.

The following tables focus on the mothers who did not receive the individual services, why the services were not received, and in cases where the services were not offered or made available, whether or not participants would have used the service had it been made available. In some cases data had to be removed from the calculations because of response inconsistencies. Also, each service question had follow-up questions for respondents who didn't receive a particular service. These questions asked participants, "If you didn't receive this service, why not?" Participants were asked to choose one or more of the following responses if applicable: “wasn't offered/available" or “didn't want/need." A final follow-up question asked was, "Had this service been offered/available, would you have used it?"

Table 4.11 presents services related to finances, medical care, and other tangible goods. Medical care for pregnant teenage girls is generally made readily 
available, and this is confirmed in this study; only $2.5 \%$ of respondents reported that they did not receive prenatal care. However, 15 participants $(18.7 \%)$ indicated they did not receive postnatal care, and $12.5 \%$ of these reported that they did not want or need these services. However, it is apparent that the Women, Infants, and Children (WIC) program obviously does a good job of connecting with young mothers; $97.4 \%$ of the sample reported to having received WIC. It is also quite apparent that welfare reform has had its impact on whether or not teenage mothers receive cash assistance; $61.3 \%$ of respondents did not receive TANF, and $67.5 \%$ of these young mothers did not receive food stamps.

Table 4.11

Research Questions 4: Services Related to Finances, Medical Care, or Other Tangible Goods

\begin{tabular}{lcccc}
\hline Service & $\begin{array}{l}\text { Did Not } \\
\text { Receive } \%\end{array}$ & $\begin{array}{l}\text { Was Not } \\
\text { Offered \% }\end{array}$ & $\begin{array}{l}\text { Did Not } \\
\text { Want/Need \% }\end{array}$ & $\begin{array}{c}\text { Would Have } \\
\text { Used \% }\end{array}$ \\
\hline Prenatal Care & 2.5 & 1.3 & 1.3 & - \\
Postnatal Care & 18.7 & 6.3 & 12.5 & 6.3 \\
WIC & 2.6 & 1.3 & 1.3 & $\ldots$ \\
TANF & 61.3 & 57.5 & 3.8 & 48.8 \\
Food Stamps & 67.5 & 60.0 & 15.0 & 58.8 \\
\hline
\end{tabular}

Table 4.12 provides percentages for services directly related to parenting home visitation services, parent training, and childcare for example. Medical clinics, hospitals, and teenage parenting programs generally either provide mother/baby home visitation services, or refer teenage mothers to programs that do. Additionally, most of the programs that the sample participants were recruited from 
offer free on-site childcare for teenage mothers so they can continue attending school to progress toward receiving a GED or High School diploma.

Unfortunately, due to cuts in funding for these types of programs, they sometimes do not have enough childcare staff to provide these services to all mothers in the program; open slots are sometimes filled based on who is the first to register in the program as opposed to family need.

Table 4.12

Research Question 4: Services Related Directly to Parenting, Parent Training, and Childcare

\begin{tabular}{lcccc}
\hline Service & $\begin{array}{l}\text { Did Not } \\
\text { Receive \% }\end{array}$ & $\begin{array}{l}\text { Was Not } \\
\text { Offered \% }\end{array}$ & $\begin{array}{l}\text { Did Not } \\
\text { Want/Need \% }\end{array}$ & $\begin{array}{l}\text { Would Have } \\
\text { Used \% }\end{array}$ \\
\hline $\begin{array}{l}\text { Home Visitation } \\
\begin{array}{l}\text { Parent training } \\
\text { education/classes }\end{array}\end{array}$ & 46.3 & 30.0 & 25.0 & 31.3 \\
$\begin{array}{l}\text { Program or school } \\
\text { based childcare }\end{array}$ & 28.8 & 22.0 & 16.3 & 12.5 \\
\hline
\end{tabular}

In addition to the help teenage mothers received for childcare from school or community programs, this sample reported that family or friends provided childcare for them as well. According to the sample responses, participants' parents and the parents of the baby's father most frequently provided childcare, the group that came in second in providing childcare was friends, participants' siblings followed closely behind friends, and participants' extended family, the father of the 
child, and participants' grandparents also provided childcare, but in lesser degrees. Finally, $71.3 \%$ of these young mothers reported "never" using a paid babysitter.

Schools or programs serving teenage mothers almost always provide some type of parent training classes and/or groups. These types of classes are generally a required part of the curriculum. It is interesting to note that although programs providing services to the study participants do provide some type of parenting classes or training (in varying degrees of intensity), $29 \%$ of the sample reported not receiving parent training, and $22 \%$ reported not being offered parenting classes or training.

Table 4.13 provides information on future and career oriented services provided to adolescent parents through both school and community based programs. Programs that provide instruction focused on helping young mothers earn a GED or High School diploma are readily available. As you can see in Table 4.13, most young mothers indicated they were working on their High School Diploma (91.2\%) and therefore did not need help obtaining a GED, and only $8.7 \%$ reported working on their GED as opposed to a high school diploma. Services providing job skills and/or job training or independent living preparation however, are less available, less accessible, and often have waiting lists. 
Table 4.13

Research Question 4: Services Related to Schooling, Job Skills/Training, Vocational Training, and Independent Living Skills

\begin{tabular}{lcccc}
\hline Service & $\begin{array}{c}\text { Did Not } \\
\text { Receive \% }\end{array}$ & $\begin{array}{l}\text { Was Not } \\
\text { Offered \% }\end{array}$ & $\begin{array}{l}\text { Did Not } \\
\text { Want/Need \% }\end{array}$ & $\begin{array}{l}\text { Would Have } \\
\text { Used \% }\end{array}$ \\
\hline Help with GED & 91.2 & -- & 91.2 & n/a \\
$\begin{array}{l}\text { Help with High School } \\
\text { diploma }\end{array}$ & 8.7 & $\ldots--$ & 8.7 & $\mathrm{n} / \mathrm{a}$ \\
$\begin{array}{l}\text { Independent living } \\
\text { skills classes/training }\end{array}$ & 73.8 & 66.3 & 24.1 & 52.5 \\
$\begin{array}{l}\text { Job skills } \\
\text { classes/training }\end{array}$ & 71.3 & 66.3 & 13.8 & 63.8 \\
$\begin{array}{l}\text { School mother/baby } \\
\text { transportation }\end{array}$ & 30.0 & 21.3 & 16.3 & 13.7 \\
\hline
\end{tabular}

Table 4.14 presents participants' responses regarding family planning (options) and adoption information or counseling. Although more large schools now have accessible and confidential health clinics on campus to provide these types of services, smaller schools (e.g., in rural areas) do not. In these cases students are frequently referred to family planning clinics. While family planning clinics are thought to offer information and/or counseling regarding adoption as well as contraception, birth control, and abortion, as can be seen below, this happens far less frequently and/or perhaps far less effectively. Due to this, a separate question was specifically included in the services questionnaire asking about adoption information and/or counseling. 
Given social concerns regarding teen pregnancy, parenting, and repeat pregnancies, options and/or adoption services data can be very important in guiding services delivery and individual service level intensity.

Table 4.14

Research Question 4: Services Related to Family Planning

\begin{tabular}{lcccc}
\hline Service & $\begin{array}{l}\text { Did Not } \\
\text { Receive \% }\end{array}$ & $\begin{array}{l}\text { Was Not } \\
\text { Offered \% }\end{array}$ & $\begin{array}{l}\text { Did Not } \\
\text { Want/Need \% }\end{array}$ & $\begin{array}{l}\text { Would Have } \\
\text { Used \% }\end{array}$ \\
\hline $\begin{array}{l}\text { Options Information or } \\
\text { Counseling }\end{array}$ & 50.0 & 41.3 & 25.0 & 27.5 \\
$\begin{array}{l}\text { Adoption Information } \\
\text { or Counseling }\end{array}$ & 75.0 & 55.0 & 83.0 & 12.5 \\
\hline
\end{tabular}

Table 4.15 reports participants' response percentages regarding psychosocial and developmental services not received. One of the core purposes of this study was to explore, in multiple ways, the potentially unmet clinical and developmental needs of adolescent mothers who have been maltreated. Therefore, responses by participants regarding any services received or not received are quite instructive as to unmet or inadequately met services needs. When compared to child abuse and neglect experience and diagnoses data, the need for developmental and clinical services takes on more clarity and urgency. 
Table 4.15

Research Question 4: Services Related to Mental Health and Socioemotional Development

\begin{tabular}{lcccc}
\hline Service & $\begin{array}{l}\text { Did Not } \\
\text { Receive \% }\end{array}$ & $\begin{array}{c}\text { Was Not } \\
\text { Offered \% }\end{array}$ & $\begin{array}{c}\text { Did Not Want/ } \\
\text { Need \% }\end{array}$ & $\begin{array}{c}\text { Would Have } \\
\text { Used \% }\end{array}$ \\
\hline Peer group counseling & 46.3 & 35.0 & 33.8 & 22.5 \\
$\begin{array}{l}\text { Anger management classes/ } \\
\text { counseling }\end{array}$ & 67.5 & 55.0 & 52.5 & 25.0 \\
$\begin{array}{l}\text { Social skills education/ counseling } \\
\begin{array}{l}\text { Domestic violence education/ } \\
\text { counseling }\end{array}\end{array}$ & 72.5 & 63.8 & 35.0 & 41.3 \\
$\begin{array}{l}\text { Sexual abuse education/ } \\
\text { counseling }\end{array}$ & 58.8 & 41.3 & 52.6 & 25.0 \\
$\begin{array}{l}\text { 1:1 Individual therapy } \\
\text { Family therapy }\end{array}$ & 67.5 & 52.5 & 47.8 & 31.3 \\
\hline
\end{tabular}

\section{Mental Health Status}

Table 4.16 provides percentages regarding participants' responses to questions about previous or current mental health diagnoses (given by a medical or mental health professional) and/or use of prescription medications for mental health difficulties. Given that $50-75 \%$ of teenage mothers in general, and $76.3 \%$ in this sample, have reported being abused and/or neglected, it was very important to directly inquire about these types of services. In this study $59 \%(n=47)$ of participants reported having received some mental health diagnosis; in some cases individual participants had received multiple diagnoses (range $=1-8)$. 
Table 4.16

Research Question 4: Mental Health Diagnoses and Medication History Reported by Participants

\begin{tabular}{|c|c|c|c|c|c|}
\hline Diagnosis & $\%$ to $N$ & $N$ & Caucasian & Latina & Other \\
\hline Depression & 44.8 & 35 & $\begin{array}{c}35 \% \\
(n=19)\end{array}$ & $\begin{array}{c}51 \% \\
(n=18)\end{array}$ & $\begin{array}{c}50 \% \\
(n=8)\end{array}$ \\
\hline Anxiety & 21.3 & 17 & $\begin{array}{c}21 \% \\
(n=6)\end{array}$ & $\begin{array}{l}20 \% \\
(n=7)\end{array}$ & $\begin{array}{l}25 \% \\
(n=4)\end{array}$ \\
\hline $\mathrm{ADHD} / \mathrm{ADD} / \mathrm{LD}$ & 5.0 & 4 & $\begin{array}{c}7 \% \\
(n=2)\end{array}$ & -..- & $\begin{array}{l}13 \% \\
(n=2)\end{array}$ \\
\hline PTSD & 11.0 & 9 & $\begin{array}{l}14 \% \\
(n=4)\end{array}$ & $\begin{array}{c}9 \% \\
(n=3)\end{array}$ & $\begin{array}{c}13 \% \\
(n=2)\end{array}$ \\
\hline Eating Disorder & 5.0 & 4 & $\begin{array}{c}7 \% \\
(n=2)\end{array}$ & $\begin{array}{c}3 \% \\
(n=1)\end{array}$ & $\begin{array}{c}6 \% \\
(n=1)\end{array}$ \\
\hline Severe Emotional Disturbance & 12.5 & 10 & $\begin{array}{l}14 \% \\
(n=4)\end{array}$ & $\begin{array}{c}11 \% \\
(n=4)\end{array}$ & $\begin{array}{c}13 \% \\
(n=2)\end{array}$ \\
\hline Adjustment Disorder & 2.5 & 2 & $\begin{array}{c}3 \% \\
(n=1)\end{array}$ & $\begin{array}{c}3 \% \\
(n=1)\end{array}$ & ----- \\
\hline Oppositional Defiant Disorder & 3.8 & 3 & $\begin{array}{c}7 \% \\
(n=2)\end{array}$ & ---- & $\begin{array}{c}6 \% \\
(n=1)\end{array}$ \\
\hline Conduct Disorder & 1.3 & 1 & $\begin{array}{c}3 \% \\
(n=1)\end{array}$ & ---- & -.-- \\
\hline Bi-polar Disorder & 7.5 & 6 & $\begin{array}{c}7 \% \\
(n=2)\end{array}$ & $\begin{array}{c}6 \% \\
(n=2)\end{array}$ & $\begin{array}{c}13 \% \\
(n=2)\end{array}$ \\
\hline Attachment Disorder & 6.3 & 5 & $\begin{array}{c}7 \% \\
(n=2)\end{array}$ & $\begin{array}{c}3 \% \\
(n=1)\end{array}$ & $\begin{array}{c}13 \% \\
(n=2)\end{array}$ \\
\hline Personality Disorder & 5.0 & 4 & $\begin{array}{c}7 \% \\
(n=2)\end{array}$ & $\begin{array}{c}6 \% \\
(n=2)\end{array}$ & --.- \\
\hline $\begin{array}{l}\text { Total Diagnosis } \\
\% \text { to } n\end{array}$ & --- & 100 & $\begin{array}{c}37 \\
(n=20) \\
69 \%\end{array}$ & $\begin{array}{c}39 \\
(\mathrm{n}=18) \\
50 \%\end{array}$ & $\begin{array}{c}24 \\
(n=9) \\
56.3 \%\end{array}$ \\
\hline Medication Now & 10.0 & 8 & $\begin{array}{c}21 \% \\
(n=6)\end{array}$ & ---- & $\begin{array}{c}13 \% \\
(n=2)\end{array}$ \\
\hline Medication Ever & 30.0 & 24 & $\begin{array}{c}48 \% \\
(n=14)\end{array}$ & $\begin{array}{c}14 \% \\
(n=5)\end{array}$ & $\begin{array}{c}31 \% \\
(n=5)\end{array}$ \\
\hline
\end{tabular}

Table 4.17 reviews response information from the entire study sample regarding all services (tangible, parenting, and developmental or clinical). It includes what services were the "least received," and "least offered" overall, as well as services that participants indicated were "most wanted or needed." 
Table 4.17

Services: Percentage of Services Least Received, Least Offered, and Most Wanted and/or Needed by Study Participants, by Category Ranking

\begin{tabular}{|c|c|c|c|c|}
\hline Service & $\begin{array}{c}\text { Least } \\
\text { Rec'd } \\
(\text { Rank \%) }\end{array}$ & $\begin{array}{c}\text { Least } \\
\text { Offered } \\
(\text { Rank } \%)\end{array}$ & $\begin{array}{l}\text { Most } 1 \\
\text { or Ne } \\
\text { (Ran }\end{array}$ & $\begin{array}{l}\text { Nanted } \\
\text { eeded } \\
\text { k } / \%) \\
\end{array}$ \\
\hline Family Counseling & 1. 76.0 & 10. 46.0 & 6. & 38.0 \\
\hline $\begin{array}{l}\text { Adoption Information } \\
\text { or Counseling }\end{array}$ & 2. 75.0 & 6.5. 55.0 & 14.5 & 13.0 \\
\hline Independent Living Training & & & & \\
\hline Social Skills Training & $\begin{array}{ll}\text { 3. } & 74.0 \\
\text { 4. } & 73.0\end{array}$ & $\begin{array}{ll}1.5 & 66.0 \\
3 . & 64.0\end{array}$ & $\begin{array}{l}3 . \\
5 .\end{array}$ & $\begin{array}{l}53.0 \\
41.0\end{array}$ \\
\hline Job Skills Training & 5. 71.0 & $1.5 \quad 66.0$ & 1. & 64.0 \\
\hline $\begin{array}{l}\text { Sex Abuse Information Training } \\
\text { or Groups }\end{array}$ & 7. 68.0 & 53.0 & 7.5 & 31.0 \\
\hline Food Stamps & 7. 68.0 & 4. 60.0 & 2. & 59.0 \\
\hline $\begin{array}{l}\text { Anger Management } \\
\text { Training or Groups }\end{array}$ & 7. 68.0 & $6.5 \quad 55.0$ & 11.5 & 25.0 \\
\hline TANF & 9. 61.0 & 5. $\quad 58.0$ & 4. & 49.0 \\
\hline $\begin{array}{l}\text { Domestic Violence } \\
\text { Training or Groups }\end{array}$ & 10. 59.0 & 11.541 .0 & 11.5 & 25.0 \\
\hline 1:1 Therapy & 11. 59.0 & 9. 48.0 & 10. & 26.0 \\
\hline $\begin{array}{l}\text { Family Planning - Options } \\
\text { Information or Counseling }\end{array}$ & 12. 50.0 & $11.5 \quad 41.0$ & 9. & 28.0 \\
\hline Mom/Baby Home Visitation & 13. 46.0 & 14. 30.0 & 7.5 & 31.0 \\
\hline Peer Groups & 14. 46.0 & 13. 35.0 & 13. & 23.0 \\
\hline Parent Training Classes & 15. 29.0 & 15. 22.0 & 14.5 & 13.0 \\
\hline
\end{tabular}

Table 4.18 provides an overall findings synopsis of the hypotheses that flow from research questions 1-3. 
Table 4.18

Findings Summary: Research Questions 1-3 and Resultant Hypotheses 1-3.2

\begin{tabular}{|c|c|c|c|c|c|c|}
\hline . & IVs & DVs & $R^{2}$ & $p$ & $\begin{array}{l}\text { Main Effect } \\
\text { Variable(s) }\end{array}$ & Null Hypothesis \\
\hline $\begin{array}{l}\text { Research Question I } \\
\text { Hypothesis } 1 \\
\end{array}$ & CTQ, TSCC & EQi-YV Total Score & .25 & $<.000$ & $\begin{array}{l}\text { Emotional Neglect, } \\
\text { Depression }\end{array}$ & Reject \\
\hline Research Question II & CTQ, TSCC, EQi-YV & AAPI-2 & & & & \\
\hline Hypothesis $2 \mathrm{a}$ & & Empathy & $-\cdots$ & $-\cdots$ & $\mathrm{N} / \mathrm{A}$ & Fail to Reject \\
\hline $2 \mathrm{~b}$ & & Corporal Punishment & .057 & $<.05$ & EQi-YV Total Score & Reject \\
\hline $2 c$ & & $\begin{array}{l}\text { Inappropriate } \\
\text { Expectations }\end{array}$ & $-\cdots$ & ----- & N/A & Fail to Reject \\
\hline $2 d$ & & Role Reversal & ---- & ---- & $\mathrm{N} / \mathrm{A}$ & Fail to Reject \\
\hline $\begin{array}{l}\text { Research Question III } \\
\text { Hypothesis } 3.1 \mathrm{a}\end{array}$ & Age, SES & $\begin{array}{l}\text { AAPI-2 } \\
\text { **Empathy }\end{array}$ & .167 & $<.05$ & SES & Reject \\
\hline $3.1 \mathrm{~b}$ & & $\begin{array}{l}\text { Inappropriate } \\
\text { Expectations }\end{array}$ & $\cdots$ & $\cdots$ & N/A & Fail to Reject \\
\hline $3.1 \mathrm{c}$ & & Corporal Punishment & $-\cdots$ & $\cdots$ & N/A & Fail to Reject \\
\hline $3.1 \mathrm{~d}$ & & **Role Reversal & .114 & $<.01$ & SES & Reject \\
\hline 3.2 & & EQi-YV Total Score & --.-- & $-\cdots$ & N/A & Fail to Reject \\
\hline
\end{tabular}




\section{CHAPTER V}

\section{DISCUSSION}

Hypothesis one of this study explored aspects of study participants' lives such as trauma experienced, and current trauma symptoms (i.e., anxiety, depression, anger, posttraumatic stress, dissociation, and sexual concerns). Further, hypothesis one also necessitated investigating the combined effects of trauma experienced and trauma symptomology on the overall socioemotional development of the participants. Strong and significant relationships between two of the predictor variables and socioemotional developed were revealed.

Hypothesis two then examined whether the experience of trauma, current trauma symptomology, and the level of socioemotional development could predict a significant portion of the variance for the adolescent mothers' parenting attitudes and behaviors domain scores. Hypothesis three analyzed the contribution of participant age and socioeconomic status towards explaining parenting attitudes and behaviors and socioemotional development. Although only two statistically significant relationships were revealed, nonetheless these types of analyses have the potential to further advance the understanding of some of the factors involved in teen parenting outcomes.

Research question four looked at the services that had been or had not been received by the study's participants. The analyses included looking at past and 
prospective services utilization, and considered the voices of the teen mothers to help guide future program planning and evaluation. Although outside the realm of formal research questions and hypotheses, participant demographics were also explored to provide a more complete sense of who these young mothers were separate from their "teenage parent" status. The demographic and services details yield some of the most interesting and instructive information obtained in this research.

Hypothesis 1: Childhood Trauma, Trauma Symptomology, and Socioemotional Development

It was expected that a significant number of study participants would have experienced abuse and/or neglect at clinically significant levels. Even so, the results from the CTQ, that $76.3 \%$ of study participants had experienced child maltreatment were nonetheless startling. In addition to this, $24 \%$ of respondents were above the validation study mean on the CTQ's minimization and denial scale

Also surprising, given respondents' high trauma scores, were participants' low scores of current trauma symptomology $(10 \%$ of $N)$. Overall children, adolescents, and adults who have been abused or neglected report much higher levels of trauma symptoms than the general population (Briere, 1996; Nicholson \& Williams, 2006; Perry \& Azad, 1999; Siegel, 1999; van der Kolk, 2000a, 2000b). However, $24 \%$ of respondents scored above the cut-off level on the TSCC's underresponse scale, as compared to only $2 \%$ of the validation study sample. 
These higher underresponse scale scores on the TSCC items are likely to be one reason for participants' overall lower trauma symptomology scale scores.

Respondents also scored unexpectedly high on the EQi-YV total scale score $(M=56.45)$ when compared with the general population in the validation sample $(M=58.11)$. Higher scores on the socioemotional inventory indicate more developed socioemotional skills and abilities.

It was expected based on theory and previous research (Carter et al., 1991; Compas et al., 1998; Ford \& Kidd, 1999; Nicholson \& Williams, 2006; Perry, 1994, 2000c; Saarni, 1999; Siegel, 1999; van der Kolk, 1996a) subscales from the CTQ and TSCC would significantly predict lower scores on the EQi-YV total scale score. The results of the hierarchical regression revealed that the main effect predictor variables were emotional abuse (CTQ) and depression (TSCC). Together these variables predicted $24.6 \%$ of the EQi-YV total score variance.

Interitem and interscale correlation coefficients for the independent variables provide support for the relationship between trauma experienced, trauma symptomology, and socioemotional development. Overall correlations between and amongst these variables were quite strong with $68.5 \%$ of correlations being significant at the $p<.05$ or $p<.01$ levels. With such strong and significant interitem correlations, it is reasonable to speculate that the statistically excluded CTQ and TSCC independent variables, laid claim to largely the same portion of EQi total score variance and thus did not make unique individual contributions. 
These results shed light on prior research on child maltreatment (Perry, 2001, 2006; Perry \& Pollard, 1997) and depression (Compass et al., 1998; Nicholson \& Williams, 2006; van der Kolk, 2001). Although other types of trauma (e.g., physical abuse, sexual abuse) have been thought to affect children in harsher ways, more recent research has shown that the more inconsistent, chaotic, and unpredictable patterns of emotional abuse and emotional neglect can potentially be far more destructive to a child's neurodevelopment, both physically and psychologically (Perry, 2000c, 2001, 2006; Perry \& Pollard, 1997; Tomison \& Tucci, 1997). Early neurodevelopment creates the foundation for all further development. Emotional abuse and neglect is often referred to as "the hidden form of maltreatment" (Tomison \& Tucci, 1997, p. 2) since the signs are more neurodevelopmental in nature and may not be recognized until the damage expands and becomes well entrenched.

The depression main effect is also supported theoretically in both research and in clinical practice. Depression and emotional neglect are as related in the real world as they are in this research $(p<.01)$, and in this study $45 \%$ of the respondents reported having received a diagnosis of depression. Furthermore, the correlation coefficient between emotional neglect and depression was significant at $p<.01(r=.31)$. As supported in the statistical analysis, the greater the experience of emotional neglect $(43.8 \%$ of $N)$ the more likely the experience of depression $(45 \%$ of $N)$. 
By its nature depression causes individuals to detach and isolate themselves from productive and healthy people, thoughts, attitudes, expectancies, and behavior (Belenky et al., 1986; Brown \& Gilligan, 1992; Compas et al., 1998; Shriver et al., 1999; van der Kolk, 1996c), and therefore contributes to delays in socioemotional development. Research has shown that many mothers who were abused as children suffer from depression and its often crippling emotional effects (Briere, 1992, 1996). Depression can hinder one's ability to focus on simple and complex tasks, such as learning in an academic environment or consistently caring for a child for example.

The theoretical causal links of emotional neglect and depression are further clarified by the analysis. As emotional neglect (predictor variable) moves into depression (predictor/intervening variable), precious and limited psychic energy is depleted and rendered less accessible for healthy, fruitful, and successful emotions and activities. Healthy socioemotional development (dependent variable) relies on these types of rewarding environmental experiences and feedback. Futhermore, because emotional neglect and/or abuse generally occurs earlier in developmental processes, these types of maltreatment can have more outcome valence.

Hypotheses 2a-d: Childhood Trauma, Trauma Symptomology, Socioemotional Development, and Parental Attitudes and Behaviors

In these hypotheses it was expected that a history of trauma experience (CTQ), current trauma symptomology (TSCC), and the level of socioemotional development (EQi total score) would significantly predict the variability in the 
individual domains of parenting attitudes and behaviors (AAPI-2). Four separate regressions were performed, one for each AAPI-2 scale.

Hypotheses $2 a, c, d$

These three hypotheses - (2a) empathy (DV), (2c) inappropriate expectations (DV), and (2d) role reversal (DV), have been grouped together for discussion purposes. In each of these regressions similar analytic problems emerged. The regression results of these hypotheses did not support the theoretical predictions. It was expected that similar to hypothesis one, main effect trauma experience variables and trauma symptom variables would operate together as joint predictors, or in predictor and intervening variable positions. This did not occur.

There were a number of potential variable problems in each of these equations. The dependent variable instrument (the AAPI-2) did not perform as expected in any of these regressions. The results of interitem and interscale correlations revealed low and generally nonsignificant relationships between the parenting variables and the predictor variables. Furthermore, these relationships contradicted the hypothesized theoretical directions. The final betas on each of the main effect variables (emotional abuse, physical neglect, and the EQi total score) were opposite in regards to expected directionality. For example, it would be expected that as socioemotional competencies increase, scores in parenting would improve as well. This is especially so considering that the EQi measures constructs that theoretically should be similar. For example, the EQi measures intrapersonal, interpersonal, adaptability, stress management, and positive mood. The AAPI-2 
measures lack of empathy, inappropriate expectations, corporal punishment, and role reversal.

It is important to note that the AAPI-2 has been one of the most widely used instruments in the field of parenting and parent training. However, as reported by the scales' authors (Bavolek \& Keene, 2001), in validation studies of the AAPI-2, it was tested primarily against the original inventory, the AAPI-1, as opposed to other instruments of parent attitudes and/or behaviors. It may have strengthened the scale to test the constructs using other similar conceptual instruments, the Child Abuse Potential Inventory (CAPI) for example.

Additionally the validation study sample for teen parents was quite small ( $N=87$ adolescent mothers). Depending on where this sample was recruited from, these mothers may or may not be representative of teenage mothers in general or more specifically, maltreated adolescent mothers.

Validation of the instrument could have also been improved by using interrater comparative observational methods to determine if scores obtained on the AAPI-2 were reflective of just information gained (i.e., cognitive abilities of information retention), or if the scores obtained were mirrored in parent-child interactions in the natural environment, including during times of stress.

Jackie Waggoner (personal communication, January 2006), Ed.D., has been a parent trainer for adolescent mothers for 25 years. According to Dr. Waggoner, the residential program she operated had stopped using the AAPI-2 for pre- and post- evaluative or program planning activities. Dr. Waggoner and program staff 
found that the young mothers were able to easily provide socially desirable answers when responding to the AAPI-2 questions, but in times of stress were not able to constructively utilize this information with their children. It is also important to note here that of this program's young mothers, $97 \%$ of them had been moderately to severely abused and/or maltreated. There is a distinct difference between retrieving information in a cognitively oriented classroom or group environment, and being able to make use of the information in emotionally charged and stressful situations.

Furthermore, the sample items on the AAPI-2 are framed within a cognitive viewpoint. That is the questions ask respondents to recall information they have been provided, as opposed to recalling situations they have found themselves in with their children. There is very little emotional representation in the language of the items to tap into emotional processes or memory retrieval. It could perhaps be more helpful to incorporate situational "what would you do," "what would you feel," "what would you think," type questions to aid in simultaneously activating bilateral emotional and cognitive brain systems.

It could also be that there is too much "noise" among the variables. For each of the hypotheses that flow from research question two (2a, 2b, 2c, and 2d), the hierarchical regression equation had a total of 13 variables. Twelve of these variables are predictor variables and one is the dependent parenting variable. Although the $k / n$ ratio is acceptable (12/80), for hierarchical stepwise regression 
Cohen and Cohen (1983, p. 125) recommend a much more conservative ratio for stepwise hierarchical regressions (i.e., 1/40).

Finally, the size of the current study sample $(N=80)$ lessens the power of the test statistic. A larger sample may increase the amount of variance accounted for, while at the same time increasing the likelihood that the sample represents the population from which it was drawn.

Hypothesis 2b: Corporal Punishment

In this regression analysis and the null hypothesis was rejected. This equation was a duplicate of hypothesis $2 a, c$, and $d$, with the exception of the dependent variable. However, this equation did not statistically encounter the same problems.

EQi total score was the main effect variable and all other predictor variables (CTQ, TSCC) were removed from the regression. Although the correlation coefficients between the EQi total score and corporal punishment were quite low, only the corporal punishment and EQi total score correlation was in the predicted direction.

Theoretically, it would be expected that as a person's socioemotional skills (i.e., intrapersonal, interpersonal, adaptability, stress management, and general mood) developmentally progressed, one's awareness of alternative options to corporal punishment would also increase and become the preferred choice of discipline (Goleman, 1995; Perry, 2000c; Saarni, 1999; Siegel, 1999). 
Hypotheses 3.1a-d: Age, SES, and Parenting Attitudes

and Behaviors

These hypotheses examine age and SES variables within the current study sample to determine if the results are similar to previous field studies with teenage parents. Teenage parenting and negative teen parenting outcomes are often cited in research as being very related to age and SES (AGI, 1998, 1999a; Maynard, 1996). Hypothesis 3.1a: Empathy

SES as an independent variable was significant $(p<.05)$ in this equation and supports the theoretical predication that as participant SES increases so does the participant's ability to feel and show empathy to her child(ren). People living with low or poverty level incomes have more difficulties finding or acquiring resources. Generally speaking, low SES is also related to lower educational attainment, and therefore fewer job opportunities overall, and more specifically less access to higher wage positions (AGI, 1998; 1999b; East \& Felice, 1996; Maynard, 1996). The availability of more resources can relate to fewer financial and family stressors, thus leaving more time and energy to reflect upon and be concerned with the feelings of others including one's children.

The fact that participant age, although entered into the regression, was nonsignificant is not unexpected. The age range and age sub-sample $n$ 's, are very restricted in this study. For this particular study therefore age lacked strength and variability. 
Hypothesis 3.1b: Inappropriate Expectations and 3.1 c-Corporal Punishment

Neither of these null hypotheses was rejected as a result of the statistical analyses. Participant age did not meet the variable criteria for regression analyses and therefore ultimately, was not included in the equation. The predictor variable of SES was included in both analyses, but was also nonsignificant in both cases as well. Although correlation and beta coefficients were in the predicted direction, they were quote low.

Theoretically the argument could easily be made that the dependent variables (parenting constructs), could be negatively affected by increased economic, personal, or environmental stressors. The lack of availability or financial accessibility to economic and support resources could easily inhibit one's ability to interpersonally relate in a positive manner to others, in spite of the intimacy of a relationship. Even so, the problem with these particular hypotheses is likely one of very restricted variable ranges and weak indicators of the constructs being tested. The null hypotheses cannot be rejected.

\section{Hypothesis 3.1d: Role Reversal}

In this regression SES as an independent variable was significant $(p<.05)$ and accounted for $11.4 \%$ the variability in the dependent variable, role reversal. The analysis also supports the theoretical predication that as participant SES (available resources) increases, so does the participant's ability to recognize and differentiate between parent and child roles, and thus establish the acceptable parent-child boundaries. In the field of parenting and parent training, low SES is 
considered another risk factor for negative parenting and child outcomes. This is especially true for teenage mothers. Individuals (adult or adolescent) with low or poverty level incomes have more problems trying to locate and obtain important and helpful resources. Less educational attainment is also associated with the inability to find and obtain family wage jobs. For parents with low or poverty level incomes, difficulty obtaining and/or maintaining any job is exacerbated due to the lack of the financial resources necessary to participate in the workplace. When a parent works, especially a single parent, childcare expenses need to borne, as well as fuel or public transportation expenses, and additional expenses for attire appropriate to workplace environments (AGI, 1998; 1999b; East \& Felice, 1996; Maynard, 1996). When parents are under these types of constant stress, they are less likely to focus on positive parenting practices and boundaries. They would also be more likely in stressful times to expect their children to fulfill unrealistic and inappropriate roles - friend, confidante, or partner for example.

Interitem correlation and beta coefficients were low and nonsignificant for both participant age and SES. The fact that participant age, although entered into the regression, was non-significant is not unexpected. The age range and age subsample $n$ 's, were very restricted in this study. Also, in general parental education is not recommended as a sole measure of SES. For this particular study therefore, neither of the independent variables were strong indicators. 


\section{Hypothesis 3.2: Age, SES, and Socioemotional}

\section{Development}

This hypothesis explored relationships between the predictor variables participant age, SES, and the dependent variable which was the total scale score on the socioemotional development instrument (EQi-YV). Neither of these predictor variables were able to significantly predict socioemotional development. As previously mentioned, in this study both age and SES were not strong indicators. Research Question 4: Services Information

Overall, adolescent mothers are receiving or have available to them many services. The categories of services that are most commonly and readily available through educational, medical, or community service programs include pre- and postnatal care, education and extra services for academic needs (i.e., GED, high school diploma), school-based childcare, school-based transportation for education services, and nutritional foodstuffs and parent education information through the Women, Infants, and Children Program (WIC), and teen parenting programs in schools or in the community.

In analyzing the services data, it becomes obvious that study participants have integrated society's expectations. For example although only $29 \%$ of participants had received any type of job training or job skills training, $64 \%$ of respondents ranked this as the most wanted or needed service. Similarly, respondents ranked independent living skills/training as third in importance. Unfortunately, this service had only been made available to $26 \%$ of participants. 
In terms of the availability of tangible financial help (i.e., TANF, food stamps), welfare reform has vastly decreased the availability of this type of help. In order for teenage mothers who are less than 18 years old to receive TANF for example, they must be living separate from their parent(s) or other adults who have legal responsibility for them. Considering the fact that $44 \%$ of the households that study participants lived in fell below the federal poverty level, it is not surprising that $49 \%$ of respondents ranked need for financial aid as fourth out of 15 services. And, food stamps were ranked second in terms of need by $59 \%$ of participants. Similar to Maslowe's Hierarchy of needs (Given, 2002; Jensen, 1998), what seems to be uppermost on participants' minds are those services that will support their basic survival efforts - jobs, food, the ability to live independently as an adult, and financial help to assist them in the interim.

Following these basic needs, it was impressive that many respondents were aware of their developmental and clinical needs and thus, reported wanting/needing social skills training $(41 \%$,$) , family therapy (38\%), sex abuse information, groups,$ or counseling (31\%), and individual therapy (26\%). Domestic violence information/groups and anger management training were also wanted by $25 \%$ of participants. It is interesting to note that many of the study mothers are aware of their clinical and developmental needs, in spite of the fact that these needs are not reflected in teen parent service offerings. For example, only $27 \%$ of respondents had received social skills training, only $24 \%$ had received family counseling, and only $32 \%$ had received information or groups on sexual abuse. Surprisingly, $41 \%$ 
of respondents had received some type of one to one counseling or therapy and domestic violence information or groups. Overall, when considering the fact that $76.3 \%$ of participants reported having been abused, and with $52 \%$ having reported sexual abuse, it is not surprising that $25-38 \%$ of participants are asking for therapeutic help.

Although only $13 \%$ of the sample wanted/needed additional "parent training," $31 \%$ of these young mothers did report that receiving Mom/baby home visitation would be helpful to them. Given the high risk factors involved in teenage parenting, increasing the availability, accessibility, and awareness regarding home visiting programs could substantially help young mothers to learn, observe, practice, and achieve important and appropriate child care abilities.

It is very interesting and quite alarming, considering society's concerns regarding teenage pregnancy, parenting, and repeat pregnancies, that $41 \%$ of respondents reported not being offered options information/counseling, and 55\% of the sample reported not being offered adoption information/counseling. It is quite likely that this problem arises from "how" the services are offered or provided, and the "intensity" of service provision.

If asked if they have any interest in adoption information or counseling, many young mothers will dismiss the offer immediately, and very rapidly discontinue the conversation. Similarly, many young mothers believe they know everything they need to know regarding birth control or other family planning options. These types of services must be provided by a trusted adult in a safe 
environment, and with a nonjudgmental attitude. Additionally, this type of information needs to be made readily available and be repeated or discussed multiple times. Options peer groups are very successful at providing this type of information at the necessary levels of exposure and intensity.

Academic assistance, pre and postnatal medical care, and parent training are all readily available. However, if medical providers, community programs, and school based programs were to collaborate on service provision, many of the needed developmental and clinical services not currently readily available could, in a cost effective manner, be integrated into current program offerings. Some of the services could be concurrently provided, and others would be most effective if sequentially provided based on individual level of socioemotional development, age, and service environment.

For example, important basic needs which are inexpensive, relatively short term, easily organized, and which can be delivered in a group environment (i.e., classroom), could be provided first and potentially concurrently with other services (e.g., options and adoptions counseling; sex abuse and domestic violence classes; peer counseling/anger management/social skills training, etc.). Furthermore, as these types of services are provided, they serve to fulfill some of the other more intense needs. For example, when bringing young mothers together in a safe group environment (i.e., peer counseling group), some of the time allotted can also be used to teach, talk, share and process difficult subjects such as sexual abuse, domestic violence, anger management, social skills. This can be inexpensively and 
easily accomplished in a school or community service environment and, most important, it is also very therapeutic. Counseling and peer groups for teenagers are a very effective way of providing helpful, necessary, and therapeutic information, within a setting where participation, sharing, and processing are not just allowed, but encouraged (Cohen, 1999a, 1999b; Given, 2002; Marans \& Cohen, 1999; Perry, 2006; van der Kolk, 1987b).

Furthermore, for young mothers in need of low-level developmental and therapeutic services, the provision of these types of services can lessen the need for more intensive services, services which are usually more expensive or inconvenient. And, for mothers in need of more intensive services, group services provision in schools or community environments serve as preparation for participation in more intensive therapeutic work.

\section{Contribution to the Field}

There were two primary audiences for this research - program directors and/or planners, and community, city, and statewide funding and policy bodies. For both of these audiences the information provided can be very useful. This research should help workers, administrators, and policy and funding representatives to consider the services that are not currently readily or affordably available for teenage mothers. Provision of services for teenage mothers is rarely considered within a developmental and mental health perspective, and seldom do assessments consider so many areas of need. 
The study approached the subject of teenage mothers, and especially teenage mothers abused or neglected as children, using an integrated biopsychosocial and neurodevelopmental theory base. The results of this study do not challenge any of the educational and community services currently provided for teenage mothers. Although this study was not able to show consistent and significant relationships between the negative effects of child maltreatment on teenage parenting, this study was able to show the ability of child maltreatment and trauma symptoms to predict socioemotional score variance. Accordingly, the results of this study do question the adequacy of currently available services to meet the neurodevelopmental needs for young mothers with a history of abuse and/or neglect.

The data gathered and analyzed for this study strongly suggest that a large percentage of teenage mothers may have been abused as children. Children and adolescents who have been abused frequently require developmental and therapeutic services to help resolve psychosocial and developmental damage caused by child maltreatment. By beginning the process of identifying and assessing all the needs of pregnant and parenting adolescents when they first enter service environments, a window of opportunity is opened to begin meeting the necessary basic, developmental, and therapeutic requirements of these young mothers.

This research involved a very detailed needs assessment. The assessment considered in varying degrees, all levels of the environment in which the problem 
is embedded, for example school, community, and personal environmental capabilities. Because of this, the research study itself can be used as a template for service providers in the field to plan and implement the assessment processes, and to begin considering what services are presently provided, and whether or not these services are appropriately developmentally sequenced to fit the mothers' current levels of socioemotional capabilities, functioning, and needs.

Expanding student/client assessments to include neurodevelopmental, trauma, and parenting risk variables will greatly inform workers in the field of the full scope of service needs of each individual mother. Every service provided to a young mother, especially important developmental and therapeutic services, will help her to become a more sensitive, caring, and nurturing parent. As such, she will be able to more capably meet her child's needs. Furthermore, these types of developmentally focused and timed services will also help young mothers to appropriately and beneficially interact within school, community, and workplace environments.

Implications for Policy and Practice

This research provides a new and expanded way of assessing the service needs of teenage mothers. To take advantage of improved and expanded assessments would not necessitate overhauling present services and/or programs. Small, incremental changes can in fact be very beneficial. Educational and community service providers for teenage mothers can and should collaborate to provide the missing services in the most appropriate service settings. 
The childhood trauma and services data gathered in this study indicate a very real need for providing enhanced developmentally and clinically based services for teenage mothers who were abused and/or neglected in childhood. According to this study's participants:

1. $76 \%$ were abused and or neglected,

2. $32 \%$ at moderate to severe levels,

3. $56 \%$ have received diagnoses of depression,

4. $21 \%$ are suffering from significant anxiety; and

5. $30 \%$ scored below average on one or more of the socioemotional development scales.

Based on recent studies regarding the neuropsychological and developmental effects of child maltreatment, these figures suggest that many of these mothers may not yet have achieved the cognitive and emotional abilities to be able to adequately assimilate academic or job-based learning. Accordingly, if we are providing services that many young mothers are not able to fully benefit from, we need to consider if the addition of developmentally sequenced and therapeutic services could help them benefit from the services they are currently receiving. In so doing, it is possible that the intended service outcomes for teenage mothers and their children could more successfully be achieved.

\section{Limitations of the Study}

There are a number of limitations to the use of the results and conclusions of this research. Teenage parenting, child abuse, and child neglect are all complex 
subjects in their own right, and cannot be easily simplified. Additionally, this research focused on a very specific population within a very limited age range (1417 years-old), who are currently parenting their child(ren). The sample recruited for this research was also located within fairly restricted geographical boundaries. Therefore, the very circumscribed nature of the sample will limit the ability to, without additional research, generalize the results and conclusions to different population groups. Additionally, although the sample size $(N=80)$ is adequate for the statistical applications, the power of the statistical tests can be compromised when using smaller subgroups with limited variability. Larger research samples would lessen these problems.

In addition to the very selective characteristics of the participants, the sample was further restricted by the types of institutions or agencies from which it was drawn - public schools, alternative schools, community service programs, group and residential settings. Young mothers who are not currently participating in educational and community programs for teenage mothers are missing from this study. Mothers from higher income brackets are missing from the sample population as well. Furthermore, there were only five participants under the age of 16 in the study and therefore the experiences and perspectives of younger mothers are very limited. Some of the statistical analyses were compromised by this restricted age range and therefore must be used with great caution (i.e., analyses using age and SES as variables). Also, because of the small number of participants, this research could not respectfully attempt to consider cultural perspectives or 
differences. Due to the low recruitment rates of ethnic groups other than Caucasians and Latinos, teenage mothers from other ethnicities are not well represented. Descriptive comparisons are provided, but these should not be used to draw potentially spurious conclusions about ethnic factors in teenage parenting. While all of the standardized instruments used were normed with a diverse population, how different cultures define child maltreatment, or define or value various parenting constructs were not specifically tested in measurement validation studies.

Within the parameters of the research design, data collection methods may have compromised the validity of research results. Because of the need for participant anonymity, all data relied on respondent self-report without verification from collateral sources (such as teachers, families, doctors, or counselors). Furthermore, whenever possible standardized instruments that include scales to measure under and/or over-response, positive impression, and social desirability response patterns should be used; the AAPI-2 used for this study did not have these types of response scales.

Additionally, research on child abuse and neglect must by its nature ask deeply personal questions regarding very private and difficult subjects. Researchers must be very respectful of participants' privacy, while at the same time being very careful about how data are measured, interpreted, and utilized. 


\section{Suggestions for Future Research}

To my knowledge, this was the first study of its type. Therefore many more research projects, large and small, will need to be planned and executed to gain a more comprehensive awareness of the scope of the issue. It is possible that through increased student/client assessments done at the service level, corporate information could be gathered and analyzed in a professional and organized manner. It would also of course be advantageous if large research groups, or groups with the resources to fund large research studies, became involved in the new ideas that this study suggests. The field could also benefit if field experts (the people whose jobs are based on helping young mothers), and research experts shared their different forms of wisdom when designing future research projects, as well as in assessment, service provision, and evaluation planning efforts. As a matter of course, this type of planning would greatly benefit from the wisdom of the young mothers as well. For example, when data were being collected for this study, the participants were thrilled that someone was asking them to share not only what they had been through, but more importantly what they had learned thus far from the experience.

Additionally, the field of parenting in general needs to come more out of isolation and begin to report what they see beyond young mothers' "teenage parent" status. In so doing teenage parenting experts from all areas of the field can increasingly join with and learn from other experts in closely related fields - child 
maltreatment, learning and motivation, neurodevelopment and neuropsychology, for example.

Furthermore, for the subjects that this research explored, norms will need to be established for valid population comparisons. Similarly, instrument validation studies for new instruments and inventories should begin including young mothers in their sample populations, as should researchers examining child abuse, learning and motivation, or stress management for example. Studies should also include parental observation in the natural environment whenever possible, as well as the collection of other types of collateral information regarding young mothers' socioemotional development, abuse and neglect histories, and parenting attitudes and behaviors for example.

Most parenting programs are small and under-funded. Even so, if necessary changes are to occur, better documentation, covering a broader scope of issues is needed. Training for field workers in assessment, evaluation, and documentation could vastly improve the amount of valid information available for research and study purposes as well. 


\section{REFERENCES}

Ainsworth, M. D., Blehar, M. C., Waters, E., \& Wall, S. (1978). Patterns of attachment: A psychological study of the Strange Situation. Hillsdale, NJ: Erlbaum.

Ainsworth, M. D., \& Eichberg, C. (1991). Effect on infant-mother attachment of mother's unresolved loss of an attachment figure or other traumatic experience. In C. M. Parkes, J. Stevenson-Hinde, \& P. Marris (Eds.), Attachment across the life cycle (pp. 160-186). London: Routledge.

Alan Guttmacher Institute. (1994). Sex and America's teenagers. Retrieved April 24, 1995, from http: //www.agi-usa.org.html

Alan Guttmacher Institute. (1998). Teenage pregnancy and the welfare reform debate. Retrieved December 5, 1995, from http://www.agiusa.org/pubs/ib5.html

Alan Guttmacher Institute. (1999a). Issues in brief: Risks and realities of early childbearing worldwide. Retrieved January 10, 2000, from http://www.agiusa.org/ pubs/ib10.html

Alan Guttmacher Institute. (1999b). Teen sex and pregnancy. Retrieved January 10, 2000, from http://www.agi-usa.org/pubs/fb_teen_sex..html

Alan Guttmacher Institute. (1999c). Teenagers' pregnancy intentions and decisions. Retrieved January 10, 2000, from http://www.agi-usa.org/pubs/ fb_teen_preg_survey.html

Alan Guttmacher Institute. (2006). U.S. teenage pregnancy statistics national and state trends and trends by race and ethnicity. Retrieved October 12, 2006, from http://www.guttmacher.org/pubs/2006/ 9/12/USTPstates.pdf

Anda, R. F., Felitti, V. J., Bremner, J. D., Walker, J. D., Whitfield, C. H., Perry, B. D., Dube, S. R., \& Giles, W. H. (2005). The enduring effects of abuse and related adverse experiences in childhood: A convergence of evidence from neurobiology and epidemiology. European Archives of Psychiatry and Clinical Neuroscience, 256(3), 174-186. 
Annie E. Casey Foundation. (2006). 2006 Kids count data book: Profiles of child well-being. Baltimore, MD: Author.

Artz, S. (1998). Sex, power, and the violent school girl. New York: Columbia University Teachers College Press.

Bachu, A. (1999). Trends in premarital childbearing: 1930-1994. Current population reports, (pp. 23-197). Washington, DC: U.S. Census Bureau.

BarOn, R., \& Parker, J. (2000a). BarOn Emotional Quotient Inventory - Youth Version: Technical manual. New York: Multi-Health Systems.

BarOn, R., \& Parker, J. (Eds.). (2000b). The handbook of emotional intelligence: Theory, development, assessment, and application at home, school, and in the workplace. San Francisco: Jossey-Bass.

Bavolek, S.J., \& Keene, R.G. (2001). Adult-adolescent Parenting Inventory (AAPI-2): Administration and development handbook. Park City, UT: Family Development Resources.

Belenky, M. F., Clinchy, B. M., Goldberger, N. R., \& Tarule, J. M. (1986). Women's ways of knowing: The development of self, voice, and mind. New York: Basic Books.

Bernstein, D. P., \& Fink, L. (1998) Childhood Trauma Questionnaire: A retrospective self-report, manual. San Antonio: Harcourt Brace.

Black, M. M., Papas, M. A., Hussey, J. M., Hunter, W., Dubowitz, H., Kotch, J. B., English, D., \& Schneider, M. (2002). Behavior and development of preschool children born to adolescent mothers: Risk and 3-generation households. Pediatrics, 109(4), 573-580.

Bowlby, J. (1969). Attachment and loss, Vol. 1. London: Tavistock Institute of Human Relations.

Bowlby, J. (1988). A secure base: Parent-child attachment and healthy human development. New York: Basic Books.

Boyer, D., \& Fine, D. (1992). Sexual abuse as a factor in adolescent pregnancy and child maltreatment. Family Planning Perspectives, 24, 4-11. 
Briere, J. N. (1992). Child abuse trauma: Theory and treatment of the lasting effects. Newbury Park, CA: Sage.

Briere, J. N. (1996). Trauma Symptom Checklist for Children: Professional manual. Lutz, FL: Psychological Assessment Resources.

Brown, L. M., \& Gilligan, C. (1992). Meeting at the crossroads: Women's psychology and girls' development. Cambridge, MA: Harvard University Press.

Buzarnescu, E. (2006). Outcome evaluation of the Center for Women, Children and Families Parenting Program. Lexington: University of Kentucky, Martin School of Public Policy and Administration. Retrieved August 9, 2006, from http://www.martin.uky.edu/ web/programs/mpa/

Capstones_2006/Buzarnescu.pdf

Campaign for Our Children. (1998). National overview. Baltimore: Author. Retrieved February 4, 2000, from http://www.cfoc.org/

Carter, S. L., Osofsky, J. D., \& Hann, D. M. (1991). Speaking for the baby: A therapeutic intervention with adolescent mothers and their infants. Infant Mental Health Journal, 12(4), 291-301.

Catalano, R. F., Berglund, M. L., Ryan, J., Lonczak, H. S., \& Hawkins, J. D. (1998). Positive youth development in the United States: Research findings on evaluations of positive youth development programs. Washington, DC: U.S. Department of Health and Human Services Office of the Assistant Secretary for Planning and Evaluation and National Institute for Child Health and Human Development Publishers and Distributor. Retrieved February 4, 2000, from http://aspe.os.dhhs.gov/hsp/PositiveYouthDev/ 99/index.htm

Centers for Disease Control and Prevention \& U.S. Department of Health and Human Services. (2006, September 29). Births: Final Data for 2004. National Vital Statistics Reports, 55(1), 1-6. Retrieved October 13, 2006, from http://www.cdc.gov/nchs/products/pubs/pubd/nvsr/55/55-pre.htm

Chase-Lansdale, P. L., Brooks-Gunn, J., \& Paikoff, R. (1991). Research and programs for adolescent mothers: Missing links and future promises. Family Relations, 40, 396-403.

Cicchetti, D., \& Toth, S. (1998). The development of depression in children and adolescents. American Psychologist, 53(2), (pp. 221-241). 
Cohen, J. (1999a). Learning about social and emotional learning: Current themes and future directions. In J. Cohen (Ed.), Educating minds and hearts: Social emotional learning and the passage into adolescence (pp. 184-190). New York: Teachers College Press.

Cohen, J. (1999b). Social and emotional learning past and present: A psychoeducational dialogue. In J. Cohen (Ed.), Educating minds and hearts: Social emotional learning and the passage into adolescence (pp. 323). New York: Teachers College Press.

Cohen, J., \& Cohen, P. (1983). Applied multiple regression/correlation analysis for the behavioral sciences. Hillsdale, NJ: Lawrence Erlbaum Associates.

Compas, B. E., Conner, J. K., \& Hinden, B. R. (1998). New perspectives on depression during adolescence. In R. Jessor (Ed.), New perspectives on adolescent risk behavior (pp. 319-362). New York: Cambridge University Press.

Craft, J. L. (1990). Statistics and data analysis for social workers. Itasca, IL: F.E. Peacock.

Dubowitz, H., Black, M. M., Kerr, M. A., Jussey, J. M., Morrel, T. M., Everson, M. D., \& Starr, R. H. (2001). Type and timing of mothers' victimization: Effects on mothers and children. Pediatrics, 107, 728-735.

East, P. L., \& Felice, M. E. (1996). Adolescent pregnancy and parenting: Findings from a racially diverse sample. Hilsdale, NJ: Lawrence Erlbaum.

Egeland, B. (1993). A longitudinal study of high-risk families: Issues and findings. In R. H. Starr \& D. A. Wolfe (Eds.), The effects of child abuse and neglect: Issues and research (pp. 33-56). New York: Guilford Press.

Elias, M., \& Bruene-Butler, L. (1999). Social decision making and problem solving: Essential skills for interpersonal and academic success. In J. Cohen (Ed.), Educating minds and hearts: Social emotional learning and the passage into adolescence (pp. 74-94). New York: Teachers College Press.

Erikson, E. H. (1950). Childhood and society. New York: W. W. Norton.

Erikson, E. H. (1968). Identity: Youth and crisis. New York: Norton. 
Evans, H. (2002). Emotional abuse. NSPCC inform: The online child protection resource. Retrieved Sept., 30, 2006, from http:www.nspcc.org.uk/Inform/ OnlineResources/Information Briefings/Emotional_asp_i

Family and Youth Services Bureau, Administration on Children, Youth and Families. (1998). Preventing adolescent pregnancy: A youth development approach. Washington, DC: U.S. Department of Health and Human Services. Retrieved February 4, 2000, from http://www.ncfy.com/ prevpreg.htm

Fischer, K. W., \& Rose, S. P. (1998). Growth cycles of the brain and mind. Educational Leadership, 56(3), 56-60.

Fish-Murray, C. C., Koby, E. V., \& van der Kolk, B. A. (1987). Evolving ideas: The effect of abuse on children's thought. In B.A. van der Kolk (Ed.), Psychological trauma (pp. 89-110). Washington, DC: American Psychiatric Press, Inc.

Ford, J. D., \& Kidd, P. (1999). Early childhood trauma and disorders of extreme stress as predictors of treatment outcome with chronic post-traumatic stress disorder. Journal of Consulting and Clinical Psychology, 67(3), 3-12.

Furstenberg, F. F. (1991). As the pendulum swings: Teenage childbearing and social concern. Family Relations, 40, 127-138.

Gardner, H. (1993). Multiple intelligences: The theory in practice. New York: Basic Books.

Garmesky, N. (1987). Stress, competence, and development: Continuities in the study of schizophrenic adults, children vulnerable to psychopathology, and the search for stress-resistant children. American Journal of Orthopsychiatry, 57(2), 159-174.

Geronimus, A. (1991). Teenage childbearing and social and reproductive disadvantage: The evolution of complex questions and the demise of simple answers. Family Relations, 40, 463-471.

Gisseman, R. D. (2005). Division of Youth Services: 2004 Annual parenting inventory report. Salt Lake City, UT: Division of Youth Services.

Given, B. K. (2002). Teaching to the brain's natural learning systems. Alexandria, VA: Association for Education and Curriculum Development. 
Goleman, D. (1995). Emotional intelligence: Why it can matter more than IQ. New York: Bantam Books.

Harway, M., \& Liss, M. (1999). Dating violence and teen prostitution: Adolescent girls in the justice system. In N. G. Johnson, M. C. Roberts, \& J. Worell (Eds.), Beyond appearance: A new look at adolescent girls (pp. 253-276). Washington DC: American Psychological Association.

Healthy Families Jacksonville Evaluation Team. (2000). Annual evaluation report. Jacksonville, FL: Author. Retrieved August 9, 2006, from http://wwwhfjep.ifas.ufl.edu.2000.pdf

Henshaw, S. K. (1999). U.S. teenage pregnancy statistics. Alan Guttmacher Institute Publishers and Distributors. Retrieved January, 10, 2000, from http://www.agi-usa.org/pubs/teen_preg_sr_0699.html

Henshaw, S. K. (2004). U.S. teenage pregnancy statistics with comparative statistics for women aged 20-24. New York: Alan Guttmacher Institute Publisher and Distributor. Retrieved August 5, 2005, from http://www. gutmacher.org./pubs/teen_status.html

Herrenkohl, R. C., Herrenkohl, E. C., Egolf, B. P., \& Wu, P. (1993). The developmental consequences of child abuse: The Lehigh Longitudinal Study. In R. H. Starr \& D. A. Wolfe (Eds.), The effects of child abuse and neglect: Issues and research (pp. 57-81). New York: Guilford Press.

Hughes, D. A. (1997). Facilitating developmental attachment: The road to emotional recovery and behavioral change in foster and adopted children. Northvale, NJ: Jason Aronson.

Illinois Department of Human Services. (2004). Healthy Families Illinois 2004 Annual Report. Springfield, IL: Author.

Institute on Educational Leadership. (1999). A synthesis of conference proceedings: School-based and school-linked programs for pregnant and parenting teens and their children - November 1997. Washington, DC: U.S. Department of Education.

Jensen, E. (1998). Teaching with the brain in mind. Alexandria, VA: Association for Education and Curriculum Development. 
Johnson, N. G., \& Roberts, M. C. (1999). Passage on the wild river of adolescence: Arriving safely. In N. G. Johnson, M. C. Roberts, \& J. Worell (Eds.), Beyond appearance: A new look at adolescent girls (pp. 3-23). Washington, DC: American Psychological Association.

Karr-Morse, R., \& Wiley, M. S. (1997). Ghosts from the nursery: Tracing the roots of violence. New York: Atlanta Monthly Press.

Kashani, J. H., \& Allan, W. D. (1998). The impact of family violence on children and adolescents. Volume 37: Developmental clinical psychology and psychiatry. Thousand Oaks, CA: Sage.

Kempe, R. S., \& Kempe, C. H. (1978). Child abuse: The developing child. Cambridge, MA: Harvard University Press.

Klem, L. (1995). Path analysis. In L. Grimm \& P. Yarnold (Eds.), Reading and understanding multivariate statistics (pp. 65-94). Washington, DC: American Psychological Association.

Klerman, L. V. (1993). The relationship between adolescent parenthood and inadequate parenting. Children and Youth Services Review, 15, 309-320.

Levine-Coley, R., \& Chase-Landsdale, P. L. (1998). Adolescent pregnancy and parenthood: Recent evidence and future directions. American Psychologist, 53(2), 152-166.

Licht, M. H. (1995). Multiple regression and correlation. In L. Grimm \& P. Yarnold (Eds.), Reading and understanding multivariate statistics (pp. 1963). Washington, DC: American Psychological Association.

Main, M. (1995). Attachment: Overview, with implications for clinical work. In S. Goldberg, R. Muir, \& J. Kerr (Eds.), Attachment theory, social, developmental, and clinical perspectives (pp. 407-474). Hillsdale, NJ: Analytic Press.

Marans, S., \& Cohen, J. (1999). Social and emotional learning: A psychoanalytically informed perspective. In J. Cohen (Ed.), Educating minds and hearts: Social emotional learning and the passage into adolescence (pp. 112-125). New York: Teachers College Press.

Maynard, R. (1996). Economic costs and social consequences of teen pregnancy: Kids having kids. Washington, DC: The Urban Institute Press. 
McCullough, M., \& Scherman, A. (1991). Adolescent pregnancy: Contributing factors and strategies for prevention. Adolescence, 26(104), 809-816.

Miller, P. H. (1993). Theories of developmental psychology (Third ed.). New York: W. H. Freeman.

National Clearinghouse on Families and Youth. (1998). Preventing adolescent pregnancy: A youth development approach. Family and Youth Services Bureau publishers and distributor. Retrieved August 5, 1999, from http://www.ncfy.com/prevpreg.htm

National Research Council, Panel on Child Abuse and Neglect. (1993). Understanding child abuse and neglect. Washington DC: National Academy Press.

Nelson, K., Landsman, M. J., Cross, T., Tyler, M., Twohig, A., \& Allen, M. (1994). Family functioning of neglectful families: Family Assessment Manual. Iowa City: The University of Iowa School of Social Work, The National Resource Center on Family Based Services.

Neuman, W. L. (1994). Social research methods: Qualitative and quantitative approaches (Second ed). Boston: Allyn and Bacon Publishers.

Newton, C. J. (2001). Child abuse: An overview. Retrieved July 7, 2006, from http://www.Therapist finder.net/Child-Abuse/Emotional-Abuse.html

Nicholson, J., \& Williams, V. (2006). The consequences of trauma for mothers in the transition years. Eighteenth Annual Research Conference for Children's Mental Health Proceedings (pp. 277-279). Tampa: University of South Florida, Florida Mental Health Institute, Research and Training Center for Children's Mental Health.

Olds, D. L., Robinson, J., Pettitt, L., Luckey, D. W., Holmberg, J., Ng, R. K., Isacks, K., Sheff, K., \& Henderson, C. R. (2004). Effects of home visits by paraprofessionals and by nurses: Age 4 follow-up - results of a randomized trial. Pediatrics, 114(6), 1560-1568.

Olson, K., \& Pavetti, L. (1996). Personal and family challenges to the successful transition from welfare to work. Washington, DC: The Urban Institute.

O'Neil, J. V. (2001). Report says youth aren't receiving adequate care. $N A S W$ News, 46(3), 12. 
Oregon Statutory Rape Laws (ORS 163.427).

Osofsky, J. D., Hann, D. M., \& Peebles, C. (1993). Adolescent parenthood: Risks and opportunities for mothers and infants. In C. H. Zeanah (Ed.), Handbook of infant mental health (pp. 106-119). New York: Guilford Press.

Perry, B. D. (1994). Neurobiological sequelae of childhood trauma: Post-traumatic stress disorders in children. In M. Murburg (Ed.), Catecholamine function in posttraumatic stress disorder: Emerging concepts (pp. 253-276). Washington, DC: American Psychiatric Press.

Perry, B. D. (1999). Stress, trauma and post-traumatic stress disorders in children: An introduction. ChildTrauma Academy Interdisciplinary Education Series Booklets, 2(5). Houston: ChildTrauma Academy Producer and Distributor. Retrieved February 3, 2000, from http://www.bcm.tmc.edu/civitas

Perry, B. D. (2000a). Our Impact. Houston: ChildTrauma Academy Producer and Distributor. Retrieved March 3, 2001, from http://www.bcm.tmc. edu/civitas/CT_Our_Impact.htm

Perry, B. D. (2000b). Violence and childhood: How persisting fear can alter the developing child's brain. ChildTrauma Academy Interdisciplinary Education Series Booklets, pre-final draft. Houston: ChildTrauma Academy Producer and Distributor. Retrieved March 3, 2001, from http://www.bcm.tmc.edu/civitas

Perry, B. D. (2000c). The vortex of violence: How children adapt and survive in a violent world. ChildTrauma Academy Interdisciplinary Education Series Booklets, pre-final draft. Houston: ChildTrauma Academy Producer and Distributor. Retrieved March 3, 2001, from http://www.bcm.tmc.edu/ civitas

Perry, B. D. (2001). The neuroarcheology of childhood maltreatment: The neurodevelopmental costs of adverse childhood events. In K. Franey, R. Geffner, \& R. Falconer (Eds.), The cost of maltreatment: Who pays? We all do (pp. 15-37). San Diego: Family Violence and Sexual Assault Institute.

Perry, B. D. (2002). Childhood experience and the expression of genetic potential: What childhood neglect tells us about nature and nurture. Brain and Mind, $3,79-100$. 
Perry, B. D. (2006). Applying principles of neurodevelopment to clinical work with maltreated and traumatized children: The neurosequential model of therapeutics. In N. Boyd Webb (Ed.), Traumatized youth in child welfare (pp. 27-53). New York: Guilford Press.

Perry, B. D., \& Azad, I. (1999). Post-traumatic stress disorders in children and adolescents. Current Opinions in Pediatrics, 11(4). Houston: ChildTrauma Academy Producer and Distributor. Retrieved February 3, 2000, from http://www.bcm.tmc.edu/civitas

Perry, B. D., Colwell, K., \& Schick, S. (2002). Child neglect. In, D. Levinson, Ed; Encyclopedia of crime and punishment, Vol. 1.; pp. 192-196.

Thousand Oaks, Sage.

Perry, B. D., \& Pollard, D. (1997). Altered brain development following global neglect in early childhood. Proceedings from Annual Meeting of the Society for Neuroscience, New Orleans. Retrieved June, 30, 1999, from http://www.childtrauma.org/CTAMATERIALS/neuros 1.asp

Perry, B. D., \& Pollard, R. (1998). Homeostasis, stress, trauma and adaptation: A neurodevelopmental view of childhood trauma. Child and Adolescent Psychiatric Clinics of North America, 7(1), 33-51.

Perry, B. D., Pollard, R., Blakley, T. L., Baker, W. L., \& Vigilante, D. (1995). Childhood trauma, the neurobiology of adaptation and use-dependent development of the brain: How states become traits. Houston:

ChildTrauma Academy Producer and Distributor. Retrieved May 15, 1998, from http://www.bcm.tmc.edu/civitas

Population Research Center. (2006, June 12). 2005 Annual Oregon population report. Portland, OR: Portland State University. Retrieved October 13, 2006, from http://www.pdx.edu/media/p/r/prc_2005completed.pdf

Rickel, A. U., \& Becker, E. (1997). Keeping children from harm's way: How national policy affects psychological development. Washington, DC: American Psychological Association.

Rothschild, B. (2000). The body remembers: The psychophysiology of trauma and trauma treatment. New York: W. W. Norton.

Saarni, C. (1999). The development of emotional competence. New York: Guilford Press. 
Saewyc, E. M., Magee, L. L., \& Pettingell, S. E. (2004). Teenage pregnancy and associated risk behavior among sexually abused adolescents. Perspectives on Sexual and Reproductive Health, 36(3), 98-105.

Santelli, J. S., Morrow, B., Anderson, J. E., \& Lindberg, L. D. (2006). Contraceptive use and pregnancy risk among U.S. high school students 1991-2003. Perspectives on Sexual and Reproductive Health, 38(2), 106111.

Schwarz, E. D., \& Perry, B. D. (1994). The post-traumatic response in children and adolescents. Psychiatric Clinics of North America, 17(2), 311-326.

Schwartz, P., \& Rutter, V. (1998). The gender of sexuality. Thousand Oaks, CA: Pine Forge Press.

Sedlak, A. J., \& Broadhurst, D. D. (1996). Executive summary of the Third National Incidence Study of Child Abuse and Neglect. U.S. Department of Health and Human Services, Administration for Children and Families, Administration on Children, Youth and Families, National Center on Child Abuse and Neglect Publishers and Producers. Retrieved September 6, 1997 from http://www.calib.com/nccanch/pubs/

Shriver, T. P., Schwab-Stone, M., \& DeFalco, K. (1999). Why SEL is the better way: The New Haven Social Development Program. In J. Cohen (Ed.), Educating minds and hearts: Social emotional learning and the passage into adolescence (pp. 43-60). New York: Teachers College Press.

Siegel, D. J. (1999). The developing mind: Toward a neurobiology of interpersonal experience. New York: The Guilford Press.

Solodow, W. (1999). The meaning of development in middle school. In J. Cohen (Ed.), Educating minds and hearts: Social emotional learning and the passage into adolescence (pp. 24-40). New York: Teachers College Press.

Starr, R. H., MacLean, D. J., \& Keating, D. P. (1991). Life-span developmental outcomes of child maltreatment. In R. H. Starr \& D. A. Wolfe (Eds.), The effects of child abuse: Issues and research (pp. 1-32). New York: Guilford Press.

St. Pierre, R. G., Layzer, J. I., Goodson, B. D., \& Bernstein, L. S. (1997). National impact evaluation of the Comprehensive Child Development Program:

Final Report. Cambridge, MA: Abt Associates. 
Sugar, M. (1993). Adolescent motherhood and development. In M. Sugar (Ed.), Female adolescent development (2nd ed., pp. 213-230). New York: Brunner/Mazel.

Thompson, R. A. (1998, August 1). Early brain development and social policy. Policy and Practice of Public Human Services, pp. 67-75.

Tomison, A. M., \& Tucci, J. (1997, Spring). Emotional abuse: The hidden form of maltreatment. Issues in Child Abuse Prevention, 8. Melbourne, AU: National Child Protection Clearinghouse. Retrieved October 10, 2006 from http://www.aifs.gov.au/nch/issues8.html

U.S. Department of Health and Human Service. (2006). Annual update of the HHS poverty guidelines. Washington, DC: Author.

van der Kolk, B. A. (1987a). The psychological consequences of overwhelming life experiences. In van der Kolk (Ed.), Psychological trauma (pp. 1-30). Washington, DC: American Psychiatric Press.

van der Kolk, B. A. (1987b). The role of the group in the origin and resolution of the trauma response. In B. A. van der Kolk (Ed.), Psychological trauma (pp. 153-172). Washington, DC: American Psychiatric Press.

van der Kolk, B. A. (1987c). The separation cry and the trauma response: Developmental issues in the psychobiology of attachment and separation. In B. A. van der Kolk (Ed.), Psychological trauma (pp. 31-62). Washington, DC: American Psychiatric Press.

van der Kolk, B. A. (1989). The compulsion to repeat the trauma: Re-enactment, revictimization, and masochism. Psychiatric Clinics of North America, 12(2), (pp. 389-411).

van der Kolk, B. A. (1996a). The body keeps score: Approaches to the psychobiology of PTSD. In B. A. van der Kolk, A. C. McFarlane, \& L. Weisaeth (Eds.), Traumatic stress: The effects of overwhelming experience on mind, body, and society (pp. 214-241). New York: The Guilford Press.

van der Kolk, B. A. (1996b). The complexity of adaption to trauma: Selfregulation, stimulus discrimination, and characterological development. In B. van der Kolk, A. C. McFarlane, \& L. Weisaeth, (Eds.), Traumatic stress: The effects of overwhelming experience on mind, body, and society (pp. 214-241). New York: The Guilford Press. 
van der Kolk, B. A. (1996c). Dissociation, somatization, and affect dysregulation: The complexity of adaptation to trauma. The American Journal of Psychiatry, 153(7), (pp. 83-93).

van der Kolk, B. A. (1998). The psychology and psychobiology of developmental trauma. In A. Stoudemire (Ed.), Human behavior: An introduction for medical students (pp. 383-399). New York: Lippincott-Raven Publishers.

van der Kolk, B. A. (1999, October). Understanding the impact of trauma. Paper presented at the Family and Addiction Conferences and Education Seminars, Seattle, WA.

van der Kolk, B. A. (2000a). Posttraumatic stress disorder and the nature of trauma. Dialogues in Clinical Neuroscience, 2(1), 7-19.

van der Kolk, B. A. (2000b). Trauma, neuroscience and the etiology of hysteria. Journal of American Academy of Psychoanalysis, 28(22), (pp. 237-262).

van der Kolk, B. A. (2001). The assessment and treatment of complex PTSD. In R. Yehuda (Ed.), Traumatic stress (pp. 127-156). Washington, DC: American Psychiatric Press.

van der Kolk, B. A., Burbridge, J. A., \& Suzuki, J. (1997). The psychobiology of traumatic memory: Clinical implications of neuroimaging studies. In R. Yehuda \& A. C. McFarlane (Eds.), Annals of the New York Academy of Sciences (Vol. 821): Psychobiology of posttraumatic stress disorder (pp. 99-113). New York: New York Academy of Sciences.

van der Kolk, B. A., \& Greenberg, M. S. (1987). The psychobiology of the trauma response: Hyperarousal, constriction, and addiction to traumatic reexposure. In B. A. van der Kolk (Ed.), Psychological trauma (pp. 63-87). Washington, DC: American Psychiatric Press.

van der Kolk, B. A., \& McFarlane, A. C. (1996). The black hole of trauma. In B. A. van der Kolk, A. C. McFarlane, \& L. Weisaeth (Eds.), Traumatic stress: The effects of overwhelming experience on mind, body, and society (pp. 323). New York: The Guilford Press.

Waites, E. A. (1993). Trauma and survival: Post-traumatic and dissociative disorders in women. New York: W. W. Norton. 
Weinfield, N. S., Egeland, B., \& Ogawa, J. R. (1999). Promises to keep: Assessing affective and behavioral qualities of mother-child relationships in the New Chance Observational Study. Evanston, IL: Joint Center for Poverty Research Producers and Distributors. Retrieved July 20, 2002, from http://www.jcpr.org/wp

Weissberg, R. P., \& Greenberg, M. T. (1997). School and community competence-enhancement and prevention programs. In W. Damon (Series Ed.), I. E. Sigel \& K. A. Renninger (Vol. Eds.), Handbook of child psychology: Vol 5. Child psychology in practice (5th ed., pp. 40-61). New York: John Wiley.

Wolfe, D. A., \& McGee, R. (1993). Assessment of emotional status among maltreated children. In R. H. Starr \& D. A. Wolfe, The effects of child abuse and neglect: Issues and research (pp. 257-277). New York: Guilford Press.

Zaslow, M. J., \& Eldred, C. A. (Eds.). (1998). Parenting behavior in a sample of young mothers in poverty: Results of the New Chance Observational Study. New York: MDRC Publisher. 
APPENDIX A

THE SERVICES QUESTIONNAIRE 


\section{Services Questionnaire}

Since this research is about what teenage mothers have experienced and what services they may need, or need more of, I need to know about what services you have received or are receiving, and also about what services you haven't received.

Some teen moms use many services and others use only a few, I am trying to discover what services teen mothers need and use the most, please indicate with a $(\sqrt{ })$ which services you have received or participated in since becoming pregnant and/or since becoming a parent. If you have not received or participated in a particular service, please indicate "why not" and whether or not you would have wanted to participate in this service had it been made available to you.

Please answer all questions

1. Did you receive prenatal medical care: yes no

If yes, for how long?

Are you receiving this service now? yes no

If you did not receive this, why not? (Check all that apply)

I didn't want this service

This service was not available or offered to me I didn't need this service

If this service had been available or offered to you, would you have used it? yes no

2. Did you receive post-natal medical care? yes no

If yes, for how long?

Are you receiving this service now? yes no

If you did not receive this, why not? (Check all that apply)

I didn't want this service

This service was not available or offered to me I didn't need this service

If this service had been available or offered to you, would you have used it? yes no

3. Have you received Mom/Baby Home Visitation Services? yes no

If yes, for how long?

Are you receiving this service now? yes no 
If you didn't receive this, why not? (Check all that apply)

I didn't want this service

This service was not available or offered to me

I didn't need this service

If this service had been available or offered to you, would you have used it?

yes no

4. Have you received WIC services? yes no

If yes, for how long?

Are you receiving this service now? yes no

If you didn't receive this, why not? (Check all that apply)

I didn't want this service

This service was not available or offered to me I didn't need this service

If this service had been available or offered to you, would you have used it?

yes no

5. Have you received cash assistance (Welfare, AFS, TANF)? yes no

If yes, for how long?

Are you receiving this service now? yes no

If you didn't receive this, why not? (Check all that apply)

I didn't want this service This service was not available or offered to me I didn't need this service

If this service had been available or offered to you, would you have used it?

$$
\text { ___ yes__ no }
$$

6. Have you received food stamps? yes no

If yes, for how long?

Are you receiving this service now? yes no 
If you didn't receive this, why not? (Check all that apply)

I didn't want this service

This service was not available or offered to me

I didn't need this service

If this service had been available or offered to you, would you have used it?

yes no

7. Have you received Family Planning or Options Counseling Services or information?

$\ldots$ yes__ no

If yes, for how long?

Are you receiving this service now? yes no

If you didn't receive this, why not? (Check all that apply)

I didn't want this service

This service was not available or offered to me

I didn't need this service

If this service had been available or offered to you, would you have used it?

$$
\ldots \text { yes___ no }
$$

8. Have you received adoption counseling or information? yes no

If yes, for how long?

Are you receiving this service now? yes no

If you didn't receive this, why not? (Check all that apply)

I didn't want this service

This service was not available or offered to me I didn't need this service

If this service had been available or offered to you, would you have used it? yes no

9. Have you participated in peer group counseling? yes no

If yes, for how long?

Are you receiving this service now? yes no 
If you didn't receive this, why not? (Check all that apply)

I didn't want this service

This service was not available or offered to me

I didn't need this service

If this service had been available or offered to you, would you have used it?

yes no

10. Have you received domestic violence education or participated in domestic violence groups?

_. yes no

If yes, for how long?

Are you receiving this service now? yes no

If you didn't receive this, why not? (Check all that apply)

I didn't want this service

This service was not available or offered to me

I didn't need this service

If this service had been available or offered to you, would you have used it? yes no

11. Have you received anger management training or participated in anger management groups? yes no

If yes, for how long?

Are you receiving this service now? yes no

If you didn't receive this, why not? (Check all that apply)

I didn't want this service

This service was not available or offered to me I didn't need this service

If this service had been available or offered to you, would you have used it? yes no

12. Have you received sexual abuse education or participated in sexual abuse peer groups?

yes no

If yes, for how long?

Are you receiving this service now? yes no 
If you didn't receive this, why not? (Check all that apply)

I didn't want this service

This service was not available or offered to me

I didn't need this service

If this service had been available or offered to you, would you have used it?

yes no

13. Have you received social skills training or participated in social skills groups?

yes__ no

If yes, for how long?

Are you receiving this service now? yes no

If you didn't receive this, why not? (Check all that apply)

I didn't want this service

This service was not available or offered to me I didn't need this service

If this service had been available or offered to you, would you have used it?

$$
\ldots \text { yes__ no }
$$

14. Have you received independent living education or participated in independent living groups?

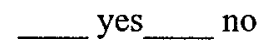

If yes, for how long?

Are you receiving this service now? yes no

If you didn't receive this, why not? (Check all that apply)

I didn't want this service

This service was not available or offered to me

I didn't need this service

If this service had been available or offered to you, would you have used it?

$$
\ldots \text { yes__ no }
$$

15. Have you received GED instruction or classes? yes no

If yes, for how long?

Are you receiving this service now? yes no 
If you didn't receive this, why not? (Check all that apply)

I didn't want this service

This service was not available or offered to me

I didn't need this service

If this service had been available or offered to you, would you have used it?

__ yes__ no

16. Have you received help in getting a High School Diploma?

yes no

If yes, for how long?

Are you receiving this service now? yes no

If you didn't receive this, why not? (Check all that apply)

I didn't want this service

This service was not available or offered to me I didn't need this service

If this service had been available or offered to you, would you have used it?

yes no

17. Have been given any job training (not "on the job" training)

yes no

If yes, for how long?

Are you receiving this service now? yes no

If you didn't receive this, why not? (Check all that apply)

I didn't want this service

This service was not available or offered to me

I didn't need this service

If this service had been available or offered to you, would you have used it? yes no

18. Have you participated in any parent training classes or groups?

_ yes__ no

If yes, for how long?

Are you receiving this service now? yes no 
If you didn't receive this, why not? (Check all that apply)

I didn't want this service

This service was not available or offered to me

I didn't need this service

If this service had been available or offered to you, would you have used it?

yes no

19. Have you received any help with child care (not from friends or family)?

yes no

If yes, for how long?

Are you receiving this service now? yes no

If you didn't receive this, why not? (Check all that apply)

I didn't want this service

This service was not available or offered to me

I didn't need this service

If this service had been available or offered to you, would you have used it? yes no

20. Have you received any help with transportation (not from family or friends)?

yes no

If yes, for how long?

Are you receiving this service now? yes no

If you didn't receive this, why not? (Check all that apply)

I didn't want this service

This service was not available or offered to me I didn't need this service

If this service had been available or offered to you, would you have used it? yes no

21. Have you received any individual therapy? yes no

If yes, for how long?

Are you now receiving this service? yes no 
If you didn't receive this, why not? (Check all that apply)

I didn't want this service

This service was not available or offered to me

I didn't need this service

If this service had been available or offered to you, would you have used it?

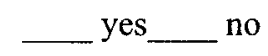

22. Have you received any family therapy? yes no

If yes, for how long?

Are you receiving this service now? yes no

If you didn't receive this, why not? (Check all that apply)

I didn't want this service

This service was not available or offered to me I didn't need this service

If this service had been available or offered to you, would you have used it? yes no

23. Have you received any couples therapy? yes no

If yes, for how long?

Are you receiving this service now? yes no

If you didn't receive this, why not? (Check all that apply)

I didn't want this service

This service was not available or offered to me I didn't need this service

If this service had been available or offered to you, would you have used it? yes no

24. If you have participated in individual therapy, please give a brief explanation of why.

25. If you have participated in family therapy, please give a brief explanation of why.

26. If you have participated in couples therapy, please give a brief explanation of why.

27. Teen mothers often report problems with emotional issues like depression (sadness, grief) or anxiety (being nervous). To help me determine the need for services to help teen moms with these 
issues, please tell me (to the best of your knowledge) whether or not, you have been diagnosed by a doctor, a psychiatrist, a psychologist, or a social worker with one or more of the following:

Please check all that apply

depression

anxiety

$\mathrm{ADD}, \mathrm{ADHD}$, or a learning disorder

post-traumatic stress disorder (PTSD)

eating disorder (anorexia, bulimia)

emotional disorder (SED)

adjustment disorder

oppositional defiant disorder

conduct disorder

bipolar disorder

attachment disorder

personality disorder

28. Have you ever been prescribed or taken medication for emotional issues (ie: depression, anxiety, ADD/ADHD, etc.)? yes no

29. Are you currently taking any medication for emotional issues (ie: depression, anxiety, ADD/ADHD, etc.)? yes no 
30. Many teen mothers report needing more help in caring for their child. Please indicate using a $(\sqrt{ })$ the box that best describes how often the people listed help you to care for your child.

Never

Sometimes

Often

Very Often

Never

Your parent(s)

Your child's

Father's parent(s)

Your Child's Father

Your Grandparent

Sister/Brother

Other Family

Members

Friends/peers

Paid Babysitter

School Child

Care Center

Other Child

Care Center

I want to be able to tell people who provide services to teen moms what services you think are the most or the least helpful, and/or the most and least needed. So, I need to know what you think in general about the teen mom services that you have received or not received.

31. What (if any) services have been the most helpful to you and why?

32. What (if any) services have been the least helpful to you and why?

33. What (if any) service(s) do you need, or need more of, and why? 


\section{APPENDIX B}

THE DEMOGRAPHIC QUESTIONNAIRE 
Date: $\quad$ Code

\section{General Information Questionnaire}

Since this research is about what teenage mothers have experienced and what services they may need, or need more of, we need to know a little bit about you, your family, and your living situation. Please remember that since you are not giving us your name or address, or the name or address of anyone close to you, none of the information you provide can be linked to you in any way. Please answer all the following questions to the best of your ability. If you have any questions, please ask the researcher for help.

\section{Respondent Information}

What is your age?

Birthdate/Month

What is your race/ethnicity?

White/Caucasian

Black/African American

Hispanic/Latino

American Indian

Asian/Pacific Islander

Other

What is the highest grade in school that you have completed?

12)

Are you still going to school?

yes no

Are you currently employed? yes no

If so, how many hours a week do you work?

Are you:

married

not married, but living with boyfriend

single

widowed

divorced

If you have a boyfriend or spouse living with you is he employed?

yes no

If so, how many hours a week does he work?

What is the age and gender (i.e., male or female) of your child (or children) living with you?

$\underline{\text { Age }}$

Gender 


\section{Family Information}

How many people live with you in your home three or more days per week?

Please list the age, gender (i.e., male or female), and relationship to you (i.e., mother, child, boyfriend, grandmother, brother, etc.) of all the people (except your children) who live with you in your home three or more days per week.
Age
$\underline{\text { Gender }}$
Relationship

What is the highest grade in school completed by:

Your Mother:

grade school or less some high school

graduated high school

GED certificate

some college graduated from college graduate degree don't know
Your Father: grade school or less some high school graduated high school GED certificate some college graduated from college graduate degree don't know

Which of the following best describes your yearly income? under $\$ 10,000$

$\$ 10,000$ to 25,000 $\$ 25,001$ to 40,000 $\$ 40,001$ or more

Which of the following best describes your household's yearly income? under $\$ 10,000$ $\$ 40,000$ to $\$ 45,000$

$\$ 10,000$ to $\$ 15,000$ $\$ 45,000$ to $\$ 50,000$

$\$ 15,000$ to $\$ 20,000$ $\$ 20,000$ to $\$ 25,000$ $\$ 25,000$ to $\$ 30,000$ $\$ 50,000$ to $\$ 55,000$ $\$ 55,000$ to $\$ 60,000$ $\$ 60,000$ to $\$ 65,000$ $\$ 30,000$ to $\$ 35,000$ $\$ 65,000$ to $\$ 70,000$ $\$ 35,000$ to $\$ 40,000$ $\$ 70,000$ or more 